a

IIf W. H.5.

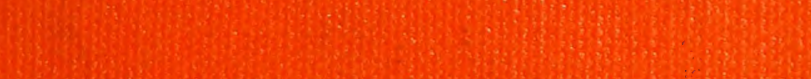

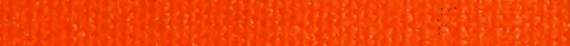
20.7. 2.

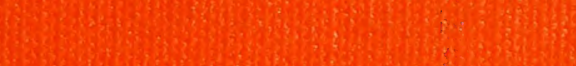
1962.

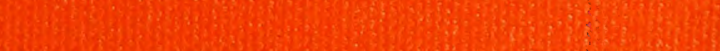

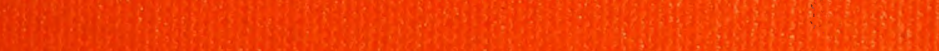
I

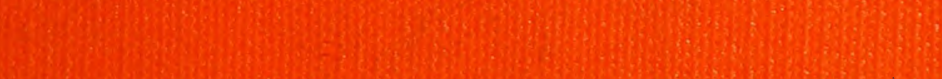
W. 2.5. It(1)

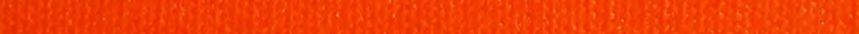

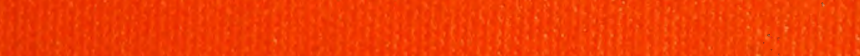

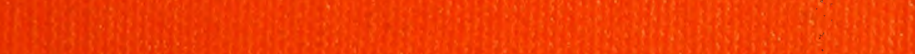
263. 3. Has W. 13)

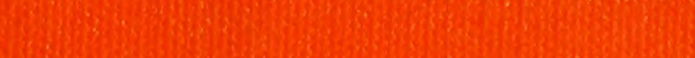
(4) Hes. Noy H. 2016) 1960) 3.5.

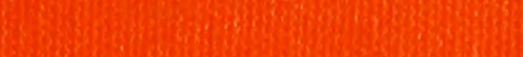
6.

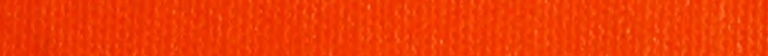
2019. 15.

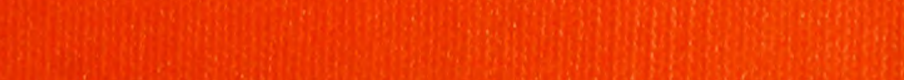




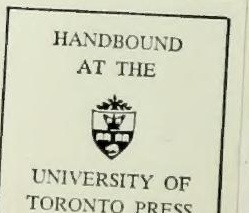


Digitized by the Internet Archive in 2009 with funding from University of Ottawa 

LES

PRINCIPES $D E$

L'A G R I C U L T UR E ETDE

LA VEGEIAIION. 



\title{
L E S
}

\section{PR I NCI PES}

$D E$

\section{L'A GR ICUL TURE}

\author{
$E T D E$
}

\section{LA VEGETATION.}

Ouvrage traduit de l'Anglois de $M$. Françors Homв, Doćfeur en Médecine, бन l'un des Membres du Collége des Médecins d'Edimbourg, auquel on a joint deux Mémoires nouveaux fur la maniere de préferver le Froment de la corruption छg de le conferver.

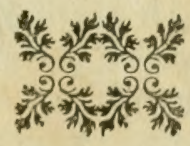

$$
\text { A PARIS, }
$$

Chez Praulr pere, Quai de Gêvres.

$$
\text { M. D. C. C. L X I. }
$$

Avec Approbation $6 \sigma^{2}$ Privilege du Roi. 


$$
\begin{aligned}
& \text { S } \\
& 5 / 5 \\
& 46 \\
& \text { IIBRARY } \\
& \text { JUN 14: } 1967 \\
& \text { ERSTIY OF TORO }
\end{aligned}
$$




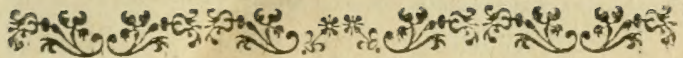

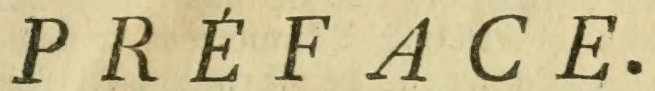

L A Société d'Edimbourg, établie en I 7 is pour la perfection des Manufactures $\&$ des Arts, propolant une médaille d'or pour la meilleure Differtation fur les Principes de la Végétation \& de l'Agriculture, M. Home, dans le deffein de contribuer à remplir des vúes fi utiles, crut devoir fe mettre au nombre des concurrens. Ce fut à cette occafion qu'il compofa l'Ouvrage qu'on donne ici au Public, traduit en notre langue, \& qui lui mérita les fuffrages de la Compagnie fçavante à laquelle il fut préfenté.

L'Auteur s'y propofe de découvrir \& de fixer, par la Chymie, les vrais Principes de la Végétation, \& d’appliquer à la perfection de l'Agriculture cette fcience, qu'on avoit regardée fuiqu ici comıne lui étant étrangere, quoiquelle ait svec elle une liaifon fi étroite. C'elt par cle qu'il entreprend de faire connoitie la nature \& les qualités des divers fols \& amtidentens, la nourriture des végétaux, \& la maniere la plus fûre de la leui procurer. 
Il a cet avantage, que dans fa Differta. tion, tout porte fur le fondement des faits: cen'eft qu'à la lumiere de ce flambeau qu'il marche dans la route qu'il s'eft ouverte. Par fes ingénieufe expériences \& fa judicieufe phyfique, il réduit l'Agriculture à un art fyltếnatique \& régulier, \& il en donne une théorie lumineufe, folidement raifonnée \& féconde en conféquences utiles par la pratique.

On ne doit point oublier de faire remarquer ici que quand l'Auteur compofa cet Ecrit, il n'avoit aucune connoiffance des trois volumes d'expériences publiés par M. du Hamel fur le fyftême de Tull. Il déclare qu'il ne les a lus qu'après, mais que cette lecture lui en a donné la plus haute idée, \& qu'il les regarde comme des modeles excellens dans ce genre. Cette obfervation eft une jultice qu'on devoit également à l'Auteur de cetteDiffertation, \& au fçavant \& laborieux Académicien f digne de la reconnoiffance de fa Patrie qu'il honore, \& du genre humain qu'il éclaire.

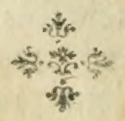



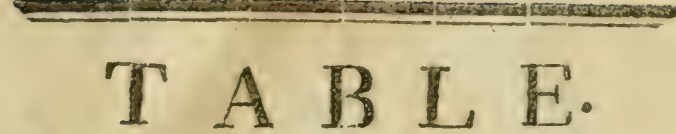

DES Principes de l'Agriculture \&z de la Végétation.

\section{PREMIERE PARTIE.}

Tre.
SECTION. AUSES de la lentezin des progra's de l'Agriculaure: Sa liaijon แขec la C'mgnize: Divifion de l'Ozvorage.

SECTII:N II. Des divers fols.

SECTION III. De la bonze terre noire. rage. $I$.

SECTION IV. De la terre argilicuse um glaifease.

SECTION V. De la terre fablomeuse.

I 4.

SECTION VI. De la terre crayeale.

IS.

SECTION VII. Du Tuf.

23 .

SECTION VIII De la tourbe ou terredes marus

Gँ fondrieres.

27.

\section{SECONDE PARTIE.}

SECTION I. Des moyens que la mature employe pour foumir aux plantes la noumature vigetale.

SECTION II. Des engrais ou moyens que :-Ait cmploye pour foumir a la terre des mounatumes sigétales.

SECTION III. De la Marme.

$3 \%$.

SECTION IV. Des corfs calcuires monz brible's, E" de la chaux vive.

47.

SECTION V. Des végétaux tant dans l'etus mu:urel que dans zun itut de putregatizon, E⿺ dics ias defumier. 
SECTION VI. Des engrais tirés des vigétant hir lés.

$690^{2}$

SECTION VII. Des enzrais tirés des fubliances an- males.

$6 \%$

$$
\text { TROISIEME PARTIE. }
$$

SECTION I. ET'ts de differentes fubftunces par rapport à la vigitation.

SECTJONII. De la mirriture des végétaux. 89.

$$
\text { 2UATRIEME PARTIE. }
$$

SECTION I. De la nécesjité d'vuvvir_ę de pulverifer la terre.

SECTION II. EFfets de l'atmofphere.

II 4 .

SELTi!)N III. Du cbanzeinent des efpeces. $\quad$ I 8 .

SECTION IV. Des labours.

SECTION V. Des anandemens.

120.

SECTION VI. De la végétation.

$1=3$.

128.

$$
\text { CINQUIEME PARTIE. }
$$

SECTION I. Des manuvaifes berbes.

SECTION II. Des terreins bumides.

SECTION III. Des plazyer.

I 36.

139.

SECTION IV. Des dérauts des fenzences. $\quad 142$.

SECTION V. Maladies des plantes.

144.

SECTIOV VI. Plan pour la periection de IAgrio culture.

Les deux $\| l$ émoirec qui fuivent ont été imprimes, par ordre du Miniftere, à 'imprimerie Roysle, is envoyés d ns tututes les Generalites du Royaume, en $1759 \$ 760$.

Mémotive jur a mancise de préferver le Froment te

la corruption és de le conl rver,

I'féninive pour fervir à izzlinuer le plan qui a ité Jizivi pour parvenir à conzuitre ce qui produat le

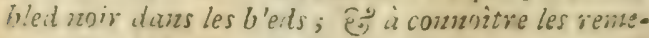
les propres à ditruire cette corruptious. 


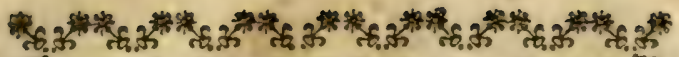

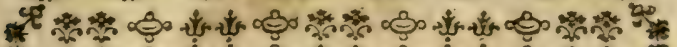

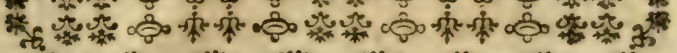

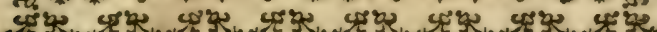

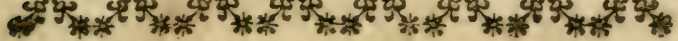

LES

PRINCIPES

DE

I'AGRICULTURE

E T

DE LA VEGETATION.

\section{PREMIERE PARTIE. \\ SECTION PREMIERE.}

Caufes de la lenteur des progrès de l' Agriculturs: Sa liaifon aver la Chymie: Divifion de l'Onurage.

L.

L Agriculture, quoique le plus nécelfaire de tous les Arts, a peut-être été jufqu'ici le plus négligé. Tous les autres ons reçu de nouveaux dégrés de perfection dans le fiecle précédent \& dans le nótre; mais on n'en fąauroit dire autant de l'Agriculture. If 
paroit au cuntraire, qu'on ne l'entend gueres micux actuellement dans l'Europe, que du tems des Anciens; \& je fuis perfuadé que Virgile \& Columelle peuvent encore être re. gardés comme les dcux meilleurs Auteurs qui aient écrit fur cettc matiere.

D'où peut venir cette lenteur des progrès de l'Agriculture? Heft ce, comme l'ont penfé quelques Anciens, que la terre, cette mere commune des végétaux, affoiblie par l'âge \& épuif'se de tant productions, a perdu fa premiere fertilité? ou qu'il $\in$ ft impolfible de faire de la cuiture des teries un art régulier, \& que fes effets dépendent plus du ha. zard que de principes fixes? On ne peut dire ni l'un ni l'autre. L'expérience prouve tous les jours le contraire; la terre, même après: avoir été épuifée, parvient encore, quand on fçait la gouverner comme il faut, à un haut dégré de fertilité; \& la régularité avec laquelle on procede dans l'Agriculture c.ft une prcuve qu'elle elt déjà , en quelque forte, réduite en art.

Il y a d'autres raifons moins recherchées \& plus fenfibles de la lenteur de fes progrès. Cet art eft prefque partout abanitonué à des hommes groffiers, qui ne fçavent ni obfer. ver, ni tirer de leurs obfervations des conféquences qui les conduilent à découvrir la 
Férité : ou bien il n'eft cultivé que par des perfonnes, qui ne manqquant ni d'efprit, ni de connoiffances, ont une fortune trop bornée pour pouvoir faire les expériences néceffajres. Ainfiles premiers ne peuvent fçavoir que ce qu'ils ont appris de leurs peres; \& les feconds, dont la fubfiftance dépend de la certitude du fuccès, n'ofent rien rifg̨uer. Que peut-on attendre des uns \& des autres? Mais en fuppofant des comnoiflances \& une fortune aifée, la difficulté de l'art en luimêne fuffit feule pour en retarder les pro. grès. Car que de circonftances délicates dans chaque expérience! Combien ne faut il pas avoir fait d'obfervations exaetes fur la chaleur \& fur le froid, fur la féchereffe \& fur l'humidité, \&c. avant qu'on puiffe être affuré du fuccès général d'unc expérience! Quel changement ne produit pas une différence léa gere dans ces circonftances! Qu'il eft rare qu'on puiffe répéter plufieurs fois des expériences qu'on ne fçauroit faire gu'une fois l'année, \& que la vie de l'homme eft courte pour une fi pénible \& fi longue entreprife! D'ailleurs les olifervations périffent avec l'Obfervateur, quand elles n'ont point été rendues publiques; \& la vanité ne permet gueres d'en publier, à moins qu'on en ait fait affez pour en former un fyltême complet.

\section{A 2}


Auffi l'Agriculture, fi aifée en apparence, eft, à en juger par le petit nombre des bons Autteurs, le plus difficile de tous les Arts.

Ce ne font pas là les feuls obftacles qu'elle sit à vaincre, en voici un plus grand encore: c'elt qu'elle dépend de Principes, que fa pratique feule ne peut aprendre. Il faut remonzer au delà de cet Art, pour le connoître à fond. Tous les Arts extérieurs tiennent, du moins quant aux Principes, ou à la chymie, ou à la méchanique, ou même à l'une \& à l'autre. L'Agriculture eft dans ce dernier cas; car quoique le fecours des méchaniques lui foit nécelfaire, j’ofe affurer que celui de la chymie l'eft encore davantage. Sane la connoiffance de cette derniere fcience il n'eft pas poffible d'établir les vrais Principes del'Agriculture. Or la fcience de la chymie ne faifant, pour ainfi dire, que de naitre, \& n'ayant encore été gueres cultivée par rapport à l'utilité que le commerce \& les manuFactures pouvoient en tirer, on ne s'étoit prefque point apperçu de la liaifon que l'Agriculture a naturellement avec elle. Je me propofo dans cet Ouvrage de la faire fentir, eette liaifon ; \& de montrer combien la chya mie peut fervir à fixer les Principes de l'A. griculture.

Mon deffein n'eft pas d'en enfeigner ici la 


\section{8 de la Végétation.}

pratique: je laiffe ce foin aux Cultivateurs. Je me contenterai d'en tracer les principaux traits, \& de faire voir que cet Art peut être réduit, comme tous les autres, à un fyftême régulier. Si d'après divers faits conftatés par l'expérience, nous pouvons établir des principes fixes d'Agriculture, ceux qui s'appliquent à la pratique ne fçauroient manquer d'en tirer quelọue utilité. La vraie théorie d'un Art contribue directement à fes progrès, parce qu'elle conduit naturellement aux exfériences qui reftent à tenter : c'eft un flambeau fans lequel on peut rencontrer par hazard quelques vérités; mais quand il éclaire nos pas, nous avons la fecrete fatisfaction que c'eft à nous mêmes que nous devons Theureux fuccès de nos expériences.

Tâchons done de trouver quelque point fixe, d'ou nous puifitions embraffer d'une feule vûe toute l'ćtendue de cet Art, \& procéder d'une maniere méthodique à la divifion de cet Ouvrage. Tous les corps organiques tirent leur croiffance de la réception ou application des parties deftinées par l'Auteur in la nature à les nourrir, \& fans ces parties mutricives, ils tie croítroient point. Les plantes, étant dess corps organiques, ne croiffent donc qu'à proportion de la quantité de nuurrisure, gुu'elles reçoivent à lcurs raci- 
nes: vîe fimple, mais qui embraffe toute l'Agriculture, \& d'oul il fuit que ce point unique, c'eft à dire, la nourriture des plantes, eft le grand objet, \&, pour ainfi dire, le centre de cet Arr.

Mais comment le Cultivateur nourrira t'il les plantes, s'il ne connoît ni la nature, ni la qualité de chaque fol, \& ne fçait pas diftinguer ceux qui font capables ou inca pables de les faire croître; s'il ne peut leur fournir les alimens nécelfaires à leur nourriture, ou qu'il ignore quels font ces alimens; s'il n'aide les glantes à chercher \& à fe procurer cette nourriture, en rendant la terre plus légere \& plus meuble; enfin s'il ne connoit \& n'écarte, autant qu'il eft en lui, tout ce qui peut s'oppofer a leur nutrition. Voilà les grands objets de l'Agriculture. Nous diviferons done se Traité cu cingy Partics, \& nous confidérerons, $I^{\circ}$. L.a nature \& vers foris. 20. La nature \& les qualités des divers engrais. $3^{\theta}$. La maniere dont ils operent. 4. Les diffúrentes manieres de labouret \& façonner la terre. $5^{\circ}$. Les obftacles à In végétation, \& la manicre dy remédier.

On ne peut raifonne: fur les opérations dos corps que diuprès des expériemes qui nous ayent fait connoitre lcurs qualités. Toute autre voye ne nous conduiroit pas à 


\section{EO de la Végétation.}

la découverte de la vérité. Ainfi je ne ferai aucun pas fans avoir l'expérience pour guide, \& je n’avancerai rien qui ne foit appuyé fur des faits. Quand les autres ne m'en fournitont point, je tácherai d'y fuppléer par moi.mème. Cette maniere de proceder eft laborieufe, mais elle eft néceffaire.

-

\section{S E C T I O N II.}

Des divers Sols.

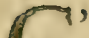

ES T dans le fein de la terre que les femences font reçìes; c'eft d'elle que les végétaux tirent toute, ou prefque toute leur nourriture; il convient donc de commencer par en examiner la nature. Puifque la terre produit plufieurs plantes, indépendamment du fecours de l'art, il faut qu'elle contienne de quoi les nourrir. Si nous pouvons découvrir quelle eft cette nourriture naturelle des végétaux, nous découvrirons aifément en quoi confilte leur nourriture artificiclle, \& com?ment'elle opere.

Les terres different extrêmement les unes des autres par leurs qualités. Les Labourours en diftinguent plufieurs fortes, \& peuttre pouffent-ils ces diftinctions trop loin.

A. 4 
Il eft vrai qu'il n'eft pas aifé de fixer le point précis où commence la différence d'un fol à un autre; mais la mème difficulté fe trouve dans toutes les divifions des corps naturels. L'Auteur de la nature les à liés les uns aux autres par des corps intermédiaires; il n's pas voulu agir par fauts, mais par gradations, afin que tous les êtres fe tinfient en quelque forte, \& que la nature ne formât qu'un feul tout. On peut réduire à fix les différences fpécifiques des terres; fegavoir, la bonne terre noire, l'argilleufe ou glaifeu. $f_{e}$, la fabloneufe, la marécageufe ou tourbe, Ia crayeufe \& le tuf.

Quand les Laboureurs parient des terres, ils les diftinguent ordinairement les unes des autres par la couleur, ou par quelque sutre qualité de leur fuper ficie, qui leur frap. pe immédiatement les f́ns. Mais la couleur ne peut jamais faire connoitre la compofition des corps oul leurs principes, defquels feuls dépendent leurs opérations \& leurs effets; \& ces qualités de la fuperficie rćfultent ellcso mèmes des parties conftitutives des corps. Wous effayerons donc de découvrir par les expériences ces parties confitutives des différentes terres, \& en quoi elles différent les unes des autres. 


\section{SECTION III.}

De la bonste terge noire.

\section{J}

E commence par cette forte de terre, parce que c'eft celle où les nourritures végétales fe trouvent en plus grande abondance, $\$$ que toutes les autres terres ne font bonnes ou mauvaifes, graffes ou maigres, qu'à pro. portion qu'elles contiennent plus ou moins de celle.ci.

Cette terse, quand elle eft fraichement fouie \& un peu moite, a une très-agreable 0. deur, qu'elle perd quand elle eft trop feche ou trop humide. C'eft cette odeur qu'on fent dans la campagne, fur-tout après des pluyes douces, précédées de quelque fechereffe. On l'attribue ordinairement aux corpufcules émanés des plantes; mais elle vient de la terre même, car on la fent partout, \& elle paroit d'autant plus forte qu'on aproche le nez plus près de la terre. Elle eft probablement dûe aux htiles \& aux fels volatils, qui s'ćlevent on plus grande quantité, lorfque la fermentation naturelle de la terre eft augmentée par une humidité ou moiteur conve nable. 
C'eft unc qualité particuliere de cetis terre, qu'elle s'énie aifément quand on la fouit ou qu'on la béche: cn quoi elle differe extrêmemcnt de la terre glaile \& de la terre tableule. La premiere ne s'émie pas; la feconde tombe en pouffiere comme le fable. La terre noire au contraile fe partage en pe. tites mottes ; \& elle paroit avoir le dég:é d'adhérence le plus propre à foutenir les vé. gétaux \& à leur permettre en même tems d'étendre leurs radicules de côté \& d'autre, pour chercher leur nourriture. Ses partics femblent avoir une tendance à fe défunir es à fe féparer les unes des autres: car on obferve que quand on l'd fouic \& laifféc à l'air, les folfes d'ou on l'a tirée ne fuffient plus pour tout concenir: effer qu'il faut attribuet à une fermentation ou putiéf,ction que l'ait: y occalionne, puifque fans air it ne fçauroit $y$ avoir de mouviment interne. Cette tendan. ee continuelle à la purrefoction dans certaincs parties de cette forte de terre, fe fait encore zemarquer dayantage par fa colileur \& par la quantité d'huile qu'elle renferme: car on fçit que l'huile eft le ftul \& unique fujet de la putréfaction. D'où il fuit qu'il doit y avoir dans cette terre un dégré de chuleur proporrionué au progrès de la fermentation putréEctive, \& indénendant du foleil \& de la 
chaleur naturelle des parties intérieures de la terre.

Une autre propriété de cette forte de terre, c'eft qu'elle admet l'eau aifément, qu'elle fe gonfle conme une éponge quand elle a été humectée, \& qu'elle fe contracte quaind elle eft feche, d'où les Naturaliftes concluent, qu'elle eft compofée de parties fpongieufes. J'aime mieux attribuer ce gonfement à la fermentation ou mouvement interne, qui eft continuel dans cette forte de terre, a que l'eau augmente: car tous les corps ont une certaine quantité de parties acjueules pour ai. derla fermentation.

On renarque que de toutes les terres, celle des marais \& fondricres cxceptées, ha plus noire eft la plus fertile. Cette coulcur eft une forte preuve que ces terres contiennent beaucoup de matieres grafles 8 huileufes; car toutes les huiles forliles \& végétales, quand elles font mèées avec une grande quantité de terre, font de cette couleui. C'eft à ces huiles qu'il faut attribucr la coulcur noire que pronnent toutes les fubltaises animales ou végétales, quand elies tournenti à la putrefaction. L'onctuofité de cotte terre, qualité que remarquent les Laboureus, eft encore une prouve de fa nature huileufe. Cette coulcur noire fait ģu'elle ne réflechit 
que peu de rayous du foleil, \& par là mêm elle la rend fufceptible d'un plus grand dégró de chaleur que les terres blanches.

Nous avons un moyen fùr de connoître fi des corps contiennent des parties huileufes ou nun, c'eft le nitre mis en fulion par le feu. Quoique le nitre ne foit pas inflammable de lui même, il le devient dans cet état, \& entre en déflagration avec les corps qui contiennent des parties huileufes.

Exper. I. Je pris de cette bonne terre à trois ou quatre pouces de profondeur, dans une plate baude de jardin, où l'on n'avoit jamais mis de fumier; j'y verfai du nitre en fufion, \& ce mélange produifit une déflagra. tion confidérable.

Pour découvrir fi cette terre contenoit des parties alkalines ou abforbantes, je fis l'ex. pétience fuivante.

Exper. 2. Je mêlai de fort vinaigre avec une double quantité d'eau: je le verfai enfuite fur cette terre graffe, \& il produifit une affe'z grande fermentation, d'où s'éleverent beaucoup de bulles d'air. Le gout acide fut détruit, \& le vinaigre réduit à un corps neutre. Cette expérience prouve, que cctte terre contient une grande quantité de parties, qui attirent les acides \& en font un fel neutre. J'ai appris par diver\{es expériences, que 
toutes les terres propres pour la nourriture des plantes contiennent plus ots moins de ces parties anti-acides.

Pour fçavoir ce qu'on peut tirer de cette ecre par la diftillation:

Exper. 3. J'en ai diftillé une demie.livre ঐ̀ un feu modéré. Dans l'efpace de deux hetk res, j'en ai tiré une once d'une liqueur jaune empyreumatique \& de la nature des alkalis. Le feu ayant été pouffé très-fortement pendant plus de neuf heures, me rendit plus d'une demi once d'une liqueur jaunâtre empyreumatique, dans laquelle nageoient des filamens huileux. Elle étoit d'une odeur approchante de l'efprit de corne de cerf, \& produifit avec le vinaigre une effervefcence confidérable.

On peut conclure de cette expérience, que les fels de cette efpece de terre font du genre des alkalis volatils; que ces fels s'y trouvent naturellement, \& qu'une chaleur modérée fuffit pour les exalter. Elle eft encore une nouvelle preuve que cette terre contient beaucoup d'huile, puifqu'elle teint l'eau d'une couleur jaune, qu'elle lui donne une odeur de brûlé, \& que dans le fegond ofrai on la voit gotter en Elamenv. 


\section{4 \\ Principes de l'Agriculture}

\section{SE C T I O N I V.}

De la terre argilleufe ou glaifeuse.

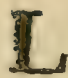

A terre argilleufe ou glaifeufe différe extrêmement de celle dont nous venons de parler. Comme elle n'eft qu'un mélange d'argille avec la terre précédente, nous allons examiner ici les propriétés de l'argille ou glaife.

La propriété diftinctive \& caractériftique de ce corps, c'eft qu'il contient toujours une ccrtaine quantité d'eau, qui empèche jufqu'à un certain point, qu'il n'en entre davantage dans fes pores. Le fluide ne pénetre l'argille qu'avec peine, par conféquent il ne peut, du moins jufqu'à un certain dégré, l'amollir ni en divifer les parties, ou agir autrement fur elle. Quand elle eft puiffamment comprimée par une force étrangere ou par fa péfanteur \& fubfidence naturelle, comme elle fe trouve au fond de plufieurs de nos terroirs, $\&$ de pref(que tous nos marais \& fondrieres, elle foutient l'eau \& elle lui devient impénéErable. A proportion donc de la quantité d'argille qu'une terre contiendra, elle réfiftera ì l'eau, \& l'empêchera de fe filtrer à travers 
de fes pores, elle tiendra les pintes dans nne hamidité continuelle, elle en aura plus de peine à être échauffée par les rayons du folcì?, \& par conféquent elle fera regardée avec ra: fon comme raturellement froide.

L'argille expofée au dégré de chaleur d'un jour d'été, fe feche \& fe durcit tellement, qu'il faut une force confiderable pour en ditvifer les parties. Cette qualité de l'argile té fait remarquer encore davantage, quand clle a été long tems imbibée d'eau, \& qu'elle vient à fe fecher fubitement. Les terres ar. gilleufes fe durcifient donc aifément au foleil, furtout fi elles ont été labourées après des pluyes, \&. dans cet état elles empecchent les racines des piantes de s'ouvrir un paffage \& de s'étendre. Cette qualité de l'argille viene de la même caufe, c'elt à-dire, de la fort ad. hérence de fes parties, dont $f a$ grande cillctilité eft encore une preuve. Mais d'où vientelle elle-même, cette adhérence? Eft.ce d'une cerraine configuration de fes parties, qui les tient liées étroitement enfemble \&i on empe. che la féparation?" ou de parties huileufes mé. lées avec les parries terreufes; car les parties de l'huile ont une athérence nature!le e̊ ne fis laifient pas aifément pénétrer par l'eau? If penche vers ce dernier fentiment, parce you j'ui trouvé que l'argille contiens une huile 
plus épaiffe que celle de la terre dont nous 20 vons parlé plus haut, très étroitement unie avec les parties terreufes, \& difficile à en fé. parer.

Exper. 4. Je mêlai de la terre glaife avec du vinaigre: il ne fe fit aucune fermenta. tion \& le goût acide fubfilta. Il paroît done qu'il n'entre dans la compofition de la terre giaife ni parties alkalines, ni parties abforbantes, en quoi elle differe beaucoup de la terro précédente.

Les Chymiftes prétendent pour la plapar que la glaife contient un acide vitriolique $\&$ une huile. C'eft par cet acide qu'ils expliquent la propriété qu'elle a d'aider à la difa tillation des acides, du nitre \& du fel, ainf que fa vitrefcibilité, parce que les fels fecon. dent puiffamment la vitrification.

M. Lemeri le fils dans les Mém. Acad. des Sciences pour l'année I 708, affure qu'il $y$ a duns l'argille des parties isuileufes, acides 82 ter. reufes, \& qu'en la poufJant par un feu confiderable, il s'en échappe des acides $\mathcal{E}^{\circ}$ des parties buileuses.

Pour découvrir par la diftillation ce que lo glaife contient, je fis l'expérience fuivante.

Exp. 5. Je mis dans une cornue une de. mi-livre de glaife feche, prife fept pieds audefious de la furface, dans uns glaifiere ou. 
verte pour une briquerie. Je la fis diftiller pendaut deux heures à un feu moderé \& j'en tirai une demi once d'eau pure. Lorfqu'elle eut foufert le feu le plus violent, que je puffe lui doner dans un fourneat portatif, pendant l'efpace de neuf heures; je trouvai dans le récipient deux dragnes ou gros d'une liqueur tranfparente qui avoit la meme 0 . deur que l'efprit volatil de corne de cerf, excitoit une effervefcence confidérable avec le vinaigre, \& rendoit verd le firop violat: le réfidu étoit rouge. Ainfi au lieu de tirec de la glaife un acide, comme les Chymiftes le prétendent, j'en tirai un efprit alksli vola. til. Il ne paroît non plus aucune forte d'huile dans cette expérience, d'ui nous pouvons conclure, que s'il y a quelque huile dans l'a-. gille, elle y eft intimement unie \& combis, née avec les parties terreufes d'une maniers analogue à ce çui arrive dans les métaux.

Qu'il y ait de lhuile dans la ghaife, c'eft un fait que plufieurs raifons me portent à croire; la nutrition des végétaux pour laquelle l'huile eft nécelfaire, l'onctuofité de l'argille, \& la propriété qu'elle a de rougir ats feu comme les mécaux.

Exp 6. Je melai de la méme giaif: que dans l'expérience précédence, avec du nure en fution. Lorfque jel'y jetto:s par perits 
morceaux, il ne fe faifoit point d'inflamma: tion; mais j'apperçus diftinctement des étincelles quand je l'y jettai en poudre; j'en conclus que l'argille contient une huile intimement liée \& combinée aves fes parties ter. reufes.

Exp. 7. Un morceau d'argille mis dans un feu de cuifine y devint rouge comme un charbon asảent, \&z quand il fut retiré, il avoit une couleur rouge, qui me parut devoir étre attribuée aux parties de fer que cette glaife contenoit. La pierre d'aiman en attira mème guelques parties, mais en très petite quantité. Sur quoi on doit fe rappeller que cette qualité dépend de la partie inflammable de ce métai, partie quilui eft toujours donnée par l'art; \& que je n'avois point ajouté d'huile à la glaife dans la calcination. Il y a très-peu de mines de fer qui ayent naturellement cette qualité, d'être attirées par l'aiman. Toutes ces expériences furent faites fur la mème glaife.

\section{S E C T I O N V. \\ De la terre fablonneufe.}

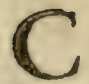

E T T E terre tire fon nom de la quantî. cé de fable qu'elle contient. Ses qualités dépendent dous de celles du fable. Ot' ce corps 
differe beaucoup des deux précédens; du dernier, eil ce qu'il admet l'eau aifóment; $\delta$ du premier, cn ce qu'il ne la retient pas de nême : car la terre noire paroît attirer fortement l'eau \& réfifter à ce qu'elle s'en échap. pe; au lieu que le fable la luiffe paffer aifément, \& ণ̧u'il ne fe gonfle pas, mais devient plus mat quand il eft mouillé. Le fable ne retient pas l'eau auffi long tems que les bonnes terres, parce qu'il ne contient point o comme elles, de ces fucs favoneux \& mucila. gineux avec Icfquels l'eau fe combine \& s'arrête. De. là vient que les terres fablonneufes manquent d'une humidité fuffifante pour nourrir les plantes, \& qu'elles font fort chaudes, car le fab!e eft fufceptible d'une'plus grande chaleur du foleil, \& il la conferve plus long-tems que l'eau.

Le fable tre fe gonfle point quand on $y$ ajoute de l'eau. Cette qualité dans les bonnes terres vient d'une fermentation intérieure qui s'y fait. Or il n'y a point dans le fable de parties fufceptibles de fermentation, \& il ne s'en trouve que très-peu dans les terres fablonneufes : aulfi manquent.elles des parties nutritives néceffaires pour faire croître les plantes. Au lieu de fe gonfter, le fable s'affaife quand il eft mouillé, parce que l'eau difpofe fes parties plus régulierement, do B 2 
forte que les interftices font plus exactemèn remplis qu'auparavant, \& que par conféquent le volume doit dininuer.

Le défaut des terres fublonneufes eft done de laiffer échapper l'cau trop aifément, \& de contenir trop peu de parties nutritives. De que'ques amendemens qu'on fe ferve pous ces terres, ils doivent corriger l'un ou l'autre de ces deux défauts. La glaife les aidera à retenir l'eau, mais elle ne leur fournira pas beaucoup de furs nourriciers. Les chiffons de laine font très-propres à remolit ces deux objets, parce qu'ils contiennent une grande quantité de fucs mucilagineux, qui fervent tout à la fois à nourrir les plantes \& à cono ferver l'humidité. Mais l'amendement guj me paroît le meilleur de tous pour les terres fab:onneufes, c'elt la terre des marais \& forlo dricres ou tourbe; car elle eft auffi impćnétrable à l'eau que largille, \& peut-étre da. vantage; \& comme elle n'eft gueres qu'uis compofé de végétaux, elle contient plus d'huile qu'aucune autre terre que je cone noiffe. Ce raifonnement eft encore appuyé par un fait. Un Gentilhomme ayant mis de cit amendement dans une petite partie d'un chamo, dont le fol étoit léger \& fablomneux 。 $f^{2}$ evoine qu'il y fena la même annnée, \& la ¿refle qui y pouffa l'année d'après, vinrent beau coup mieux que dans le refte du champ. 
Le fable, tout fec \& dur quı'il eft, paroît pourtant compofé en granle partie d'une fubftance huilcufe mucilagineufe. On va le voir par l'expérience fuivante.

Exp 8 Le g Février je pris 10 grains de purfuble de mer pilié dans un mortier, \& je les mis dans une phiole avec une dragme ou gros d'huile de vitriol. Je mis une égale guanticé de fable avec une ég le quantité d'efprit de nitre dans une autre phiole, \& dans une troifiéme phiole la mème quantiré de fable arec de l'efuit de fel murin. Le 28. Mars les acides parurent troubles. Je verfai un peu d'eaud. ns chicune des phioles, afin de faire affirfer le fubie, \& que les parties melécs avec les acides fe féparaffent plus ai. fément, \& je tiouvai que le fable de la pre. niere phiole péfoit fepr grains, \& celui des deuz autres fix \& demi. Pour précipiter \& Éparer des liqueurs tout ce qui aroit été diffous par les acides, je melai dans chacune autant de cendre de fougere qu'il en fallus pour faouler les acides. Après l'effervefcence, il fe tronva une poudre brunatre au fond de l'huile virriolique; \& une fubltance huileufe au fond des deux aurres, enticremont diftinguée de l'eau. Ce qui fut précipité de l'efprit de nitre étoit jaune, \& ce qui le fut de l'efprit cie fel étrit blanc. La pre-

133 
miere matiere, quand clle fut féparée ds l'eau, s'entamma avec le vitre diffous, ce qui me prouva que c'étoit une fubftance huileufe : la derniere ne s'enflamma pas. J'obferverai ici quie la fine poudie de picreà fufil s'enflamme fenfiblement avec le nitre diffous.

La chanx ćtant un puifiant diffolvant, fur-sout des corps huileux, je m'imaginai qu'elle pourrsit produire quelque effet femblable fur le fuble \& le diffoudre en mucilage, \& que par-là le fable pourroit fournir une nourriture propre aux plantes : je crus que c'étoit peut être par cette raifon que la chaux $\&$ le fable prennent enfemble une confiftence plus grande, \& fe lient plus fortement que les parties de la chaux ne font entre elles lorfqu'elles font feules. Cette conjecture me partut encore plus folide quand je confudérai que les fubltances mucilagineufes \& huilctfes, telles que les blancs d'aufs, l'hnile de baleine, \&c. melécs avec la chaux, lui font prendre conflitence. Pour m'en affurer, je fis l'expérience fuivante.

Exp. 9. On convient que la pierre à fufil eft de la même nature que le fable. Je pris un certain nombre de petits morceaux de picrre à fufl, pcfant en tout une dragne $\$ 2$ grains \& demi, \& $\overrightarrow{j y}$ mêlai une certaine quantité de chaux \& d'eau. Ils refterent 


\section{ES de lis Végétation.}

dans la chaux depuis le g Février jufqu'as 23 de Mars. Quand je les eus retirés \& fechés, je les péfai \& j’y trouvai le même poids que d'abord.

Exp. 10. Pour voir quel effet le mucilage extrait du fable par les acides produiroit fur la chanx vive, je mèlai avec de la chaux vive une petitc quantité du mucilage extrait par les deux acidies, \& j'en formai une pâte. Je pris une autre quantité de la même chaux, dont je fis aulin une pate avec de !'eau feulement. Je laiffai ces pâtes pendant quatre femaines, \& lorlqu'elles furent entierement feches je trouvai que ni l'une ni l'autre n'avoit pris liaifon.

Ces expériences paroittront contraires aux principes que nous avons établis plus haut. Cette queftion eft fi importante, fur tout pour la conftruction des bâtimens, qu'elle mérite d'être examinée avec plus de foin.

\section{SE C T IO N VI.}

De la terre crayeufe.

Je dirai peu de chofes de cette forte de terre. Comme elle nicft pas commune en Angletcrre, je n'ai point ell oceation d'en 
sencontrer, \& je ne veux rien rapporter fue ba foi de ceux qui raifonnent fans s'appuyer fur l'expérience.

La craye eft un abforbant, \& il n'entre aucunes parties huileufes dans fa compofition, mis elle les atire puiffamment. D'où nous pouvons cunclure, que les amendemens les plus convenables pour les terres de cette nature doirent étre les corps qui contionnent beancoup d'huiles, comme les chiffons, les crins, \&ac. Elles n'attirent l'eau que föble. ment, ainfi éles font en général trop feches. Les Labouret:rs ont rinarqué qu'elles fe curciffent après de fortes pluyes.

\section{SECTION VII.}

\section{Dii Tuf.}

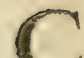

ET T E forte de terre cft rouge ou grife ou jaunatre. Elle ne produit d'elle méme aucune plante, \& n'eft pas auffiaifément ni auti promptement renduc fertile, que colles ciont nous avons parlé. Quelquefois mè. me elle réfifte à tous les frins qu'on peut prentre, \&rend uns les cfforts du Cultivascur autiles. (es tcores done non feulemente ne contiennont aucure nourtiture your les 
végétaux, mais renferment fulvent un poi. fon qui les fait mourir; autrement on viendroit toujours à bout da les lertilifer à force d'engrais. Mais qual eft il ce poifon? C'eft ce que nous allons examiner ici: car ce ne pourra ètre qu'après l'avesir connu, que nous Eçaurons s'ily a du remede ou nor.

J'ai fair les expériences fuivantes fur quelques-unes de ces mauvaifes terres, que m’avoit montrées un Fermier très intelligent.

Exp. II. Elles produifirent une tfiervef. cence fenlible avec le vinaigre \& l'huile de vitrio! délayée daus de l'eau: elles avoient un goút de fer, \& noirciffoient avec la diffo. lution de noix de galle.

Exp. 12. Quelques mottes de cotrcterre calcinées dans un feu violent pendant deux heures, furent prefque toutes attirées par l'aiman.

Exp. I3. Elles ne produi irent aucune dé. figgration, étant nelécs avec du nitre cus fufion.

Exp. 54. Quatre onces de cette terre de couleur brume, bien fiches, ayant éré diftil. lées, ilonnerent en fix heurts deux dragmes d'un ph'egme qui parut n'è:re ni de la nature des acides, ni de celle des a kalis.

Il paroît par ces expériencss, que cette forte de terre ne contenoit ni fels ni huiles, 


\section{6 principos do isgriculatre}

mais qu'cl'e n'étoit qu'une compofition de parties terreufea \& e ferrugincufes. Le poiton. ou mauvaife qualité de ces torres, vient is ce dernier cosps, qui, comme on peut lo voir par la premiere expérience, fe finout dans tous les acides, \& qui, quand il c!t ainfi diffous, pénetre dans les vilfeans des piantes. Nous verrons dans la fuite qu'il y trouve des acides. L'expérience fuivante net cette conjecture hors de doute.

Exp. 15. Je pris une livec de bonne terre, \& j'y mêlai une dragme de fel macial: je la mis dans un pot \& j'y femai de l'orge au commencenent de Mui. Qhilques grains poufferent, \& crîrent à peu press a la hau eur d'ua pouce. Ils paroilioient jaunâtres \& ma. lades, \& ne tarderen pas à mourir, tandis que d'autres grains finés dans un autre pot rempli do la meme terce, vinrent très bien. Ainfi line tres perite quantité de fer, diflous par l'acide ritrioligue, fuffiz pour rendre ftérile une guande quantité de bonne terre, i parconfénuent il boir ćtre regardé comme le poifon q̨ui caule la ftérilité des terres dont non's parlons ici. Sil'on peut y temédier, je crois que ce ne peut gueres être gue par la marne ou la chitix, qui attireront les acides dn fer, \& le rendront, du moins en grande partie, indiffoluble dans l'eau. 


\section{E9 de la Vegétatici.}

Quoique le mélange du fer arec la terre foit la ciufe la plus générale de fa ftérilité. il paroîr pourtant qu'elle n'eft pas la feule: le manque des principes néceffaires à la végó. tatiun doit produire le mème effet.

Les Fermiers regardunt ordinairement $h$ craye durcie comme une forte de tuf, particulierement quand ils la trouvent fous la terre en labourant. Les Laboureurs ordinaires craiguent de l'entamer, parce qu'ils la jugent ftérile; mais les plus judicieux ne font point difficulté d'y enfoncer la charrue, ils en prennent peu à peu, \& trouvent que la chaux, le fumier \& l'air la fertilifent aifément.

\section{S E C T I O N VIII.}

De le tourbe ou terre des marais ou fundrieres.

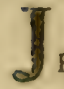

E n'entremi point ici dans une difcuffion lur l'sigine \& la nature de cette terre. On convient mantenant que c'elt une fubftance végétale. L'expérience fuivante en fournit la preuve.

Exp. 16. Une demi - livre de tourbe réduite en poudre, me donna, par la diltilidtion, dans l'elpace de deux hcures, deus un- 
ces d'une liqueur acide empyreumatique de $c$ :uleur jaune, \& qui fit conroî:te fa nature acide en tirmentant avec l'huile de tartre par? défaillance. Un feu violent continté pendant plus de neuf heures, me domna dis drog. mes d'une liqueur rougeâtre empyreumatique plus acide que la premiere, \& un furt. pule d'une huile épaiffe \& noire. Ontre cela il fe trouva autour dia col de la cornue une grande quantité d'huile rouge, que fon po.ds avoit empé hé de s'élever p'us haut. Le réfidu étoit noir.

Exp. 17. De la tourb brulée à $f(u$ nud medonua environ trentculeux parties de fel alkali.

Nous voyons par.là que la tourbe cionre les mèmes princip.s que les aun! es végćtaux. \& que par conféquent on doit la ranger dans cette claffe.

Le foul moyen de rondie cotie forte de rerre fertile, c'eft de rébuire les végétaux en pourriture, en labourant la terle, \& faifant par li mourir les plantis. Tous les vécét :ux de tournent en bonne terme enand its nnt foud:rt un dégré de purtéfenti n. L'ícrecc meme du chen fuit de la bume tore quant cile at pentrie. Les parties te léparcront

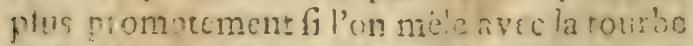
ce la sateus de l'argille; car la tuube it 


\section{É de la Végetation.}

a'elle méme ennemie de la putrélaczion. Toutes furces de fubltances vígécales \& corr's d'animaux mis dans la turbe y font préfervés de la corrupionn pour toujuurs. On fg̨it q̧ue les abforbans fervent puifimment à $l_{3}$ putréfaction. Les diverfes fortes de marne guand on peut en avoir, \& fur-tout celle çui eft formée de coquilles, me parcîtroiunt lengrais le plus propre pour les terres des marais ou fondrieres. La chaux, qui paroît étre un puifiant diffolvant de toutes les fubffarces végétales, peut avoir aufin de bons effets fur cette forte de terre.

\section{SECONDE PARTIE。}

PREMIERE SECTION.

Des moysus que la nuture employe pour fournis aux plantes las nourriture végétaie.

A proprićtés des divers lols, l'ordre naturel des chofes demande que nous traitions maintenant de la nature \&́x des piopriécés de tous les corps, que rous fçavons par expérience sontribues is fertilifer la terr? fuit ygu'ils $y$ 
foicint apprliqués par la nature ou par l'art. Si solis pouvons découvrir quelques qualités communes à tous cos corps, nous parviendrons plus aifément à connoître ce qui fait J'objet de nos recherches, c'eft à dire, quelle eft la nourrituie propre des végétaux, ou du moins gquels font les principes qui entrent dans fa compofition. Examinons done d'abord les voyes que la nature prend pour ren. dre la terre fertile.

L'expérience nous apprend, que la terre épuifée de nourritures végétales, en recouvre de nouvelles lorfqu'cin la laife repofer: preuve que ces nourritures augmentent continuellement dans la terre, quand elle n'en eft pas dépouillée par les plantes. Pour découvrir d'où lui viennent ces nourritures végétales, il fuffit de fuire attention à deux faits: le promier, que plus la terre eft expofée à lair, plus ces fuss nourriciers font réparés promptement \& en plus grande abondance: le fecond, que quand la fuperficie du fol eft enterrée par le labour, \& le fond du fol expo. $f^{\prime}$ à l'air, cette nouvelle terre, quoiqu'en apparence aufi bonne que la premiere, ne produit gueres que de mauvaifes herbes jufqqu'à ce qu'elle ait reçu pendant quelques an. nées les influences bienfaifantes de l'atmof. phere. 
Les façons qu'on donne aux terres font ane preuve de ce que nous venolis d'avancer. Les labours brifent, retournent la terre \& en expofent les différentes parties à l'influence de l'air. Or que ce brifenent, cette tritura. tion de la terre, parl'action méchanique du labourage, ne foit pas, comme Tull l'affure, le principal moyen d'augmenter la nourriture des végétaux, c'ift ce que prouvent clairement deux autres faits: l'un, que le fol même le plus léger s'améliore par le labour: l'autre, que quand la terre eir jachere eft difpofée en fillons, clle devient plus fertile, \& recouvre plus de nourri ures véréiales que quand on la laiffe toute plate.

Cette influence de l'air fur la nourriture des plantes, fe fait remarquer encore davantnge dans les mortes de terre qu'on éleve en forme de mur autour des parcs à molltons. Ces mottes de terre reftent expofées à l'air, qui pafte \& repaffe entre elles, pendant plufieurs mois. La terre ainfi expofée de. vient fi prodigieufement fertile, qu'on la diftingue très-aifément à la quantité $\&$ au verd foncé des grains, d'avec les parties intérieures du parc, quoique bien engraiffées par l'u. rine \& le fumier des troupeaux. Il a méme été obfervé par les Laboureurs, que cette terse rcfte fertile pendant trois ou quatre ans pius 
que les autres parties do parc.

Lair eft doac le premier moyen que la nature employe pour ferritifer les terres: les meilianres mème ont continuellement befoin de fon influence. Nous ne pourrons connoide quels principes de l'air dépend la propriété qu'il a de fertilifer la terre, jufqu'à ce que nous nous foyons affurés de la nature des divers engrais, qui paroiffent opérer en attirant ces principes. La force végétative puiffante \& durable, que l'air communique à la terre, doit potter à en faire plus d'ufege qu'onne fait communément. Pourquoi ne pas préparer toute la furface d'un champ, comine ces murs de pare dont nous venons de parler? Toute autre préparation, tout autre en. grais n'opere que deux ou trois ans après quu'on les a emplnyés : celle-ci opere inmmé. diatement. Un Fermier ne peut, année commune, fumer un acre de terre à moins de 5 livres, l'opération, que je propofe, ne coûteroit que trente fols. Le fumier remplit la terre de quantité de mauvaifes herbes: notre méthode l'en délivre. On ne trouve pas du fumier \& des engrais par tout : notre pria. tique peut être empioyée daņs tous les pays. Elle fernit fur tout avantageufe dans les ter. res glaifeufes, que les vicififitudes \& change. nuelis fuccefiff de l'air pulvériferoient. 


\section{ể de la Viegetation.}

L̇a rofée contribue auffi beaucoup à fertilifer les terres: tous les Labourcurs en conviennent. Elle eft formée de la tranfpiration de la terre, de celle des végétaux \& animaux dans leur état naturel, \& de leurs exhalai. fons, quand ils font dans un état çe corrup. tion. La chaleur que la terre conferve, même après que l'influence du foleil ct affoiblie, exalte ces corpufcules atténués; mais l'air . qui $\int e$ réfroidit plus promptenient à caufe de fa raréfaction, les condenfe à une diftance médiocre de la fuperficis de la terre, où re. tombent ceux qui deviennent fpécifique. mnent plus péfans que l'air. Les rofées diffé. rent donc entre elles à proportion de la différence des corps d'où elles font élevées, \& les principes qu'elles contiennent ne font pas par tout les mèmes. Néanmoins l'expérience nous apprend qu'elle eft compofée communément d'huiles is de fels, mêlés avec une grande quantité d'eau. Nous verrons dans la fuite de quel ufage font ces principes pour la végétation. L'eau de pluye, fur-tout dans le printerms, eft compolée des mémes man ticres.

On met avec raifon la neige au rang des corps qui fervent a fertilifer la terre. Jairemarqué un léger fédiment au fond de l'eau de neige findue, après l'avoir gardéc trois 
ou quatre jours. Lorfque la neige fe fond, fa fuperficie mente fur le fommet des mone tagnes, cft couverte d'une poutfiere brune. L'eau de piuye is de neige fe pourriffent plus prompt: mont que l'eau de fource, preuve certaine qu'elles contiennent plus de parties huileufes.

Exp. 18. Une livre \& demi d'eau de neige évaporée me donna deux dragmes d'une liqueur rougcâtre, qui n'avoit que peu de goút, \& n’annonçoit aucune partie faline. Je la mis dans un fellier pendane quatorze jours, \& quand je la retirai je la trotivi couverte d'une fubftance moifie. Lorfque cette fubftance fut deffechée, elle prit feu fur un fer rouge, \& fe réduifit en poudire: d'où l'on peut conclure qque la neige contient une fubftance huileufe.

Les inondations dans les terreins bas font encore mis au rang des moyens naturels d'amender les curres, foit que les eavix de pluye y tombent directement, ou qu'elles y coulent des terrcins plus élevés. L'Egypte eft iizondie tuus les ans par le Nil, \& devient par-là extrimement fertile. L'cau de fource eff encore de quelque utilité pour fertilifer la terre, mais elle y contribue beaucoup moins que l'eau tes rivieres, principalement de celles qui paffent par des pays fertiles: parce 
qu'alors elle eft remplie des plus fubtiles parties terreufes, que les pluyes ont emporté des bomes terres. Lorfque les eaux inpregnées de ces parties terreufes $\&$ des fucs favo. neux des terres oì elles ont coulé, féjournent dans les terreins bas, ces parties nutritives tombent au fond \& les fertilifent. Le Nil dépofe une vafe riche, un limon fertile \& $f$ rempli de parties tendantes à la putréfaction, que fon odeur forte femble être la caufe des fléaux dont l'Egypte eft fouvent affligée. C'eft cette augmentation annuelle du fol qui a élevé le niveau de la terre beaucoup plus haut qu'il n'étoit. C'eft auffi pour la même raifon que dans tous les pays les vallées font plus fertiles que les terreins élevés; les pluyes emportant toujours des hauteurs une partie des matiéres végétales, qu'elles laifiente dans les fonds.

L'art imite fouvent la nature dans cette maniere d'améliorer les terres; on conduit l'eau des rivieres dans les champs, où l'on les laiffe féjourner quelque tems : ce qui fe pratique fur-tout dans le printems, lorfque ces caux font plus impregnées de parties nutritives. Quand elles ont dépofé ces parties, ce qu'elles font en quatre ou cinq jours, on les filit écouler enticrement, de crainte qu'en s'ćvaporant par dégrés, elles ne refferrent

C 2 


\section{$3 \dot{6}$ Trincipes de l'Agriculture}

trop la terre, \& n'empêchent l'herbe de poufo fer. En effet c'eft ce que cette opération a de plus dangereus, \& par cette raifon on ne doit pas l'employer dans les terres argilleufes.

Il faut obferver ici qu'il y a des caux extrê. mement préjudiciables aux terres; par exemple, les caux qui pafient par des mines de fer ou de chaıbon, car les parties ferrugineules que ces caux contiennent font mourir les végétaux. Les eaux fulphureufes font aufi tres-nuifibles aux terres. Nous verrons dans la fuite que le foufre $\epsilon$ t un poifon pour les plantes.

\section{S E C T I O N II.}

Des engrais ou moyens que l'art employe pow' fournir à la terre des nourratures végétales.

$\mathbf{L}^{\prime}$ que certaines fubftances jettées fur la terre avec certaines précautions la fertilifent. Css fubftances font tirées ou du regne minéral, ou du regne vćgétal, ou du regne animal. i.e regne minéral comprend les diverfes fortes de marne, les pierres calcaircs telles que la pierre à chaux, la craye, \& c. \& la chaux 
vive. Le regne végétal comprend tous les végétaux \& leurs fucs, foit duns l'érat natu. rel, foit dans un état de corruption, les cendres des végétaux \& la fuye. Lercgne anima! renferme les coquillayes calcaires dans leur état naturel ou dans l'état de putréfaction, les os, cornes, crins, chifions de laine, \& autres fubftances animales, comme les fientes, urines, \&c. Je traiterai par ordre de tous ces divers engunis.

Je ne dirai rien de la maniere de los em:ployer, je ne parlerai que de ce qui pourra fervir à faire connoítre comment ils operent, \& les qualités par lefquelles ils produifent certains effets fur la végétations des plantes.

\section{SECTIO.N III.}

De la Marne.

\section{\%1,}

EsT un corps folfile, qui an toucher parríc onctucux \& gras: il reffemble beaucoup a la terre glaife; \& quoigu'il foit fort différent, on le confond fouvent avee elle. On en diftingue pluficurs efpeces, que zous renfermerons toutes fous les deux fuivantes, l'argillcufe \& l'ardniliere; car celle 


\section{8}

\section{Principes de l'Agricularure}

gुu'on appelle Morne coquillaire, eft une fut: tance animale, \& par conféçuent elle doic étre placée dans une autre clatle. Les différentes couleurs des marnes ne caufent aucune différence dans leurs propriétés.

Exp. Ig. C'ctt une qualité diftinctive \& caractériftique de ce corps, que quand il efe mis dans l'eau, il tombe au fond en poudre. La marne argilleufe fe diffout plus vîte que la marne ardoifiere. Cette propriété vient de ceque fes parties n'ont qu'une foible ad. hérence entr'elles; de forte que l'eau, quoiqu'entrant avec très peu de force dans fes pores, en divife aifément les parties. Cette qualité la diftingue fuffifamment de toutes les autres terres lont nous avons parlé, \& par. ticulierement de !a terre giaife, qui n'admer pas l'eau fi facilement.

La marne étant fi aifénent divifée par l'cals, qu'elle perd enticrement fon adhérence naturelle, il eft clait q̨u'clle aidera l'eau c̀ s'échapper des terres où on l'aura employce. Les terres glaifeufis, quand elles ont été matnées, deviennent plus féches. C'st auffi, je crois, parce que l'eau s'en échappe plus vîte, que les terres, q̧uand elles ont été marnées, fint ainfi qu'on l'a obfervé, moins fisjettes à la gclée, qque quuand elles ne l'ont pas été. 


\section{5 de 7o Végétation.}

Exp. 20. Elle fermente avec tous les diffésens acides, \& combinéc avec eux, elle fe convertit en un fel neutre. Pendent qu'elle fermente avec l'huile de vitriol, on fent une odeur fulphureufe; forte préfomption qu'elle contient quelque fubfance huileufe. La marne argilleufe m'a paru fe diffoudre plus promptement que la marne ardoifiere, \& elle détruifit environ un tiers d'acides de plus. Cette propriété qu'a la marne d'attirer \& de détruire les acides, eft une de fes qualités diftinctives, fans laquelle une terre ne fçıuroit être regardée comme vraye marne. Cette qqualité la diftingue auffi de la glaife.

Les Lahoureurs, qui d'ordinaire font très-peu exacts dans les termes, donnent fouvent le nom de marne à des corps qui ne fermentent pas avecles acides. On ne fçauroit douter que ces corps ne puiffent fervir \& ne fervent réellement à fertilifer la terre, mais on ne doit pas fur cela les regarder comme des marnes. Affurément des corps, dont les uns fermentent \& les autres ne fermentent pas avec les acides, ne font pas de la mème nature, \& ne doivent point avoir le méme nom. Le nom de marne ćtant donc donné communément aux premiers, on do. vroit en domner un autre anx demiers, poun: les diftinguer de la vérituble marne. 
axp. 2 I. Une autre propriété de la mấ: ne, yui la diftingue de la terre glaife, c'elt qu'on ne fçaurnit en faire de la brique. La force du feu l'altére confidérablement: elle y perd fa qualité anti-acide, \& n'cft plus diffo. Iuble dans l'eau comme auparavant. Mais elle differe encore beaucoup d'une fubftance demi-vitrifée; \& je ne f̧̧ais fi elie pourroit ou ne pourroit pas fe vitrifier en y ajuutant quelqu'autre corps. C'elf une forte preure qu'elle ne contient ui acide, ni fols akalis ou neutres: car ces matieres mêlées avec la chaux, rendent la chaux même capable d'être vitrifiée.

Exp. 22. Je n'ai pû tirer de ces marnes aucun fel, foit par fimple leffive, foit par diftillation, quoique je les euffe pouffées à un feu irès-violent. Le feu n'en fépara qu'un peu d'eau, qui me porut a.kalifante; ce qui venoit peut être des plus fubtiles parties de la marne que l'eau avoit emportées. Jo n'apperçus aucune huile dans la diftillation : mais ja poudre de narne jettée dans du nitre en fufron, produifit quelques étincelles. Ces étincelles \& l'odeur fulphureufe qui fe fit fentir quand la marne fût diffolue par l'huile de vitriol, me porteroient à croire qu'il entre dans fa compofition une très.netite partis de mntiere huileufe. 
Miais, quoique peut être la marne ne condienne aucune huile, elle les artire puitiom. ment: c'elt une qualité qu'ont toutes les terres abforbantes, comme les Chymiftes le fçavent; auffi s'en fervent ils pour féparer les huiles des autres corps. Il fuic de là que la marne attirera \& fixera les huiles qui fe srouveront dans la tcré, \& qui y feront tombées aver la neige ou la pluye, \& mème celles qui flottant dans l'air toucheront à la Luperficie de la terre.

La marne eft donc compolée d'une terre anti-acide, dont les parties font aifément féparées par l'eau, \& artirées jufqu'à un cerrain point par ce fluide, lors même qu'il ne les diffout point, \& d'une tres petite quantité de matiere huilcufe.

Il y a un corps tres reffemblant à la marne en apparence; mais quicn elt fort uifiterent quant à feseffets. On le trouve fouvent dans la meme couche que la marne. Il eft d'une coulcur plombée \& noiratre; \& au-licu de fertilifer la terre, il rend les meilleures ménes incapables de produire aucune forte de vefótaux pendant plufieurs années. J'ai vú dos morceaux de terre, où l'on en avoit mis, tout-à-fait ftériles trois ans après; jai sui dire mene qu'us d'autres endroits ces pnauvais effets duroicnt encore plus long- 
tems, \& l'on ne fçait pas certainement quand ils doivent finir.

Un corps fi pernicieux dans l'agriculture mórite bien d'ère exact ment dépeint \& caractérifé, ấn qu'on ćvite d'en faitc ufage. Il faut l'examiner avec foin pour reconncitre d'où provient fà mauvaife qua'ité, \& comment on peut y remédier, quand il a été mis dans une terre.

Ceux qui ont le mieux conmu la marne, ont déjà remarqué une différence entr'єlle, Es le corps dont il s'agit ici. Ils ont obfervé que la marne prend un certain poli, quand les ouvriers la travaillent avec leurs outils; ce que le dernier corps ne fait pas: mais cette qualité ne fuffilant pas pour diftinguer affez ces deux corps l'un de l'autre, recou. rons aux expériences, afin de le reconnoitre encore plus fürement.

Exp. 23. Qu'on prenne de cette mauvaire terre, une motte qui n'ait pas été long tems expolée à l'air, on verra qu'elle a un gnût tout à fait différent de la marne; au licu que la marne a un goût doux \& onctueux, l'autre corps a un goût acide \& tres-altringent.

Ce corps refiemble à la marne en ce qu'il tombe en pouffiere au fond de l'eau; mais méme alors il differe notablemert en ce qu'il n'excite aucune fermentation avec les acides, 
Q qu quil n'en détruit pas l'acidité.

Il rend fe frrop de violettes rouge, ce qui montre qu'il contient un acide; au lieu que la marne, comme toutes les terres abforban* tes, lui donne une couleur verte.

Ces qualités fuffifent pour apprendre aux cultivateurs à diftinguer de la marne ce corps pernicieux \& à l'éviter. Effayons maintenant de découvrir de quels principes dépend fa mauvaife qualité: car fi nous pouvons en connoître une fois la nature, peut être trouverons-nous quelque remede à y apporter; outre que toutes les recherches de cotte nature conduifent toujours directement au vrai fylteme de la végétation. Les végétaux, comme les fubftances animales, font également connoître leur nature par leurs mau. vaifes \& par leurs bonnes qualités,

D'après mes expériences fur le tuf, j’ai penfé que la mauvaife qualité du corps, quue nous examinons, pouvoit venir de ce qu'il contiendroit quelque fet martial. J'ai done dirigé vers cet objet mes expériences.

Exp. 24. J'en ai infufé daus l'eau chaude. L'eau prit une couleur verdâtre, un gouit affez acide, \& une qualité très altringente. Il donna au firop de violette une couleur rouge pále. L'huile de tartre par défaillance que 'y mis goute à goute, n'y caufa aucune effer- 
vefcence fenfib?e, mais clle en fépara quel. ques bulles d'aik, le dicolora \& cn précipita me poudre d'un rougc-pale, je nis de certe poudre dans un cöeuter, S la laifili fur le feu pendant une demi heure. $J$ o n'en retitas ฤ̧u'une très-petite quantité, qui mème étoit mélée avec quelques parties de la maticre du creufet; cependant laiman cn attira quelques particules, preuve qu'elles contiennent dufer. La liqueur évaporée me donna un tartre vitriolé.

L'infufion pure ne changea print de cou. leur quand j'y mis de la noix de galle : mais ce n'êtoit pas une preuve que la liqueur ne contenoit aucun fel martial; cir un feul acide détruit cet effet de la noix de galle, \& mous avons déjà vâr que cette liqueut en consenoit quelqu'un. Pour dérruite cet acide, je verfai de l'huile de tartre par défaillance, dans le mélange de l'infufion \& de la noix de galle. Il prit aufitôt une couleur brunatre; il fe tit une précipitation abondante, qui en vingt quatre heures devint de couleur de pourpre.

Je fis bouillir dans l'eau une certaine quantité de cetce terre pendant une denil heure. Je la paffai \& l'évaporai. Il me relta une fubfance frive blanche, dans la proportion de IIx grains pour chaque once, \& qui avcit 


\section{ê de la Vigétation.}

Trécifément le mème goût que le fel martia?. Cette fubitance faline diffoute dans l'eau donna au firop de violette une couleur verte, comme fait le fel de Mars, \& prit une couleur noire foncée avec les noix de galles : preuve fuffifante que c'étoit un fel martial, Et fa couleur ne peut faire ici une objection 3 car le felde Mars réduit en poudre par la tri= turation, l'évaporation, \&c. eft blanc, \& le mien étoit en poudre.

Il parcit donc hors de doute que cette fubftance eft compofée d'un corps terreux, fem. blable à l'argille, a vec un quatre vingtieme de fel martial, \& une très-petice quantité d'acide vitriolique. D'autres expériences, que i'ai faites, m'ont appris que les mauvais effets de ce corps ne vicnnent point de cet acide vitriolique, principalemsnt parce qu'il paroît y être très-volatil; \& d'un autre côté nous avons déjà reconnu la pernicieufe qualitédu fel martial. On ne cloit pas être furpris que ce corps acifie ici avec tant d'efficacité, li l'on confiủere en quelle quantité on ie jette fur les terres, \& combien il contient de $\mathrm{fcl}$ : le fol doit en être critiersment impregné.

Mais comment cerriger cette mauvaife qualité, fi par méprile on venoit à employet sette matiere ou queluqu'autre femblable; 


\section{Princiyes de I Agriculiture}

car la charbon de terre produit les mèmes efo fets par la mêne caure? Il paroît qu'il n'y a point d'autre remede que d'en décompofer tellement le fel, que la partie ferrugineufe ne puiffe plus fe diffoudre dans l'eau. L'air en volatilifant les acides, \& en féparant les parties de fer, produxit peu à peu cet effet fur le fel martial diffous dans l'eau; mais dans le cas préfent, l'acide ne pourra agir fur les fels, à moins que la terre ne foit fréquemment retournée; \& même alors la plus grande partie du fel fera défendue par les parties huileufes de la terre. La marne me paroît le vrai remede: car cette terre abforbante ayant, avec l'acile vitriolique, une plus grande affinité que n'en a le fer, elle s'unira avec l'a. cide, f́́parcra les parties de fer, \& les rendra indifolubles dans l'eau, \& par-là mème in. capables de pénétrer dans les vaiffeaux des plantes. La plus grande partic des bons efrets de la marne lur les terres, vient peutêtre particulierement de ce'ui-ci ; c'elt.à-dire, de la ciefruction d'un corps, qui proportionneilement à fa quantité, détruit toute végétation.

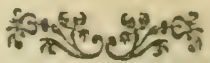




\section{SE C T I O N IV.}

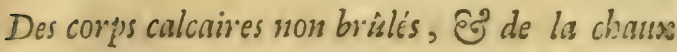
vive.

I a craie eft reconnue par la plûpart des Ecrivains comme un engrais propre aux terzes humides \& argilleufes. Ce corps divife la terre \& l'attenue: il y produit des cavités \& crevalfes; il la tient féche, \&, comme p.rlent les laboureurs, il l'adoucit. La craie la plus donce \& la plus onctueufe eft la meilleure. Les fermicrs croyent qu'elle épuife extrèmement la terre; \& par cette raifon, ils croyent communément qu'il faut en même-tems y mettre du fumier. La pierre à chaux en gravois eft fouvent employée com. me engrais dans l'Irlande.

Ces corps calcaires ne fe diffolvent que par les acides. Lorfqu'on les méle avec eux, it furvient une forte effervefcence, la folution du corps fe fait, \& de leur union réfulte un fel neure. Co fel ncutre elt toujours difionluble dans l'eau, à moins qu'on ait fait uiage de l'acide de vitriol.

Les pierres calcaires, quand elles ont paffé par un feu ardent, fe convertiflent en chaux 
vive, matière dont les Laboureurs font for:vent ufage. Alors elles attirent les acides beaucoup pius fortement qu'elles ne faifoien's auparavant; \& peuvent jufqu'à un certain point, fe diffoudre dans l'eau fans le fecours desacides. Cen'elt pourtant pas de ces partiss folubles que dépend la qualité qu'elles ont de ferti:fer la terre : car elles n'y produifent aucun effet fenfible, finon qu'elles font mourrir les vers la premiere année, où ces parties font le plus folubles dans l'eau. Pro. betlement la chauz n'elt plus vive ni foluble, quand elle commence à agir fur la terre, \& qu'c!le y feconde la végćtation. La cliaux des vicilles maíons, \& qui pour lors a perdus toute fa force, paffe pour meilleure que h chaux vive toute fraiche.

Il y a une forte attraction entre la chaux vive \& tous les corps huileux : elle s'unit immédiatement avec les huiles; c'eft pa: cette raifon qu'on s'en fert dans les manufacturcs de favon, pour procurer \& conferver l'union des fels alkalis \& des huiles. Elle doit donc attirer puiflamment, tant de l'air que de la terre, les huiles qu'elle y trouve, les diffoudre, \& les rendre propres à f́c mê. ler avec l'cau. Ainfi elle épuifé promptement to ites les parties hrificules de la terre, fi les Labouteuls ne preinent foir d'y fuppléer 
par le fumier \& par les fubttances animales. L'expérience leur avoit appris que la chaux appauvrit les terres; mais ils ignoroien* comment elle produir cet effet : elle l'opere en épuifant les huiles de la terre. La chaur mife dans une terre épuifée par de continuelles récoltes, la détériore donc pluttôt qu'elle ne l'ameliore; parce que ne trouvant plus d'huiles fur lefquelles elle puiffe agir, elle agit fur la terre mème, \& l'affoiblit. Le meil. leur remede contre cet inconvénient, c'eft de mêler du fumier avec la chaux, afin qu'elle trouve fur quoi agir.

La chaux eft un puiffant diffolvant de tous les corps, tant végétaux qu'animaus, mais fur-tout des derniers. On fçait avec quelle promptitude elle réduit les crins, les chiffons de laine en une fubftance pulpeufe. Cet effet elt fi prompt que dans le langage ordinaire on dit qu'elle les brûle. Elle opere af. furément de la même maniere dans la terre, en y diffolvant toutes les fubitances animales is végétales, qu'clle change en nourriture des végétaux beaucoup plus vite qu'ils ne pourroient le devenir fans cela.

Elle réfifte puiffamment à la putréfuction. ninfi que l'expérience le démontre. On is donc tert de mêler comme on le fait quelque. fuis, la chaus vive avec des fumiers, quii na 
font point fuffilammeni putréfés, car elle les empecha de le pourrir davantage. Quand In putrétuction eft achevée, ce mélange peuts produire plutieurs bons cffets, \& particulierement celui de fixer les huiles \& d'en em. pêcher la volatilitation.

On a ohfervé que la chaux s'enfonce tous. jours dans la terre; de forte qu'en peu d'années on en trouve la plus gran te partic fous terre à la profondeur de la charue; ce qui vient de la gravité fpécifįue.

Les Labuureurs ont encore obfervé que duran les trois premieres anriées, la chaus produit de meilleurs eff.ts dans les terres légeres \& po eufes, que dans celles qui foni plus fortes \& plus denfes; mais ce terme paffé, f.n opération s'affoiblit. L'air pénetre plus aifément les fols légers; \& crommz les bons cffets de tous les ingrais dépendent de l'air, lon influtuce doit être plus grande dans les terres porcufis que dans celles qui fone plus comfacisa; mais autfi les terres légereß Erant plus porcufes, la chaux paffe prompreo mont à travers.

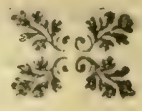




\section{SECTION T.}

Des végétaux tant dons l'citut natuvel que dasus un icat de putréfuction, $6^{\circ}$ destas de fumiss.

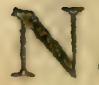

o U $\mathrm{s}$ allons paffer maintenant aux en. grais tirés du regne végétal. Tous les végé. taux, exceptés quelques uns qui font perni. cieux, nourriffent les plantes. La poudre de dreche eft regardée comme engrais exce!lent: l'écorce d'arbre \& la fcicure font recommandées par quelques Ecrivains: Columelle nous apprend que les Anciens jettoient fur leurs terres les lies d'huile d'olive, \& trouvoient qu'elles y faifoient beaucoup de bien. Et affurćment il n'eft point étonnanc que les fucs des végécanx déjà préparés par une forte de coction, devienisent un alimens pour d'autres végétauz. Mais il faut braucousp de tems avant qu'ils puiffent être rélluits en parties afiez déliées \& affez Enes pour pouyoir entrer dans lis vaifficaux des plantez. La purréfaction ett le moyen le plus piompe \& le plus efficace pous y parvenir. On veit Far la pouryuoi la cirenevorce, ou partic ligneufe dis lin, ne profuit pas de bonis effe is fir lcs terres: ceit rue les fucs en ont déjà éiş

D 2 
extraits par la putréfaction que le lin a éprout: vélorfiu'on l'a roui, \& qu'il n'y refte plus que la terre.

Les differentes efpeces d'horbes marines font aulfi fort bonnes pour les terres, fur. tout lorfque ces herbes font d'un tiflu douse \& pulpeux, \& fe diffolvent aifément: d'nilleurs il n'y a point de plantes qui contiensent autant de fel \& d'huile à proportion de leurs parties terreufes. Les fels y font en fi grande abondance, que l'algue, quoique très-feche, ne brûle pas aifement : car tous les fels, excepté le nitre, font, comme on f̧̧ait, ennemis du feu. On a remarqué que les huiles s'y trouvent auffi en grande quantité, \& c'eft ce qui fait que cette plante, malgré fes fels, fe pourrit fi promptement. Ses cendres font compofées de parties à peu près égales de fel alkali, de fel marin, d'une fubltance huileufe, \& de terre.

Le fumier a été probablement le premier engrais employé par les Lahoureurs, parce que tous les végétaux fe convertiffent d'eux.memes en fumier, \& que le hazard en aura Rait connoître plâtôt les bons effets. C'ęt maintenant l'engrais le plus ufité. La man niere dont il fe forme eft donc un objet digne de notre attention, \& peut ouvrir des vîcs utiles fur ce qu'on doit obferver en faifant les tus de flimier. 
La putréfaction eft défnie par lcs Chymi* ftes un mouvement interne des parties d'un corps, par lequel l'union, le tifí, la couleur, l'odeur \& le goût de ce corps font détruits.

Il n'y a point de changement plus com: mun dans la nature, que le paffage des corps d'un état fain à un état de corruption. Tous les végétaux acides, acefcens, alkalefcens, aufteres, aromatiques, infipides, froids ou chauds, y font fujets, \& firiffent ordinairement par fe corrompre. Les alkalefcens telo que les oignons, le celeri, \&c. tendent immédiatement à la putréfaction fans pafier par. les deux autres fermentations; mais les acef. cens peuvent recevoir d'abord la fermenta. tion vineufe, \& en général ils paffent d'euxmêmes par l'aceteufe avant la putride. Les aninaux font continuellement menacés $d \varepsilon$ putréfaction, \& ils y tombent dès que la mort cmpeche la circulation \& l'admiffion de fucs frais. Les animaux \& les plantes alkalefcentes manquant de l'acide qui abonde dans les plantes acefcentes, ont une forte tendance à ja putréfaction, qu'on đçait être arrétćc ous prévenuc par les acides. Après les excrémens qui y font déjà dans un haut dégré de putréfaction, le fang eft de tous les fluides dis anys, lo plus aifé à fe putréfier; apris le 


\section{Irincipes de l'Agriculture}

fang c'eft l'urine, \&z enfuice les folides. La putrétaction ne s'opére que par le conicours de trois caufes, lhumidité, la cha leur \& l'admiffion de l'air étranger. L humidité eft nécefli ire pour amollir les fibres des plantes, \& les rendre fufceptibles d'un mou. vement interne: c'ćt pourquoi la paille fech: ne fe pourrit poist. La chaleur ift aufSi néceflaire pour exciter le mouvement inrerne, qui conftitue la putréfaction. Le fioid, qui arrete ce mouvement, eft enne. mi de la putréfaction. Il faut encore que l'air extéricur s'unfinue dans les parties du corps, qui fe pounit, parce que le mouvement interne ne commenceroit point fans le fecours de l'air. C'elt par cette raifon que les corps qu'on cmpèche d'éprouver le contact inmé. dat de l'air extéricur, foit en les tenant daits un récipient pompé, ou en les couviant de graiffe, font préfervés de corruption.

Outre la fechereffe, le froid \& le manque d'air, plufieurs autres chofes réfiftent encore à la corruption. Mais il n'y a aucuns corps qui y foient plus contraires que les fels en général, foit laalkali, foit le neutre ou l'âcicie, \& fur tout ce dernier.

Le fiege propre, ou le fujct de la corruprion, paroît être dans les parties mucilagio reufes ou huileufs: car plus un corps cunw 
bient de ces parties, plus il fe corromps promptement, toutes pioportions gardées. Ainfi l'eau remplie des parties muci agineufes d'unc terre grafie, fe co:lompt plus víto gue calle qu'on tire d'un fol fiblonncux.

Le progrès naturel de la putréfactirn dano les vígétaux s'opere di citte maniere. Ils commencent par s'éthatffict au centre, \& Eendent une unteur forte \& acide, gui proo vient de la fermentation acéreufe. La cha. leur augmentant, cette odur $\mathbb{f e}_{\mathrm{dif}} \mathrm{dipe}_{\mathrm{B}} \mathbb{B}$ il lui cn fuccete une très foride. Leur coun leur, fi elle étoit claire, devienic noire; \& plus !a putréfract on avance, plus cetre cou. leur noire devient foncée; ils perdent leus goút diftinctif, \& en prennent un déligréable \& caldavereux. Leurs fibrcs, qui avoient in certaili dégré de fermeté, le perdens promprement. Il ne fubfifte plus d'adtićren. ce entre les petites parties dont elles font com. pofé s, \& elles fe changent en une pulpe puiride. Tilles funt lis circonftances générales Gont la putréfaction eft aci ompagnéc.

Si apres la purréfaction on examine les vé. gétaux par lá voie de la chymie, ils donnene des principes très diffircns de ceux qu'ils dorinnient auparavant. Leurs f:Is de Exacs gu'ils étoient, deviennent alors vo'atils, \&. bear, huiles plus volatilcs \& plus leotudes

$$
\text { D } 4
$$




\section{Şo Frincipes de I'Agiculture}

qu'elles n'étoient d'abord. L'odeur fortide des corps putréfiés doit être attribuée aux huiles fortides \& volatiles qui s'en exaltent continuellement; cette grande volatilité de leurs fels \& de leurs huiles, vient de ce que ces deux fubftances font alors plus atténuées qu'elles ne l'étoient auparavant.

Il n'eft pas facile de dire comment la Nature produit ces changemens. L'explication la plus commune \& la plus plaufible, c'eft que les petites particules d'air qui fe trouvent renfermées en grande quartité dans tous les corps, s'échappant des fibres des végétaux amollis par l'humidité, \& érant fans ceffe agités par la chaleur \& par les continuelles altérations de la preffion de l'atmofphere, excitent un mouvement interne dans le corps. Ce mouvement occafionnant un frotrement continuel entre les fels, les huiles \& les parties terreufes de la plante, doit les brifer, les atténuer \& exciter un grand degré de chaleur. Les parties huileufes, altérćes par la chaleur, acquierent une odeur foctide, \& en s'uniffant avec les particules d'air qui s'echappent du corps putréfié, elles devien. sent plus volatiles, \& affectent le fens de l'o. dorat. Il eft aifé de voir que le mouvement interne doit détruire toute l'adhérence dos fiores \& de leurs partics, \& çu'ainfi elles doi- 
vent fe eonvertir en une fubltance pulpeule. Les huiles \& les fels ayant entre eux une liaifon \& une affinité naturelle, doivent s'unir enfemble, \& par conféquent ceux-ci emportés par la volatilité naturelle des huiles, doivent devenir volatils, de fixes qu'ils étoient auparavant.

Cette théorie, ou explication de la putréfaction, eft tout-à fait plaufible, yuuoiqu'elle Soit encore, car il faut en convenir, fujette aे plufieurs objections. En effet la chaleur \& le poids de l'atmolphere, doivent faire fur les corpsquel'on conferve par le moyen de lhuile, autant d'impreffion que s'ils n'en éroient pas enduits. D'ailleurs on ne voit pas que les végétaux, qui font plus fujets quo d'autrcs à fe currompre, contiennent plus d'air que ceux qui font moins fujets à la putzéfaction. Enfin l'air fixe des végétaux n'eft point chaffé par la chaleur, \& l'on n'apperçoit ici aucune caufe quile mette en liberté. Il eft difficile de trouver quelque chofe de ecrtain dans ces obfcurcs fpéculations. Pour moi, il me femble que le premier moteur de la puiréfaction eft le feu élémentaire renfermé dans tous les corps, lequel eft mis $\mathrm{cn}$ mouvement par la chaicur extérieure de l'atmofphere. Ce mouvement détache les pas tiss \& les férare; l'air fixe devcrant alors 
élıftique, brife les vaiffeaux des plantes.

On vais bien plus aif ment le but \& la fin que l'Aureur de la nature s'ent propulés dims la purré act:on, que les moyens gqu'is employe pour l'opérer. Si les végétuu: n'éroi: nt détruits que par une force extérieure, la plûpart de leurs parties refteroient dans leur prentier état, \& par conféquent feroient un pouds inutile dans la nature; \& s'ils é. toient détruits par une fermentation intégieure nas fins que leurs parties fe volatilififlenr, ces parties, auxquelles ils aurcient écé rédıiss, feroient continucllement détachies de ia terre par les pluyes, \& entralżées dans la mer; \& par confequent elles ge puturoient être que d'une médiucre wii. té pisur la mourriture des plantes.

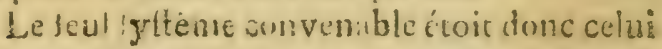
que nous vi yours s'exécuter. Les huiles \& les fels, de rixes qu'i!s font, develnienteva. latsis, s'éleven: dans l'air, \& enl retombene pour fentilifer is terre d'c ù i's venoient d'ètre enlevé - La croruption , It ronc la mere de la végétation, \& ne punvoit l'ètre que de la maniere qu'elle l'ett. Ainli quoiqu'elle paroiffe un mal dans la nature, don elle nous montre la deficuctim; quoiquelie frittrèsdéfigréable aux fens, \& fuuv:nt préjudicia. bic à la fatté, clle cô néanoins d'wne wt: 
Lité beancoup plus graia fe yus iss ḋux autres fermentations, en ce qu'clle mus procure la nourriture done nous arons befoin, \& forme ce crcle armiliable, que la nature parcourt Eans celfe par l'ondre de fon grand futcur is conftant Confervareur.

Les fubitances putréfiées font toutes ite mature alkaline; il eft viai que le fel alksti y eft fouvent tellement invilqué de parties huileufes, qu'il a peine à fermenter avec les acides, C'eft ce qui a fait que quelques Auteurs ont avancé, que les fuhltances putréfiées n'é. coient point alkalines: aff:rtion contraire à I'expérience. On fçait avec quelle facilité une chileur modérée éleve les fels volatils des corps putréfiés. S'ils n'exiltoient pas, sette chaleur ne les produiroit point, mais elle fuffic pour les élever quand ils fout une Eois formés. La fiente de pigeon étant lo fumier le plus fort (car les fubltances végétaies S. animales devienment égales quand elles Dont putcéfiées) oil y trouve plus de fels alka. lis que uans tous ics auties. J'ai vula liupertrie de cette fiente couverte d'un fel bl:nc, чqui avoit une odeur auff forte que le tel vo. Latil de corne de cerf; \& fi l'on fe fent les yeux nouiliés quand on entre dans un pigeonnier, c'ett parre que l'air y clt rempli de fels picotans qui voltigent. Los fubltan. 


\section{0}

\section{Principes de l'Agrieulaure}

ces bien pourries fermentent avec les acides: M. de Reaunur parlant de feuilles de vignes qu'il avoit amafíes pour les faire pourrï, dit, que quand elles eurent été pourries juf. qu'au point où elles perient leur non, elles fermenterent vivement \& fubitement avec les acides qu'il verfa deffus: au lieu que l'clprit de nitre verfé fur des feuilles feches olz qui ne faifoient que commencer à fe pourrir, n'y produifit aucune fermentation fenfible. Cette expérience met abfolument la quef tion hors de doute.

Les Laboureurs ont découvert par un long ufage, que les fientes de divers animaux différent beaucoup, quant à la quantité qu'il en faut employer, \& quant aux terres où il convient d'en faire ufage. Il faut une plus petite quantité de fiente de pigeon que de toute autre; \& l'on ne ủoit gueres l'emplo. yer que dans les terres froides \& humides. La fiente de cochon \& de brebis femblent, par expérience, devoir être préférécs à toute autre. Ces différens effets dépendent des différentes quantités d'huiles \& de fels volatils que ces ficntes contiennent; \& ces huiles \& ces fels eux. mêmes dépendent des diffés rentes nourritures des animaux, ciu ten?s qu'elles fójournent dans lcurs inteltins, ds la nature des fucs qui s'y mêlent avec los 


\section{E: de la T'égétation.}

alimens, enfin de la chaleur naturelle de leurs corps.

Faifons ici que!ques obfervations prati: ques fur la maniere de faire les tas de fimmicr; car c'eft un cbijer de la plus grande am. ur. Eunce, \& fur lequel les Furmicis paroiltent fort peu inftruits.

Les végétaux fics ont befuin d'un dégré onfuderable dhumidicé avant qu'ils puiffent pourrir. Je fuis perfuadé qu'on tient ordindirement les tas de fumier trop fecs : on lea met cummunément fur des hauteurs \& ils font eux-mêmes très-élevés. Des fonds, des trous qui retionnent l'humi. lité conviennent bien mieux. L'excès d'humidité n'eft pas moins préjudici: be. Pour remédier à cet inconvénient, il fera bon de pratiquer à côté des tas de fumiers, des trous dont le fond foit revêtu de terreglaife, ou l'eau qui eft de trop puiffe s'écouler, \& d'où l'on punfe la rej:tter fur le fumier quand on le jugera à propos.

La fituation ordinaire des tas de fumier a encore un autre inconvénient: c'elt que les fucs des fumiers, diftous par ieau, font continuellement emportés par los pluyes, \& que par conféquent les alimens des végétaux fe touvent perdus pour la plus grande partie, ou mème tout à- ínt. C'oft donc un mauvais 


\section{Principas de is Agriculture}

confeil que celui du journal Oeconomique de placer lis tas de fumicr fur des pentesa Une foife, ou large trou dont le fond foit revêtu de terre glaife eft plus favorable à la pus tréfaction.

Le foleil \& le vent emportent les fels \& huiles volatiles, \& le trop grand air retarde p'ûtôr la putréfiction qu'il ne l'accélere. Je crois done qu'il fer oic fort à propos de mettre le fumier à l'rmbre \& de l'environner d'arhres. Cette fituation renfermée \& humide harcra la corruption.

J'ai vu des Fermiers qui recommandoient de couvrir de terre les tas de fumier, afin d'empêcher les parties volatiles die s'échapper; mais comment le faire, quand on a tous les jours de nouveau fumier à a outer au tas? Il elt vrai que le fumicr pourriroit pluttôt, mais aufíi on perdroit l'influence de Jair, qui feul le rend propre à nourrir les plantes. Les effets de l'air fur les tas de fumier doivent être confidérsbles, car le fumier elt très-poreux. Je conviendruis plus aifé. ment avec ces Fermier d'unc autie obferva. tion; 'çànoir, qqu'il elt ben dày iailler un lim bre acces aux vents de Fond \& d'ift, furtout pendane l'iyver. Nous verron par la fuite qu'on a diclouvert par expérience que ces deux vents, princiyalemat un byyer. 


\section{3 de lo V'getsution?}

Tont plus impregnés que tout autre de la nourriture que l'air fournit aux plantes.

La putréfaction fe fait ordinairement avec le nteur; ce qui fait que fouvent une grande gartie du fumier eft tirếe du tas, avant d'être entierement pourrie, \& qu'ainfi elle n'eft pas fuffifamment préparée pour les végétaus. Il ne feroit donc pas inutiie d'accélcrer la cor. ruption, fi l'on connoifoit quelque moyen de le faire aifément. Or il y a des levains pour la fermentation putréfactive comme pour la fermentation vineufe. Stahl nous affure qu'un corps en pourricure la comunique facilement à un autre, qui en feroit exempt, parce que celui qui éprouve déjà ce mouvement interne de fes parties, occa. finnne facilement la même agitation dans l'autre corps, qui, quoiqu'en repos, ne laiffe pas d'avoir une tendance vers ce mouve. ment.

Les fubftances animales déjà pourries; relles que les urines, fientes, carcalfes d'ani. maux, \&c. font les vrais fermens putrides. Si l'on conduit le piffat des chevaux \& des bêtes à cornes dans des rélervoirs, qu'on l'y laiffe fermenter quelque tems, \& yu'enfuite on le jerte fur le tas de fumier, la fermentation s'y fera plus promptement.

Les curps putréfiés font d'une nature très. 


\section{Ga Triscipes do IAgriculure}

volatile, de forte que s'ils reftent expoís \% un air fec \& chaud, leur volume diminue confidérablement jufqu’à ce que toutes les parties volatiles érant emportées, il ne refte plus qu'une terre très abforbente. D'nù l'on. doit conclure que les tas de fumier ne doivent pas être gardés long rems après qu'ils ont été fuffifamment putréfiés, \& qu’il ne faut pas laiffer le funier fur la fuperficie de la terre dans un tems chaud, comme on fait fouvent , mais qu'on doit labourer auffitôt, fi le fumier y a été mis par un tems fec. Quelques Formiers affurent, d'après plufieurs olıfervations qu'ils en ont faites, que le fumier quand il a été étendu cinq ou fix femaines fur la fuperficie de la terre, la fertilife beaucoup plus que quand on la laboure auffitôt après pour y mêler le fumier. Si cette obfervation eft vraic, l'hyver \& le printems feront les fai. fons les plus propres à étendre les fumiers. Un léger labour, après qu'on a mis le fu. mier, fembleroit le meilleur moyen de fe procurer les avantages \& d'éviter les inconvéniens de l'une $\&$ de l'antre méthode.

La vafe des étangs \& le limon des foffés doivent être mis au rang des corps putréfiés , parce que ces matieres font compofécs dé terre \& de parties de végétalix putréfiées.

SECTION 
and

\section{SECTIO N VI;}

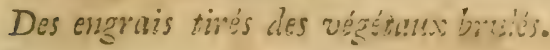

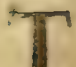

1 o u s les végétaux rédults an cerdme par l'action du feu, foumilfent beaucoup da nourriture ponr les planes, \& Ipécialenyens pour therise: con leur action ćant trèse prompte, clle fo fuit cemarquer plutôr fur 'es lierbages que fur los terros à bled. La chy mie nous aprent que ces condres font cuntpofées d'une terre indifioluble \& d'un fol al. kali; \& que ce dernier corps attire les acides plus puifinment qu'aucun autro, Les ceno dres de fougere contiennent plus de fel qu'au. cun végétal qui me foit connu. On en tire un friene de fel alkali: elies font dinncles plus propres pour cer ufage. Aur manufactu. res d'alum, pres de Scarboroug, le rebut de ces cendres, après qu'on en a tiré prefyue tout le fel, eft encore acheté par les fermiers ?. liv. 7. l: la chatrettée. Les rebuts des manu. factures defavon \&e des blanchiferies font aulfi de tris bon engrais. Les cendres die tourbe, defquelles on fe fert ordinaitement, ne donnens gucres qu'un trente deurieme 
66. Principes de PAgricalture

de fel, \& font les plus foibles que je cris? noiffe.

Nous ne devons point oublier ici l'ufags de mettre le feu aux inottes de gafon ou fisnerficie de la tetre; ce qu'on pratique pour améliorer les terres maigres. Les Laboureurs croyent que par cette opération on chaffe un fuc âcre, que la terre a contracté, en reftant long-tenis fans être labourée. Ils recommandent furtout cette pratique pour cette forte de terre; car ils s'accordent tous à dire qqu'elle eft préjudiciable aux bonnes. Mais je crois que l'utilité de cette pratique vient plu. tôt des fels alkalis qu'on exalte en brûlant les racines des plantes; car les Laboureurs recommandent de ne point faire pénétrer le few plus loin que ces racines; \& on a éprouvé que plus il y a de racines, ce qui arrive dans les terres qui font reftées long-tems fans être labourées, plus le feu y fait de bien.

Il y a encore un autre engrais, que le fers nous procure, \& dont nous ne devons pas manquer de parler dans cette Section à là civelle il appartient; c'eft la fuye. On a trouvé par des expériences de chymie, que la fisye eft un compofé de fel alkali volatil. d'huile \& d'un pen de terre. Ses effets font zrès-prompts; ils fe font fentir aufititot apròs bes premieres pluyes. 


\section{SECTION VII.}

Des engrais tirés des fubftunces animales.

T

II O U TES les fubftances animales fertilifent prodigieufement la terre; tels font le fang, les tripes, les urines, \& c. parce que ces maticres fe pourriffent aifément. Comme mous avons déjà parlé des fientes, nous n'en dirons rien ici. Mais il y a d'aucres fubltances animales, telles que les cornes, les crins, cheveux, foies, laines, \&c. que leur texture ferme paroît rendre moins propres à fe pourrir. Toutes ces matieres contiennent une grande quantité de fubltances mucilagimeufes \& gélatineufes, diffolubles dans l'eau, d'une nature favoneufe, \& compofées, à ce qu'il paroît par les expériences chymiques ? de fels \& d'huiles intimement unis, \& qui demandent beaucoup d'eau pour êrre diffous. Cette fubftance mucilagineufe doit donc ètre tune nourriture propre aux plantes.

On attribue ordinairement l'action de ces engrais s̀ la propriété qu'on leur fuppofe de s'imbiber de rofée, \& d'entretenir de l'humidité dans la terre. Mais les chiffons de laine, 
à caufe de leur fubftance huileufe, repouŕ fene plutôt l'humidité qu'ils ne l'attirent: \&. s'ils ue fervoient qu'à attirer l'eau, \& entrstenir de lhumidicé dans la terre, les chiffons de linge $y$ ftroient autant de bien; ce qu'ils ne font pourtant pas. Les chiffons de laine étant communément plus emp oyés dans les serrcs crayeufes, qui font naturellement férhes, on s'eft inaginé que c'étoit pour les rendre plus humides: mais ce dont ces terrcs ont le plus de befoin, c'elt d'une fubftance mucilagineufe dont ces étoffes font plein nes.

Les coquilles, telles que celles des huit tres, des pétoncles, \&c. doivent être comp* tées parmi les fubftances animales. Elles font long tems à fe diffoudre; mais on a oh: fervé qu'au bout de fix ou fept ans, elles ren dent la terre fi tendre \& fi meuble, qu'il fau Ia laiffer fo raffermir pendant un ou deurs ans, autrement elle ne pourroit fousenir les bleils. Cette expanfion de la terre vient, comme on va le voir, de la force expanfive de la marne coquillaire. Les différentes co. quilles font un compofé de parties calcaires propres à être converties en chaux vive par. ie feu, \& de parties d'huile animale.

Il faut examiner ici le corps appellé marna coģuillaire, qu'on range communémesse. 
Guoligulimproprement, dans la claffe des snarnes. On devroit plutôt le nettre parm: les coquilles; car ce n'eit proprement qu'un smas de coquill: s purréfices C'eft une fubr. tance blanche \& légere: ellea de l'ud ur, $E$ jaroít aux yeux compolée d'une multicute: de petites coquilles. Elle fe rencontre ordi. s.airement à un ou deux pieds de profondeur, dans les terreins bas gui ont été autrefois fubmergés. J'ai trouvé dans un étang un des animaux qui vivent dans ces coquilles. Ils font fort rares maintenant; mais ils doivent avoir éré ici très communs. Il paroít qu'ils ont été riétruits dans la plûvart des pays par çuelque fléau général, dont l'efpece a été affigée. Les terres que ces eaux ont dépclées. auront enieveli ces cuquilles à cette profon:deur.

Exper. 25. Quand on verfe die l'eau fur cecorps, il l'attire \& la fuce avidement : il fe gonfle comme une éponge, \& s'amollis ; mais il ne toinbe pas sn poutite comme la marne. C'eft à caufe de cette qualité que toutes les coquilles, foit cau'on les jette en serre déjà pourries, foic cu'elles s'y pourrififent, rendent la terre fi meuble \&s fi fpor gieufe.

Je n'ai pû y découvrir aucun fel, malgri

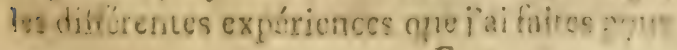

E. 3 
70 Principos de PAgiculute

cela. Il fermente vivement avec les acides; \& il eft fix tois plus de tems à les faoulei qu'aucune des marnes que j'ai vîes.

Il donne par la diftillation, comme toutes les fubftances animales, un efprit urineux alkali , \& une huile du genre des pefantes.

Quand il eft calciné dans le feu, il fe convertit en chaux vive. Toutes ces expériences font voir clairement que ce corps eft une écaille animale putréfiée, que l'cau diffout airément, \& qui attire puiffamment les acides.

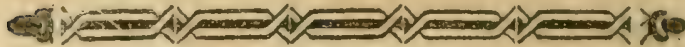

\section{TROISIEME PARTIE.}

\section{PREMIERE SECTION。}

Effets de différentes fulfances par rapport is lis végésation.

N

o us 'n'avons parlé jufqu'ici que des engrais \& amendemens que le hafard a fait connoître comme utiles à la végétation, \&

1. alont on fe fert dans la pratique, parce qu'on peut fe les procurer aifément \& à bon marché. Mais outre ces engrais connus, il peut $y$ avoir d'autres matieres qui, fans être en atlez grande quantité pour que les laboureurs 
les employent, pourroient produire ties $E$ Sers confidérables fur la végétation, \& par conféguent aider à découvrir la nature des nourritures végétales. Plus on connoît les effets des différens corps fur les plantes, plus on a droit d'efperer qu'on pourra parvenir z̀ favoir avec quelque certitude quels en fon: les alimens; c'ent du moins la feule voye çui puiffe y conduire. Dans cette penfée, je tis l'expérience fuivante.

Exper. 26. Le 2 de Mai 1555 , je pris de la terre vierge fur un côteau efcarpé, \& qui n’avoit jamais été ni fumé ni labouré. J'en remplis plufieurs pots, que je plaçai dans mon jardin, après avoir mêlé avec cette terre vierge les matieres qque je vais indiquer. Chacun des pots contenoit environ 6 livres de terre. Je femai dans chaque cinq grains de la même orge; \& pour m'affurer que tous les grains étoient bons à femer, je ne pris que ceux, qui, jettés dans l'eau, tomberent à fond. Ne. I ne contenoit que de la terre vierge pure, \& devoit me fervir de régle poue juger des autres. N8. 2 fut toujours arrofé avec une eau falée. No. 3 contenoit, outre la terre, une once de falpetre \& deux onces d'huile d'olive. No. 4 , une once de falpêtre. $N^{\circ} .5$, une once de tartre vitriolć. $N^{\circ} \cdot 6$, uns once de fleur de foufre. N9. 7 , mm

$$
\text { E } 4
$$


deni-once d'efprit decorne de cerf. No. E. deur onces d'huile d'clise. No.y, in domi-gros d'efprit de nizre diffout dans l'eala, No. 10, un gros defel de net. No. I I rie contcnsit que de la terre pure, \& cir grains d'orgo trsmpés pendant feize heures dans une forte lie de fiante de poule \& de falpêtre.

Le 9. Iviai, quand j'allai voir mes pots, ${ }_{11}^{\circ}$. I \& 2 avoient chacun une plante, qui commençoit à fortil de terre. No. $6 \mathrm{cn}$ avoit deux plus grandes \& plus hautes que les deux premieres. $N^{\circ} .8$ en avoit cinq, chacune defquelles étoit haute de trois à quatre pouces.

Le I I Mai $n^{\circ}$. I avoit toutes ces cing plantes forties de terre, \& d'cnviron un demi pouce de haut. No. 2 en avoit deux de la meme hauteur. No. 3, 4 \& 5 cn avoienc chacun une qui commençoit à paroitre. No. $6 \mathrm{en}$ avoit quatre de trois à quatre pouces de haut. No. $8 \mathrm{cn}$ avoit cing d'un pouce de haut. $N^{0} .9$ en avoit deux qui commenw ritient à pointer. $\mathrm{N}^{\circ}$. Io n'en avoit aucunc. 2y․ Ir en avoit quatre. Quelques.uns de ces memes grains fenés dans le terreau du jardin à côté des pots, étoient de trois à qua. tre pouces de haut.

2 I Mai, il y eut quatre ou cinq jours de pluye fuivi de keau tons. No. I avoit ciny 
plantes de quatre pouces de haut. $\mathrm{N}_{2} 2$ de même. $N \cdot 3$ en avoit quatre de trois pouees de haut. $N^{\circ} .4$ en avoir cinq d'environ deux pouces. Celles du $\|^{\circ}$. 5 étoient hautes de trois pouces. $N^{\circ} .6$ en avoit cinq égales au $m^{\circ}$. I \& 2. N०. 7 en avoit deux d'environ un pouce. $N^{\circ} .8$ en avoit fix d'un demi pouce. d'une mauvaife couleur. $N^{\circ}$. ro en avoit une d'un pouce. $N^{\circ}$. I I en avoit cing qui é. toient les plus belles de toutes.

I Juin, $N^{\circ} \cdot 2$ étoit le plus beau de tous; Ies plantes étoient de cinq pouces de haut \& d'un verd foncé. $N^{\circ}$. I I en approchoit le plus par la hauteur \& la couleur, \& ne leur cédoit sueres. $N^{\circ} .6$ en approchoit affez pour la hauteur, mais il avoit plufieurs feuilies páles. $N^{0} \cdot 3,4 \&$ \& avoient environ cinq pouces, \&étoient de la même couleur. No. 7 n'avoit qu'un pouce cie haut \& pliticurs feuilles páles. $N^{\circ} .10$ avoit trois plantes d'un pouce de haut.

Le 10 Juin Ne. a encore le plus bcau. $N^{\circ} .6$ prefque tout pale. $N^{\circ} \cdot 7$ entierenent. N.9 \& Io plantes maigres \& malades.

18 Juin, $N^{\circ} .2$ le plus beau encore \& dix neuf tiges. $N^{\circ}$. I I en approchoit le plus pres \& avoit dix tiges. No. I n'étoit pas ii haut, mais il avoit treize tiges, $N^{\circ} .3$ venoit agres, $N^{\circ} .5$ prefque n!ort. $N^{\circ}$ ? toutsi- 
Fit mort, No. \&\& 9 tous deux égaux. No ro le moindre de tous.

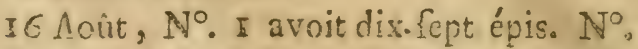
2 diz ncuf. $\mathrm{N}^{\circ} \cdot 3$ treize. $\mathrm{N}^{\circ} \cdot 4$ quinze. $\mathrm{N}^{\circ}$. 5 vingt neuf. $N^{\circ} .8$ neuf épis, \& très gros. $N^{\circ} 2$ vingt, \&t gros. $N^{\circ}$. Io avoit environ nu pied de haut, \& quatre ou cinq épis longs न'un pouce feulement. No. I I en avoit dixhuit, tous très bons.

J'ai rapporté cette expérience avec fidélité SE en détail, comme il convient à quiconquue en fait: car on devroit toujours rapporte! leo faits féparément 8 les diftinguer des raiSnnemens, parce qu'on peut fe tromper dans ceux.ci, au lieu gue ceux-là font la vó. sité mème. J'aurois fouhaité de répéter ces eapériences, fur tout dans une terre plus maigre, \& avoir un fonds plus confictérable, afin de raifonmer en conféquence, car il y a toujours du danger à le faire d'après une $\mathrm{cx}$ périence feule; mais on doit fe fouvenir que celles dont il s'agit ici ne fe peuvent faire qุu'une fois par an. Je vais donc tâcher de tirer quelques Corollaires de celle que je viens de rapporter.

Covollaive I. La terre vierge prife à un gied de la fuperficie d'un coteau, expofée an liord, contient une grande quantité de princiges w'érératifs. Les rabourents fe ti: . 
zent de cette terre comme d'un bon engrais, \& ils obfervent que la terro vierge paroît donner aux terres plus de fertilité qu’elle n'en a elle méme.

Cur. 2. Le grain parô̂t venir mieux quand il a été trempé dans la fiente \& dans le falpétre. C'elt un fait obfervé depuis longtems, que le grain devient plus fort, qu'il pouffe plus vite, \& qu'il eft moins fujet à la nielle \& aux brouines, quand il a été trempé dans des liqueurs qui contiennent du fel \& de l'huile, tels que l'eau de la mer, l'urine, \&c. Il inporte certainement beaucoup de quels fucs les vaiffeaux des fimences ont été remplis d'abord, fi c'a été de fucs humides \& aqueux, ou de fucs forts \& nourriffans. C'elt une des principales raifons pour lefquelles un tems lec eft plus propre pour les lemail. les. Car quand la terre eft feche, les fucs qui alors imbibent la femence font forts \& nourrifans, au lieu que dans un tems plu. vieux ils font détrempés avec une trop gran. de quantité d'eau, \& la jeune plante en eft affoiblie. En faifant tremper les grains dans ces prćparations, on remplit leurs vaiffeanx d'huiles \& de fels qui leur donnent de la vigueur, \& leur font pouffer beaucoup de racines, d'ou dépend la nutrition des plantes. Le vrai moyen de rendre un homme fort \& 
T5 Irincipes de ligricultare

vigoureux, c'elt de lui donner dans l'enfafics de-honne nourriture.

Cor. 3. Les eanx dures \& crues, telies que celles qui ont une certaine âcleté ors anertume, fourniflent aux plances une nourriture abondante. Cette alfertion contredic Jopinion commune; car les Jardiniers nif. fe lervent jamais de ces eaux quând ils petivent en avoir de douces; \& s'ils foupçonnent que lcurs eaux foient telles, ils tácheno de les adoucir, autant qu'il eft en eux, en los laiflint quelque tems expofées au folleil; ciz Gitoi mème ils fe trompent : car la chaleu: cu fucil peut bien rendre plus âcre ou plus amzre l'eau qui l'ett déjà, maits elle ne fçau1okit adoucir une eau qui, par elle mème, a bezucoup de crudité, d'ácreté \& d'amertunie. Ces quualités daus l'eaus dont j'ai fait ufase, \& mene dans toutes les eaux femblables que jai vîses, venoient, ainfi que je m'cns fuisafurépar l'expérience, d'un acide de nim tre joint à une bafe de terre abforbante. La bafe de l'eau employée dans mon expérience étoit une terre calcaire: dans la plûpart de ces eaux, c'elf fculement une terre abfor. bante.

Cor. 4. L'huile d'olive dans la proportion. d'un gros à trois livres de terre, parut pro. duire d'abord de bons effets, mais cesc? 


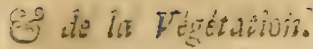

sinituerent dans la fuite: cependane les epis furent bons, quoique en petit nombre, Seroit ce que l'huile étoit en trop grande quantité, ou qu'elle n'avoit pas étéaffez at. tenuée par les fels dans la terre, \& qu'ainfi elle ne pouvoit pénétrer dans les pores des racines? Ou bien n'avoit elle pas ea arez ile tems pour s'incorporer avec la serre? Ce font là des queltions que je ne puis réfoudre.

Cer. 5. Il paroít que le falpêtre en proportion d'une once à fix lives de terre, retarda plittôt qu'il ne favorifa la végétation. J'en fus tres-furpris, parce qu'on croit commune. ment que le nitre contribue beaucoup à ferilifer les terres, \& qu'il clt même la cauí propre de leur fertilité. Je ne crois pas l'avoir employé en trop grande quantité dans mon expérience. Le cas qu'on en fait pour: 1.t fertililation desterres doit rendre douteus l'effet qu'il m'a paru produire. Il faudroit o pour s'en affurer, un plus grand nombre d'expériences.

Cor. 6. Il ne paroît pas que j'aye augmensé les effets végétatifs du nitre en y ajoutant deux fois autant d'huile d'olive. L'huile d'o. live femble pourtant avorr mieux réuti avec le nitre que fans lui. Les fels l'auront peutêtre attenuée, \& préparée par. là à entrer plus aiférnent dans lka vaiffeaux des plantes. 
78 Principes de l'Agriculiure

Cor. 7. Le tartre vitriolé, qui eft unse compofition d'acide de vitriol \& d'un fel alkali, paroît avoir aidé puifiamment la végétation. Un Gentilhnmme voulant détruire de l'herbe qui poufloit dans fa cour, on lu: confeilla d'y répandre de l'huile de vitriol, comme très contraire à la végétation; ille fit, mais à fon grand étonnement l'herbe vint plus forte qu'auparavant.

Cor. 8. Le lel marin dans la proportion d'une once à fix livres de terre, paroît très. préjudiciable à la végétation. La plîpart des Laboureurs le recommandent comme un bon amendement, quoiqu'il y en ait qui doutent de fes bons effets. Peut ètre eft-il utile lorfqu'on l'employe en petite quantité, furcout s'il a quelque amertume; car cette amertume vient d'un mélange d'acides vitrio. liques, d'une bafe d'abforbens \& d'une huile bitumineufe, deux matieres dont chacune favorife la végétation. Le fel dont j'ai fait zfage étant du fel de table, il ne pouvoit s'y trouver que très peu de l'une \& de l'autre.

Cor. 2. L'acide de nitre femble avoir d'a: bord retarué la végétation, peut être parce qu'il n'étoit point fuffifamment uni avec les parties abforbantes de la terre; ruisis il paroît qu'enfuite il a contribué confidérablenent s. faire croitre les plantss. 
Coi. 9. L'efprit de corne ảe cerf (qui ê: un fel volatil) diffout dans l'eau, paruît avoir été un poifon pour les jeunes plantes.

Cor. I1. Il paroît que la fleur de foufre Eavorife d'abord la végétation des plantes, mais qu'elle les fait périr comme un poifon dans l'efpace d'un mois. Ois répand affe: communément de cette matiere fur les graines de navet avant de les fomer, ef l'on croit qu'elle contribue à les faire croâtre \& à pré. ferver leurs feuilles contre les mouches. El:ce que j'en aurois employé une trop grande quantité dans cette expérience? Les plantes ont donc leur poifon comme leur nourriture. Le foufre artificiel, qu'on tire de plufieurs plantes enles brûlant, \& qu'on trouve en grande quantité dans les cendres de favonicre \& autres qu'on employe dans les blanchifiesies, aurvit il le mème mauvais effet que le foufre naturel?

Après avoir fait cette expérience, je reconnus qu'il y aroit une grande différence entre la maniere dont je m'y étois pris, \& le cours ordinaire de la nature dans ces općrasions. J'àveris mielé tout à la fois avec la terre les matieres dnint je voulois découvrir les effets fur la végétation; mais dans le cours ordinaire de la natuze ces maticres ne font rieléé avec la terreque par décrés S: en pe. 
tite quastité. A la vérité la terre qqui a refté quelque tems en jachere, \& qui par confé. quent a récouvré, du moins en partie, les principes de végétarion, fe trouve à peu près dans le mène état que celle que j’ai enployée dans mon expérience, quoiqu'elle ne foit pas impregnée d'autant de principes de végétation que l'étoit la mienne quand je l'eus mêlée avec ces différentes matieres. Outre cola la premiere terre reçoit fans ceffe de nouveaux: fecours pour végéter. Afin donc d'approcher de plus près du cours de la nature \& de forr. nir les matieres à mefure que les plantos croitroient, je fis l'expérience fuivante.

Exper. 27. Je remplis fix pots d'une terre maigre \& légere. Chaque pot contenoit cinq livres de terre, \& cinq grains de bon orge. No. I n'avoit que de la terre pure, fans aucun mélange. $N^{\circ} .2$ fut arrofé d'une dragme de falpêtre, diffout dans trois onces d'eau. NN. 3 avec la même quantité de fel de mer. $N^{\circ} .4$ avec la miêne quantité de fel d'epfon: qui eft compofé de l'acide de vitriol \& d'une terre appellie magnécic blanche. $N^{\circ}$. 5 avec deux dragnios de la compolition fuivante, dilfoute dans de leau: une demi-once de chaux vive faoulée d'un foible efprit de nitre ce qui prodait une liqueur très cauftique. No. Go avec deus dragmes de la compofitions, précie: 
mícédante, mélé avec une dragme d'huile d'olive. Ce dernier mélange me parut approcher de plus près de la nourriture natuo relle des végétaux. Je femai mes grains d'orge le I 6 Juin I 756 , excepté $n^{\circ} .6$ que je ns femai que le $\mathrm{g} g$ du mème mois. Je fenai aufra quelques grains de la même elpẹce dans dut terreau de jardin à côté des pots.

23 Juin. $N^{\circ}$. I avoit une plante d'un demi-pouce de haut. $N^{\circ} .2$ en avoit une d'un pouce, \& une autre qui commençoit à pointer. $N^{\circ} \cdot 3$ n'ell avoit point. $N^{\circ} 4$ en avoik quatre, deux defquelles étoient hautes d'un pouce, $N^{\circ} .5$ n'en avoit point. $\mathrm{N}^{\circ} .6 \in \mathrm{G}$ avoit trois d'un pouce.

27 Juin. $N^{\circ}$. I en avoit quatre de deux ponces \& demi. $\mathrm{N}^{\circ} .2$ en avoit quatre. $\mathrm{N}^{\circ}$. 3 en avoit deux, dont la plus haute étoís d'un pouce. $N^{\circ} .4$ en avoit cing de deux pouces. $N^{\circ}$. s n'en avoit aucune. $N^{\circ} .6 \mathrm{en}$ avoit quatre de la même hautenr que $n^{\prime \prime}$. 4 Celles du terreatu de jardin avoient trois poum ces \& demi.

4. Juillet. $N^{\circ}$. 2 plus haut \& plus ver? que $n^{\circ}$ r. $N^{\circ} .4 \& 6$ égaux à $n^{\circ} .2$.

10 Juillet. $N^{\circ} .2$ le plus beau. $N^{\circ} \cdot \sigma$, an pres. Enfuite $n^{\circ} 4$. Puis $n^{\circ}$. I \& $三$. N. $N^{\circ}$ avoit une plante de trois pouces.

if Juillet. $\mathrm{N}^{\circ}, \mathrm{s}$ uguatre de ces cing planis. 
res avoient des feuilles jaunes \& páles. $N^{\circ} .2$ \& 6 étoient les plus hautes, \& d'un verd plus foncé. $\mathrm{N}^{\circ} .3 \& 4$ égaux. $\mathrm{N}^{\circ}$. 5 une plante foible de fix pouces. Il avoit fait chaud pen. dant dix jouts. Ajouté alors au $n^{\circ} .2,3 \& 4$. une dragme de plus de l'un \& de l'autre fel, $\&$ aux $n^{\circ}$. ร \& 6 la même quantité des mếmes mélanges.

24. Juillet. Il plut pendant cinq jours. $\mathbb{N}^{\circ} .2 \& 6$ étoient d'environ quinze pouces 。 \& de plus belle venue que tous les autres furtout $\mathrm{n}^{\circ} .6 \mathrm{~N}^{\circ}$. 4 venoit après, \& avoit douze pouces de haut. Puis $n^{\circ} .3$ qui avoit sieuf pouces. Enfuite $n^{\circ}$. I. No. s n'avoir qu'une plante d'environ douze pouces de haut. Celles du jardin avoient près de deus pieds, \& avoient pouffé plufieurs tiges.

I9 Août. Pendant les quinze jours préce. Sens pluye froide avec des vents d'Eft. $N^{*}$. 6 étoit le plus haut, \& d'un verd plus foncé , par conféquent le plus beau. Le refte comme ci-devant. Ajoutez la même quantité de fels $\&$ de drogues qu'auparavant.

Premier Septembre. Il avoit fait un bon tems chaud. Les plantes étoient dans le mô. me état que ci-devant.

26 Septembre. N $N^{\circ}$ I avoit dix épis, \& le plus gros portoit vingt grains. $\mathrm{N}^{\circ} 2$ en avoit douse, le plus gros étoit de vingt- 


\section{छ̊ de la Végétation.}

Guatre grains. $\mathrm{N}^{\circ} .3$ au deffous de $n^{\circ}$. I. $\mathrm{N}^{\circ}$. 4 avoit treize épis, le p'us gros étoit de vingt grains. $N^{\circ} \cdot 5$. n'avoit qu'un épi qui n'étoit pas auffi mur, \& tont les grains écoient plus petits que les autres. $\mathrm{N}^{\circ} .6$ avoit feize épis, dont la plùpart étoient de vingtquatre grains: il avoit un double épi qui en portoit quarantc. Plufieurs des épis dus jardin avoient jufqu'à trente deux grains.

Tirons maintenant quelquues corollaires de cette expérience.

Cor. I. Le fel marin mis en petite quanqité \& par degrés dans une terre maigre, paroît plus préjudiciable qu'utile. On ne f̧̧ă. zoit conclure de cette expéricnce que! effet: it produiroit fur une terre remplis de parsin cules huileufes.

Cor. 2. Le falpêtre adminiftré de la mônese manierc feconde puifiamment la végétation o \&. paroit avoir rendu la terre capable de produire un quart de plus.

Cor. 4. Le fel d'epfom employé de mème, cft, à peu de chofe près, égal au falpêare, pat rapport à la nutrition des plantes. ¿'expérience précériente m'avoit affuré des hors efícts de l'acile de vitriol faoulé de fel ilikali s celle.ci me fit connoître que le mêo Ine acide faoclé d'une terre abforbante, augwente la fertilité. C'êt delà que j'ai concliz

$$
\text { E } 2
$$


dans la Part. II, Sect. III, que la mame ajoutée au mème acide, après que les parties suifibles de fer en ont été féparées, elt pliı. tốt utile que préjudiciable aux terres.

Cor. 4. La chaux vive faoulée d'efprit de nitre en petite g̣uantité, \& bien diffoute dans l'eau, paroît avoir arrété le pouvoir végéta tif de la terre. Seroit ce que j'en aurois trop mis, ou qu'il ne trouva point dans ma terre,

- ce çui n'eit pas moins néceffaire que lui mème à la végétation, une jufte proportion de parties huileufes, que la Nature fournit toujours dans la même proportion qu'elle fournit les fels? A en juger par le curollaire fu:vant, il femble que cette derniere raifon eft la véritable.

Cor. 5. La précédente liqueur mêlée \& bien battue avec moitié huile d'olive, paroit avoir augmenté profạue de moitié la fertilité cie la terre.

Cor. 6. Alucune des drogues dont je fis unage, ne put donner à la terre maigre que javois employée la fertilité de la honne terre de jardin; \& cela n'eft point étonnant. Dans ie rerreau des jardins les fels \& les hui. les font très-atténués, propolitionnés convenablement, bien mêlés esıfemble par la longueur du tems, \& par conféquent pré[arés à cutter dans les petits vaiffeaux des 
racines. D'ailleurs la terre de jardin, par le mélange des matieres qui s'y pourriftent étant dans un écat continuel de fermentation, les racines des plantes y pénetrent pius aifé. nent, pour y chercher leur nourriture.

Comme la chaux n'agit fur la terre que quand elle eft éteinte \& qu'elle a perdu $\int_{a}$ force, $j$ 'ai voulu voir quels effets elie prom duiroic ćtant, dans cet état, fanulee d'acicie de nirre, quoique les expériences femblents nontrer que le produit eft le même, foit qu'elle foit éreinte ou vive. Je pris donc une demi. once de vieille chaur che mur, \& je la froulai d'efprit de nitre.

Lip. 28. Le is Juillet 1756 je remplis: deux pots de la mòme terre dont j'avois fait ufage daus l'expérience précédente, \& en mème quaistité. Je femai trois grains d’orge daus chaque por; $n^{\circ}$. I ne contenoit que de la terre feule; $n^{\circ} .2$ fut arrofé d'une dragme de cette folution bien délayée.

2ร Juillê, $N$. I avoit trois plantes cha: cune d'un pouce de haut. $N^{\circ} .2$ n'en avoit qu'une, de la mêne hauteur.

1) Août. $N^{0} \cdot 2$ n'en avoit qu'une, mais d'un verd plus foncé qu'aucune du $N^{\circ}$. I. J'afoutai au No. 2 la même quantité de la folucion que ci-deffus.

ne. Sentembre, No 2 d'un verd plus fonet

$$
\text { F } 3
$$


86 Irincipes de l'Agriculiure

avoit plus de rejettons \& un épi plus long qu'aucun du $N^{\circ}$. I.

Je ne puis décider fi ma com'nofition ren: dit la terre mailleure ou moins bonne; car d'un côté une feule des femences poutla, \& de l'autre la plante que cette femence produifit étoit plus belle, plus forte \& plus touffuc equ'aucune de celles de la terre pure. Il paroit all $\mathrm{m}$.ins que cette comsofition n'eut pas les mouvais effets de l'clprit de nitre \& de la chaux vive de l'expérience précédente. D'où vint cetre différence? Fut-ce de ce que la chaux étoit vive dans l'aurre exp'é ience, \& éteinre dans celle ci? Ou de ce qu'en celle. ci elle étoit en moindre quantité? Je pen. cherois plûtós puur ce dernier fentiment, parce que l'expérience nous fait voir que ces deux mélanges font de la mêm: nature.

Pour déccuvrir les effets de la mème com: pofition fur le terreau de jardin, je tis l'expérience fuivante.

Exp. 29. Le I \& Juillet 1756 je remplis deux pots, chacun de cinq livres de terreau. Je femai quatre grains d'orge dans ch sque pot, \& j'arrofai le n. I avec une égale quanrité de la folution employée dans l'expérience précédente. Le 20 Juillet il fe trouva trois plantes dan chayue pot. Celles du nº 2 é. toicut plus hautes que celles du n०. 1. Le I 3 


\section{0 de la Végétation?}

Août les plantes du no. I étoient plus hautes que celles du $n^{\circ} .2$, mais aucune d'elles n'étoit de belle venue, foit parce qu'elles avoient été plantées trop tard, ou parce qu'elles ézoient dans un coin où deur hayes affec $z$ hautes venuient fe joindre \& les cmpêchoient de recevoir de l'air. Je retirai les pots \& les plaçai dans un endroit plus découvert. Le premier Scptembre $n^{\circ}$. I aroit une p'anto plus haute \& plus verte qque $n^{\circ}$. 2. Les plantes avoient crü plus promptement qu'auparavant. Le 30 Scptembre les plantes ne vinrent point à maturité.

Cor. I. Les plantes dans les deux dernieres expériences ne végéterent pas dans le même efpace de tems aulfi promptement qu'avoient fait celles de l'expérience précédente. Lo printems n'auroit il pas, par quelyues caufes particulieres, un pouvoir végétatif propre que l'été n'a point en un fi grand dégré? C'eft ce qui m’a paru, quoique cette année là l'été eut été froid \& pluvieux comme notre prin. tems, \& que la terte dans la derniere expérience fut très bonme, au licu que dans la premiere elle avoit été prife au mêne endrois que celle de l'expérience précédente.

Cor. 2. Il femble que les plantes ont befoin qu'un air libre fust conftamment appliqué is leur fuperficie. Aurfif tous !os arbres daus lco

$$
\text { E } 4
$$




\section{Erincipas de 1 Agriculiurie}

enillis étendent leurs branches littéralenerit ou longitudinalement du côté où ils peuvent avoir le plus d'air. L'air agit il feulement fur leur furface, ou entre-t-il dans les vaif. feaux de la plante? S'il y entre, n'a-t-il pas befoin pour y pénétrer d'une impulfion de l'air agité? car la preffion feule de l'air eft toujours la mème dans les hauteurs égales.

Cor. 3. Les plantes paroiffent n'être ni améliorées ni détériorées par le mélange \& ad. dition des fels.

Voilà toutes les expériences que j'ai pı faire fur les effets des différens corps par rap. port à la végétation. Cette matiere n’a point encore été traitée avec l'attention que mérite limportance du fujet. Il eft vrai qu'elle eft d'une étendue immenfe, puifqu'elte comprend les opérations de tous les curps qui peuvent être affez diffous \& attenués pour entrer dans les vaiffeaux des plantes. Mais ce n'eft que d'après un très-grand nombre de différentes expériences qu'on peut efpérer de découvrir la vraie théorie de la végétation. J'aurois fuuhaité, avant que d'entreprendre ce fujet, d'avorr un plus grand nombre d'expériences \& plus fouvent répétées, afin que les conféquences que j'ai tirées fuffent plus générales \& plus certaines. Je les propore relles qui'elles n'ont paru réfulter naturello. 


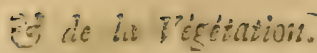

ment cie mes expéricnces. Je laiffe à chacun la liberté de juger quelle certitude elles méritent.

\section{SECTION II.}

De la nourriture des végétaux:

Novs eft la nourriture des végétaux, queftion inzportante, louvent difcutée, mais qui n'eft point encore fuffifamment écldircie. On a mème deniandé fi chaque plante n'a pas une nourriture propre \& particuliere qu'elle choiiit parmi les autres, par une faculté élective inhérente à ces racines. Ceux qui embrallent ce fentiment, s'appuyent fur l'utilité du changement d'efpece; car fi la méme nourriture fervoit à toute efpece de granns, le mêne grain viendroit dans la meme terre auffi bien qu'un autre. Or q̧uoique la méme terre ne puiffe porter du froment deux années de fuite, on voit que dautses grains y réulfiffent. Ils remarquent gue la nature ox les prosriétés différontes des fucs régétaux font oncore une preure de leur opinion.

Ceux qun prétendent au contraire que to *: 


\section{Principes de I'Agriculture}

les végéraux ont la même nourriture, éta? blifent ce fentiment fur les raifonnemens fuivans. Plus, difent-ils, une terre eft en rapport, quoique chargée fucceflivement de différentes fortes de grains, plus elle s'épuife $\&$ devient hors d'état de produire. Or c'eft ce qui n'arriveroit pas fi les diff'rentes plan. tes tiroient de cette terre une nourriture dif. férente. Ils ajoutent que toutes les efpeces de plantes affament le bled, en enlevant pour elles mênı 's une partie des fues qui le nourriffent: qu'on auroit tort de laiffer repofer la terre, puifqu'on a tant de fortes différenres de grains qu'on peut femer; qu'il feroit fort inutile pour les plantes d'avoir un goût propre \& particulier, puifqu'elles n'ont pas de mouvement local: que fi le changement d'efpece réuffit, ce n'clt pas que les plantes ne tirent de la terre d'atutre nourriture que la leu propre, mais parce que les unes divifent \& relâchent la terre, tandis que les autres la refferrent \& la durciffent: que quelquesunes pouffent de profondes racines en terre, randis que les autres ne fe répandent que peu au.deffous de la fuperficie: que fi le froment ne réulfit pas denx années de fuite dans la mìme terre, c'eft qu'il a befoin d'une nour. riture plus abundante que cette terre n'en peut fotituir, qquigu'clle en ait affez pous 


\section{Eे de la Végettation.}

d'autres grain: : que d'ailleurs il ne refteroit point aff $z$ de tems pnur labourer la terre, le froment fe femant prefqu'autitiôt après la moiffon; en un mot, que la différence des Sucs des végétaux ne dépend pas de la différence de leur nourriture, $m$ is de la ftrucEure particuliere des vaiffeus des plantes.

Cette derniere opinion paroîtra à tout le monde plus vraifemblable que la premiere, en ce que ceur qui la foutiennent penfent ๕̨u'une fcule \& même nourriture fert à tous les végétaux. Pour moi je fuis d'un fentiment tout différcnt. Nous avons vu par les expériences de ta derniere Section que le fel commun diff ut dans l'eau, le fel d'epfom \& le tartre vitriolé, fels très différens l'un de l'autre, nourriffent également les végétaux de la même efpece: par conféquent les végétaux ne funt pas horiés à une feule efpece de nourriture. On fçait que certains arbres conti.nnent de l'acide de vitriol, parce qu'on peut faire du foufre avec leur charbon. On fecit de mense que certaines plantes crntiennent un fal nitreux, au lieu que d'autres en contiennert un qui reffemb!c au fel marin. Quelques végétaux demandent une plus grande quantité d'eau, d'autres une plus petite. Leur nouniture n'eft done pas la même. 
Thalés prétendoit que tout venoit de l'ears?.

Van Helmont étoit du méme fentiment o \&: il s'appuyoit fur une expérience que tout le monde connoît. Il planta un faule péfant cing livres dans un pot rempli de terre feche, \& il arrofa cette terre d'eau de pluye. En cinq ans le faule, funs compter les feuilles qui en étoient tombées, péfoit 164 livres, fans que la terre ent diminué de poids. Infó. rer de là que l'eau élémentaire eft la nourrio Łure des végétauz, ce feroit tirer une concli:" fion trop forte. Tout ce que pruuve cette expérience, c'eft qu'il y a dans l'eau des parties capables de nourrir les plantes. Nolis avons fait voir plus haut que la neige \& l'ean de pluye contiennent de la terre, de l'huile, de l'air, ex par conféquent les fels qui s'y tronvent toujours.

D'autres croyent que les parties terreus fes font celles qui nourriffent les plantes. Lo célebre Tull étoit de ce fentiment, parce que, difoit-il, la terre les fait croître, \& que tout ce qui les fait croître doit être leur nourriture. Selon lui, le fumier \& autres engrais n'agilfent que par voye de fermentao. tion, ils ne fervent qu'à atténuer la terre \& divifer la nourriture des plantes: la terrs: feule ne lçauroit agir : elle a befoir de que!. qque principe plus actif. Si Tull avoit été Clyy. 


\section{0 de la Végetation: 93}

mifie, il auroit fçu que la terre ne fait que la moindre partie de toutes les plantes, Elle ne prendroit jamais affez de confifo tence pour former les végéraux, \& dès qu'elie auroit éré fuffifamment atténuée, les engrais ou amendemens ne ferviroient plus à rien. D'ailleurs d'où viendroient les fels \& les huiles des plantes? Voilà des objections aufquelles les partifans de ce fylteme ne répondront jamais.

D'autres, voyant la néceffité de l'air pour les plantes, \& ubfervant qu'elles en pompent une grande quartité pendant la nuit, comme les expériences du Docteur Hales l'on: démontré, ont prétendu que la terre ne fournit aux plantes qu'un foutien, \& que l'air feul les nourrit. A ceux-ci il fuffit de répondre en peu de mots, que les plantes valant mieux dans certains terreins que dans d'autres, \& dans les mèmes à proportion des engrais qu'on y met, c'eft une preuve décifive que la terre fournit aux plantes leurs principales nourritures, car l'air elt le mêne dans les terres qui tiennent les unes aur autres.

L'Autcur de l'hifto:re phyfique forme tollo' tes les plantes de certaines parties fimilaires organifées, qu'il fuppofe voltiger çà \& là dans l'air en très.grande quaritité, \& qu qui 


\section{Principes de $P$ Agriculture}

s'attachont d'elles mémes \& d'une mamiere qui no:is eft inconnue, à celles du méme genre. Si certe cpinion étoit vraie, le fumier fait de plantes de la même efpece, devroiţ réulfrr mieux que tout autre, ce qui n'er: pas. Laiffons cette opinion, fi peu digne d'un efprit philofo: he, tomber d'elle. même, comme elle le doit faire saturellement, puif. qu'elle n'eft appuyée d'aucunc expérience.

D'autres enfin attrihuent la végétation aux différentes efpeces de fels. Mais d'ou' viennent ces fels, \& quelle en eft la nature?

C'elt un défaut ordinaire yue dans toutes les dilputes chacun s'attache à un parti, fans vouloir reconnoitre rien de vrai dans le partê oppofé. J'ai trouvé au contraire par cxpéw rience qu'ordinairement chaque parti a du vrai: \& qu'une dec fources les plus communes de nos erreur, c'eft qu'on veut donner pour vérité gérérale tne vérité pariculiere; le vrai réfulte des vérirés particulicres qui fe srouvent dans chaque fentiment. Ceux qui ont raifonné fur l'Agriculture fe font trom. pés, parce qu'ils ont prétendu que les plam tes tirent leur nourriture ou de l'air, ou de l'eau, ou des fels, exclufivement. Je me réunis en quelyuc forre avec eux tous : car je penfe que les plantes font nourries par tous ces corps joints à deux autres, l'huile \& le 


\section{Eீ de la viégétanion: ?!}

Feu, dans un état fixe. Ces fix principes unis enfemble conftituent, felon moi, ha nourriture végétale.

Il eft aifé de le voir quand on confidere, $x^{\circ}$. que les diverfes fortes d'engrais tels que les cuirs, cheveux, crins, rognures de corne, chiffons, tous les végétaux \& :ous les fucs des végétaux dans un etat fain, font des alimens propres aux plantes. $2^{\circ}$. Que tous les végétaux \& tous les fucs de végétaux donsncnt précifément ces principes \& non d'cutres, dans toutes les cxpériences chymiques qu'on a. faites avec le feu ou fans feu. Nous pourrions en apporter plufieurs autres pressves, mais ces deux font fuffifantes.

L'air fize ou en action fe trouve par-tout: iे moins qu'on ne prenne beaucoup de peines pour le chaffer. Le feu élémentaire fe trouve de même dans tous les corps. La terre peus étre fournie aux plantes par tout terroir pré. parḱ avec le foin convenable. L'eau tombe des nues. L'huile eft un principe taturel de toute forte de terres; elle deficend avec les pluyes \& les neiges, \& elle cit communiquée à la terre par tous les engrais ti.. rés du regne végétal \& du regne animal, foit dans un état fain, foit dans un ćta de corruption, ainfi que nos expériences l'ont fait voir, Maais d'où vient le fel, if 


\section{Principes de lifgriculare}

principe de tous, le pius actif, \& par cians féfuent le plus néceffaire? On ne l'a point encore découvert, méme dans les meilleures trres, ni dans les amandemens dont on fai le plus d'ufage, comme la chaux, la marne, les coçuiles, la craic, \&c. C'efi une queftion importante, qui peut nous faire cons noitre l'action de tous les amandemens, \& de Ja honne terre, \& nous apprendre on quoi confitte l'effet de l'air : elle mérite une dif cuffion particuliere.

Les expériences précélicntes nous ont fait voirque toutes les bonnes terres \& tous les amandemens, excepté ceux qui font déjà convertis en une fubl?ance mucilagineufe, font compofés de particules, qui toutes enfemble, ou de moins en partie, attirent les acides. Le funicr, les ccnires des végétiaur, la terre brûlée, contiennent de ces particules: la chaux, la marne, les cotuilles, la craie, \&c. font toutes de la mene nature. Ces fubftancer doivene done attirer \& retenis les acides, quand ils fe trouvent dins !a fphere de leur atcracion. Par confóquent, fuppofé que l'air atiquel la terre cett fans ceffe expofće contienne quelques acides, ces corps les attireront \& les convertiront en une fubftance faline neutie, qui aura les proprice tés du fol, c’eft à diie, yुui fera foluble dans 
l'eau, qui diffoudra les huiles, \& les rendra capables de fe mêler avec l'eau. Il ne refte donc qu'une feule chofe à prouver, c'eft que l'air contient un fel acide.

C'a été l'opinion des plus grands Chy: miltes, \& ils l'ont appuyée cette opinion. non fur la théurie feule, mais fur ce qu'ils ont remarqué, que les fels alkalis fe convertiffent en fels neutres, \& que les métaux, tels que l'étain, le cuivre, le plomb fe corrodent \& fe convertiffent en un fel. Si ce fel exifte, \& quelle eft fa nature, c'eft fur quoi on peut s'éclaircir, en confiderant de quelle maniere on fait le nitre ou falpêtre dans les manufactures. Les procedés qu'on y fuit, nous apprendront en même-tems comment les divers amandemens agiffent fur les terres; car c'eft des principaux amandemens qu'on fait ufage dans ces manufactures.

La matiere la plus commune dont on fait le nitre, \& qu'on appelle par cette raifon fa matrice, ce font des décombres \& platras de vieilles maifons, particulierement de colombiers, étables \& nefs d'Eglife, de certaines terres graffes, des cendres de végétaux brûlés, des fubftances animales \& végétales pourries, \& quelques efpeces particulieres de pierres. On laiffe ces matieres expofées al l'air pendant quelques mois, fur-tout en 
36 Irinsipes de PAgriculiuir.

hyver: car c'elt dans cette faifon que le ni. tre fe forme en plus grande abondance. La place où ces matieres font expofées à l'air. eft rellement difpnfée que l'air \& les vents $y$ ayent un libre accès, mais elle doit être à l'a. Gri de la pluye \& du foleil. L'air y eft nécef. Faire, parce que c'eft l'air qui forme le nitre, au lię que le foleil le détruit en l'exaltant ou évaporant. Les pluyes \& la f'́chereffe Sont préjudiciables, parce que les phyyes lemportent quand il eft fait, \& que la féche. reffe en exalte les particules auffitót qu'elle: font forméce, \& qu'elle artête la fermentation néceflaire pour attirer le nitre, \& lui ouvrir La matrice qui doit le recevoir. On a obfervé cue les vents du Nord font les plus propres pour la production du nitre. Dans les Indes, d'où nous vient prefque tout le nôtre, on ex. pole à l'air une elpece particuliere de terre. mêlée avec des végéraux pourris; \& c'elt delì guton tire le nitre. Tournefort rapporte clans le deunieme volume de fes voyages, gu'ils apprirent de ceux de la caravane de Wan, ville de Turquie, fur les frontieres de la Perfe, qu'on y ramaffe foigneufement la poufière des grandes routes fréquentées Lar des caravanes de chameaux; qu'on lave cette terre, \& gu'on en tire chaque annće envisos cant guintaux de nitre. 


\section{E5 de lu Végétations.}

Dans la manufacture de falpêtre de Paris s où l'on en fait une grande quantité, on ex. pofe des platras de vieilles maifons, mêlés avec des cendres de végétaux brûlés, aux inQuences de l'air pendant plufieurs mois; \& on les humecte de tems en tems d'urine putréfiée. C'eft de ces maticres qu'on tire le nitre. Lorfqu'on l'en a extrait, elles reftent \&uffi propres qu'auparavant à en former de nouveau, \& on les remet fur les tas: ce qui prouve que ce fel n'eft pas le fel naturel de la terre, mais qu'il s'y forme pendant qu'elle eft expofée à l'influence de l'air. Lorfque ces terres font reftées expofées à l'air pendant un tems fuffifant, on les met dans des tonneaux: on verfe de l'eau par deffus, \& on les remue fouvent avec l'eau, pour diffoudre les fels. Quand l'eau en a été affe'z impregnée, on la tire, \& on y mêle de la chaux vive \& des cendres de végétaux ou des fels alkalis: la chaux, afin de féparer l'huile d'avec le fel; \& les cendres ou fels alkalis, afin de fubftitues une bafe d'alkali fixe à la bafe de terre. On y met des fels alkalis, jufqu'à ce que ces felø ayent donné à la liqueur une couleur de lait , \& produit une précipitation. La précipitationt finie, on tranfvafe la liqueur, \&: on la fail bouillir.

Cherchons maintenanţ quelle eft l'origine 


\section{$\$ 00$ \\ Principes de I'Agriculture}

du nitic. T es opinions font partagées fut $\mathrm{c}:$ : oijict, \& les Chymiftes n'ont encore pû s'aco corder entr'eux. Quelques uns prétendent que le nitre eft tiré \& extrait de l'air, tel qque nous le vnyons: d'autres, qu'il eft produis par les fubftances végétales \& animales, ou par lcurs fucs mélés \& pourris avec la terre vitreufe: ceux-ci, qu'il eft formé de l'acide vitriolique, joint au phlogiftique ou partie inflammable de ces fubftances: ceux-là, que l'acide de nitre eft un acide qui differe du précédent, \& qui eft attiré par ces corps, qui ne font proprement que fa matrice: examinons ces divers fentimens.

Le falpêtre eft un corps artificiel, \& juf. qu'ici on n'en a point découvert dans les entrailles de la terre. Sur ce principe quelques Auteurs ont penfé que le nitre eft ahlolument extrait de l'air par les matieres qu'on y expole: mais cette opinion paroit fauffe, parce qu'on ne fçauroit tirer le nitre de ces macieres, qu'on u'y air mélé du fel alkali. L'a. cide cxifte bien dans ces matieres, comme jele ferai voir par la fuite; mais il faut lui denner une ba?e artificielle d'alkali, avane que la criftallifation du nitre s'opere. D'ail feurs, le falpêtre de lui méme n'eft pas un corps volatil, \& par conféquent il ne fçauroit Gotter dans l'air. Le nitre de l'air qui s'att?o 


\section{है? de la Végćtation?}

Ior

che aux vieux murs, eft une fubftance très: différente du nitre dont nous parlons ici. Il a des propriétés que l'autre n'a pas, telles que la volatilité \& un goût calcaire.

M. Lemeri, dans les Mémoires de l'Académie des Sciences pour l'année I 7 I 7 , fou. kient un fentiment qui, je crois, lui eft particulier; f̧̧avoir, que le nitre engendré vient des fubftances animales \& végétales qu'on employe pour le faire. Les preuves qu'il produit en faveur de cette opinion fons tout-is fait foibles. La principale, c'eft, ce me femble, qu'il a tiré un fel nitreux de quelques végétaux. Il elt vrai que certains végétaux conticnnent, dans leur état naturel, un fel infammable, qui paroît avoir plufieurs propriécés du nitre. Tcls font le chardon bévit, le concombre fauvage \& la parietaire. M. Boilduc, dans les mêmes Mémoires pour I'snnée 1 734, dit qu'il a extrait du vrai nitro d'une décociion de bourrache, furtout quand il y eut ajouté de la chaux vive pour fixer davantage les particuls s huileufes, afin çue les fels fe criltallifaffent. Il ajoute qu'une moififure qui fe forma d'elle-meme fue la décoction, après avoir '́té gardée quelque tems, brûla comme l'huile \& le nitre. Mais tout sela ne prouve nullement que le nitre vienne des végétaux qu'on employe pour le faire. Cav 
coutes fortes de végétaux y font égalemene propres, même ceux qui contiennent ur fel vitriolique. D'ailleurs le fel non fxe vient voujours de végétaux pourris, ou de quelques fubftances animales, ce que $M$. Lemery Semble avoir oublié; \& il eft furprenant qu'un fi habile Chymifte ait pu donner dans une erreur fi groffiere. Ces fubftances végétales \& animales, comme nous le verrons bientốt, agiffent d'une maniere toute diffésente, c'eft a dire, en fourniffant une terre abforbante \& un fel alkali volatil, \& par-là aidant la matrice à extraire de l'air l'acide qui s'y trouve, \& la tenant toujours ouverte à l'air. par la termentation (yu'elles y occafionnent.

La troifiéme opinion que prefque tous les Chymiftes embraffent eft, que les feis alkalis volatils produits par la fermentation des fubl. tances végétales ou animales pourries, \& lcs parties terreufes abforbantes, qu'on employe comme matrice pour faire le nitre, attirent l'acidum vagum, ou acide vitriolique, dont íair eft rempli, \& que cetacide fe joignant à Thuile de la matrice \& s'uniffant avec elle, devient l'acide de nitre. C'eft de cet acide univerfel, felon M. Homberg, que tirent leur origine l'acide nitreux \& l'acide marin : car joint z. une natiere inflammable, il donne l'acide nitrenx , \& joint à une matiere arfénicale, it 
devient acide marin. Les preuves qu'on ap. porte en faveur de cette opinion, font, Io. Qu'on employe pour faire le nitre des fubl tances pourries, \& que par conféquent l'huils doit fe joindre à l'acide vitriolique. Mais cette conféquence ne fçauroit ètre accordéc comme vraie, puifque les fubltances pouro ries peuvent avoir un autre ufage, commc :ous le montrerons par la fuite, \& l'on va roir tout à l'heure qu'on peut faire du nitre fans maticre huileufe. $2^{\circ}$. Que l'elprit de zitre eit ronge, ce qui eft, difent.ils, une preuve qu'il contient une fubfance inflammable: car c'eft cetre fubltance qui donme cette couleur à tous les corps. Intais nous connoifons beaucoup de corps qui ont cette couleur, fans qu'on air jama is pu parvenir is Saire voir qu'ils contiennent quelquise huile. 5. L'infammabilité du nitre qu'il doit à for acicie, prouve, difent-ils, qu'il contient: un principe huilcux, l'huile étant le feul. corps infammable que nous connoifions. Il eी aifé de leur répondre que le nitre n'ef́ point inflammable de lui méme, \& qu'il ne ie devient que quand il fe trouve uni avec um corps inflammable. Cetre preuve mène fe wume en objection cuntre cux : car on pese leur répondre que lo nitre s'enflamme avec exun les corps çui contiennent de l'huils; \&

$$
\text { G } 4
$$


YO4

Priscipes de "Agricultus'z

que puifqu'il n'eft point inflammable par luimême, il ne contient par conféquent aucune Iubftance inflammable.

Ceci nous conduit à l'examen de la derniere de ces opinions; fçavoir, que l'acide nitreux exifte dans l'air \& qu'il en eft extrait. Ce fentiment, qui n'elt fuivi que par un petit nombre de Chymiltes, me paroît le mieux fondé, quoiqu'il ne foit pas encore Ians difficultés.

La premiere preuve fur laquelle on l'éta: blit, c'eft que les fels alkalis \& les corps calcaires d'eux-mèmes \& fans aucun mélange de matieres végétales \& animales, produi. fent du nitte, ainfi qu'on le voit par l'expé. rience de Stahl, qui tira du nitre en expo. fant à l'air des fels alkalis: j'ai moi même ciré du fel de nitre de chaux prife des murs d'un parc. La feconde preuve, c'elt qu'on le trouve actuellement exiftant dans la na. sure. Plufieurs eanx minérales contiennent un fel nitreux, ainfi qu'il paroît par les expériences de $M$. Duclos, faitcs en préfence de I'Académie des Sciences de Paris. J'ai découvert aufi qu'il fe trouve des acides nitrcux dans toures les eaux crues \& dures, \& q̧ue enutes celles des puits contiennent un acide nitteux joint à une bafe abforbante; lequel El imparfait, pourvu quon y ajoute reule 


\section{Ė de la Viégétation.}

ment un fel alkali, fera converti en nitre réel. Troifiemement, fi l'on fait bouillir de l'eau crue \& dure, ou qu'on l'expofe à un grand dégré de chaleur, l'acide nitrenx eft réellement volatilıfé, \& la terre abforbants tombe au fond: ce qui prouve que l'acide nitreux eft volatil \& exifte dans l'air. L'efprit de nitre fumant, s'évapore continuellement dans l'air. Ces expériences démontrent, ce me femble, inconteltablement que l'acide nitreux diftingué de l'acide vitriolique, exifte dans l'air. Cet acide nitreux paroît étre le principe fertilifant que nous avons d'abord découvert dans l'air.

Ce point établi, rendons raifon des pro: cédés qu'on fuit dans la façon de faire le niere- Toutes les terres n'y font pas propres, mais feulement celles qui attirent les acides; c'eft-à dire, les terres abforbantes; fçavoir, ia chaux, la marne, $\&$ autres abforbans ou Subftances végétales \& animales, qui donnent une terre abforbante \& un fol volatil. Prefque tontes les terres contiennent plus ou moins de partics abforbantes. Ces te:res abforbantes retionnent lacide nitreux qui y cntre avecl'air, ou le tixcnt \& le recueillent yuand il s'éleve des parties intéricures de linterre: car je ne fuis point für qu'il ne s'en élere pas, groiqu'il me monte jamais beau. 


\section{Sob Principes de Agriculsure}

coup au deffus. L'expérience de M. Mariotis en eft une preuve. Il expola la matrice dus nitre pendant deux ans fur le haut d'une maifon, \& il n'en put tirer de nitre; au liews qu'il cu tira de la même matrice gardée dans. un cellier.

Les urines \& fubftances végétales \& ani. males qui fe pourriffent, font d'une grande utilité : elles excitent un mouvement inte, rieur dans la matfe terreufe: clles en tien. nent les pores ouverts, \& y donnent un li. hre accès à l'influence de l'air. Sans ces corps pourris, qu'on mele avec la terre, elle auroit une adhérence trop for te : fa furface fcule agi. roit, au lieu que dans le caspréfent c'clt touts la mafie qui agit. C'eft à ccla principalemen: que fervent les fubitances aninalce \& végé. tales, car je re crois pas qu'clles cutrent. comme quelques Chymiftes l'afiurent, dans la compofition du nitre, puifqu'on peut faire du nitre en expofant les feis alkalis feuls à l'influence de l'air. Ces fels attirent les acides, \& leurs parties font d'un tiflu fi lâche quu'ils n'ont befoin d'aucune fermentation pour l'ouvrir. Le vent du Nord eft particus lierement propre à la formation ciu nitres parce que ce vent porte avec lui une plus grande quantité d'acides nitreux; \& c'eft fur tour à cet acide qu'il faut attribues le 
Foid que ce vent nous fait fentic: je crois du moins la chofe très-probable, quoiqu'clle ne puifle ètre démontrée. Les mois dhyver y font très propres, parce que le vent du Nord y fouffle plus qu'en aucune autre fai. fon; \& qu'alors il y a moins de chaleur poux exalter le nitre pendant qua'il fe forme.

Voilà de quelle inaniere la matrice clt im. pregnée de l'acide de nitre. Voyons maintemant ce que cettc matrice contient. Nous en avons une analyfe par M. Petit, de l'Acadéfnie des Sciences.

Il prit 0 . livres de vieux platras qu'ill fit uremper dans 72. livies d'eau; ce qui donna une liqueur rougeâtre piquante \& amere, qui étoit à l'eau commune comme 32 cft à 31. Quand cettc eau, à force de buuilir, cut été réduite à un extrait liquide, car elle ste durcit point, elle attira promptemene 'humidité \& redevint tout à fait liqzuide. E!le rendoit rouge le papier bleu, ne faifoit point effervefcence avec l'efprit de nitre, ou t'efprie de fel marin; \& mêlée nver le pre. mict, elle rliffolvoit les feuilles d'or. L'huia le do virriol mèlé avec cotte liqueur, caula ane fenmentation violente fuivie de précipitatint. L'huile de tartre par défaillance ne Ce mela pas aifément avec cotte iịneur, mais

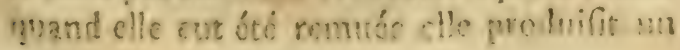




\section{8}

Irincipes de PAriculsurs

coagulum femblable au beurre, \& qui aroic une forte odeur d'urine. Le fublimé mêlé avec l'huile de tartre ne rendit aucune odeur l'urine. Le coagulum étoit l'effet d'une fé. paration \& précipitation d'une partie de la terre. L'efprit d'urine produifit le mème effet; mais l'efprit de fol ammoniac fait avec la chaux ne le produifit point. Le papier gris trempé dans cette liqueur brûloit comme les allumettes. Ces expériences prou. vent qu'elle contient une terre abforbante, ciu fel volatil, de l'acide de nitre, \& du fe! marin.

II diftilla cette liqueur pendant ciny jours, $\&$ elle ne donna qu'un phlegme chargé do beaucoup de bitume. Quand il y appliqua le feu le pius violent, des nuages blancs paIurent dans le récipient, \& ces nuages fe condenlerent en eau régale. Deux autres diftillations lui donnerent de l'efprit de nitre. Quand il y eut ajouté de l'huile de vitriol, il fe fit une ébullition violente ; cetre opération lui donna de l'eau régale: \& avec la chaux vive il tira de l'efprit volatil d'urine en petite quantité. Il paroît encore que cette liqueur contient une fubltance huileufe, une matiere terreufe, un peu de fel volatil, de l'acide marin \& une grande quantité d'efprit de nitrea Il n'elt pas difficile de voir d'oin 


\section{Ef de las Dégetration?}

Fenoit la matiere inflammable \& le fel volan cil; c'étoit des fubftances végétales \& anic males pourries, qui y avoient été mêlées. Le fel marin venoit de l'urine des animaux répandue fur la matrice du nitre; mais il ne put jamais extraire de cette terre nitreufe du nitre réel. On ne peut en tirer qu'en y ajoutant un fel alkali en nature, ou contenu datis les centres des végétaux. On les ajoute ordinairement à la maffe nitreufe avant d'y jetter l'eau; finon il faut y en mettre après:

L'effet qu'elles produifent eft de s'unir के l'acide nitreux quand on $y$ a ajouté affez d'eau pour les mettre en action. Car les fels alkalis attirent l'acide de nitre plus puiflama' ment qu'une bafe terreufe, \& chaffent mên me la terre. C'eft par cette raifon que la li. queur en bouillant dépore beaucoup de cette terre. Il faut y mettre autant de fel alkali qu'il eft néceffaire pour faouler l'acide nitreux \& chaffer la terre abforbante. Le fel alkali ne peut s'unir à l'acide marin, parce que celui. ci a déjù une bafe rerreltre.

Si ces terres abforbantes attirent de l'air l'acide de nitre dans les manufactures, elles doivent affurément faire la même chofe quand elles font répandues fur la terre, \& fe convertir en ce même fel compolé d'acide nitreux \& d'une bafe abforbante. Ce n'eft 


\section{IT To Trincipes de l'Ligriculinrs}

donc pas, comme on l'a cru, un nitre rée? yui elt la caufe de la végétation, mais un fel nitreux imparfait. Cette illée eft confirmés par ce que nous avons déjà vu dans les ex. périences précédentes, que ce même fel qui fe trouve dans l'eau falée paroît favorifes puitramment la végétation; \& qu'un fel arti. Liciel de la même nature, compofé avec la chaus \& l'efprit de nitre, \& joint à une quantité convenable d'huile, a rendu uns torre maigre extremement fertile.

Si ce raifonnement eft julte, les effets die: divers aniendemens doivent être d'autant plus grands, gue les amendenens auront plus deforce pour attirer les aciles. Or c'eft ce qui arrive réellement, \& ce yui confirme par conféquent la vérité de notre conjecture: car la cendre a un effet p!us prompt qu'aucusz autre amandement, parce que les fels alkalis qu'elle contient attirent les acides plus forte. ment que ne fait aucu: autrecorps. La fuic \& le fumier viennent après; ce font dies al. kalis volatils \& leur attraction approche le plus de celle de la cendre vient enfin la claf. fe des ierres abforbantes, On peut remarquer la même chofe fur les marnes : car elles agiffent fur la terre a chacune aे proportion de la faculté qu'elle a d'attirer les acides; d'a. bord la marna coquillaire, puis l'aruilleufe, 
\& enfuite la picrreufe, qui refte quelquefois ģuatre ou cinq ans dans la terre avant d'y produire aucun effet. Ces amandemens perdent leur efficacité dans la même proportion: ceux qui fe convertiffent plus promptement cu fel font aufi les premiers épuifés.

Il-viendra naturellement à tout le monde une objection contre ce fentiment, quoiqu'appuyé fur des expériences fi concluantes; c'eft qu'on ne tire aucun fel femblable des terres les plus fertiles. En général, ces parties abforbantes font en fi petite qquantité dans les meilleures terres, \& elles y occafionnent une fi légere fermentation, qu'il n'y a qu'un très.petit nombre de ces partiss qui fe trouvent fur la fuperficie \& qui puiffent fe convertir en cette forte de fels. D'ailleurs elles n'y font pas platot converties, que quelques plantes les abforbent. Cette obfervation fait affez voir qu'on ne doit gueres s'attendre à tirer du fel nitreux d'aucune terxe; mais qu'on en ait pourtant tiré quelque. ¿vis, c'eft ce qu'on peut voir par ce palfage de Bacion, Hift. vit. E' mort. "Il eft trèss) certain que toute forte de terre, pure \& 2) fans mélange des fels ou acides nitreux. "quoique entaffée \& couverre die maniere 2) qu'elle ne puiffe recevoir les rayons du fos. leil ni produire aucun végétal, atsire !s 
„) nitre, \& en amafe en aflez grande abornd is dance.

Néanmoins prefque tous ceux qui ont décompofé de la meilleure terre, nieut qu'il s'y trouve de ce fel nitreux : recourous donc \& l'expérience pour décider la queftion.

Exp. 30. Pour la mettre hors de doute, je pris une taupiniere de bonne terre au mois d'Octobre. Je verfai de l'eau deffus \& je filtrai cette eau à travers le papier gris. Cette liqueur, quand elle eut bouilli, fe trouva jaune \& d'un gout falé. Ce fel me parut vifiblement nitreux; car le papier gris trempé dans la liqueur \& feché, brûla comme une allumette. Quand j'y mis de l'huile de tartre, la liqueur devint laiteufe, \& il tomba au fond une poudreblanche; preuve que ce fel eft de la même nature que celui des eaux crues \& dures. D'abord je ne pus tirer de fel par la cryltallifation, parce que la liqueur étoit très onctueufe \& en petite quartité; mais en m'y prenant comme font les ouvriers des manufactures de nitre par rapport aux matieres nitreufes, c'eft à dire; en mê. lant avec la liqueur de la chaux vive pour féparer l'huile d'avec les fìls \& la laiffant repofer quelques jouts, j'en tirai de vrai falpêtre. Cetce expérience fait voir à l'ovil la partie faline de la nosriture végétale. 
De tout ce que nous venons de dire nous pouvons conclure :

Coroll. I. Que puifque la chaleur empêche la formation du nitre, en l'exaltant; \& que l'hyver \& le printems font les faifons ies plus favorables à fa génération, c'eft dans l'une ou l'autre de ces deux faifons qu'on doit réo pandre les fumiers fur les terres

Coroll. 2. Que ces amandemens tiratic leur fertilité de l'action de l'air, plus ids ref. tent expofés fur la fuperficie de la terre, plus ils doivent $f e$ convertir promptement en fels nitreux: c'eft de quoi les Laboureurs fone convaincus par l'expérience. Mais les corps qui contiennent un fuc nourricier déjà formé, tels que les chiffons de laine, les cheveux, crins, rognures de corne, le cuir o les fcieures; ou ceux qui exiltent déjà dans la forme de fel neutre, tel que le fel marin, ne peuvent recevoir aucune amélioration de l'influence de l'air. L'expérience a confirmé pareillement certe obfervation. Voilà de fortes preuves de la vérité de notre précédente conjecture.

Coroll. 3. Puifqu'on a obfervé que le vent du Nord porte le plus d'acide nitreux, il femble qu'on en doit conclure, que les hau. teurs ou coteaux expofés au Norid en reçoi. yeint davantagc. Autli a.t it été obfervé 
qu'ils funt communément plus fertiles çtso ccux qui font cupofés au midi; mais les pre. snicrs n'étant pas aufi expof́s au foleil que les icrniers, ils doivent ctre d'un moindre rappoit. Notre théorie de la végétation en rend fuffremment raifon.

Coroll. 4. Il paroit par les opérations de la manufacture de nitre que toutes les terres abforbantes dont on fait ufage dans l'agriculturc, deviendiroient plus propres à remo flir lobjet quu'on fe propofe, fi l'on y ajozs. toit quelques fubfances végútes ou animales pourrics, povr ouvris le tiffu de leurs parcies \& les rendre plus acceffibles aux infiuences de l'air.

\section{QUATRIEMERARTIE PREMIERE SECTION.}

Dé la niceflé Gouvrio ô de fulutrifor lo ระง \%.

L fe borner à fournir de la nourriture aux plan. tes; il faut encore qu'il les mette cn état de chercher cette nourriture. Elle n'oft d'au. 


\section{E? de le Véglamion:}

Cuine utilité pour les plantes, fi leurs racines me peuvent percer la terre pour $y$ attcindre \& s'en nourrir. Delà la nécelfité d'ouvrir \& de pulvérifer la terre. Les plantes fe nourtiffent principalement par lcurs racines: elles ne commencent même à croitre que quand leurs racines font affez fortes \& affez nombreufes pour fe nourrir elles-mêmes, \& lenr tige avec elles. Plus elles s'étendent, plus la plante reçoit de nourriture, plus elle devien forte \& répond avec fuccès au deffein de la nature.

Mais ce n'elt pas dans cette vîe feule. ment qu'on doit favorifer l'accroiffement des racines. Elles paroiffent encore par un autre endroit, être la principale caufe de la fécondité des grains. Car non-feulement elles nuurriffent les plantes, mais elles pouffent elles-mêmes plufieurs jets ou tiges. Une petice partic de racine fuffit fouvent pour produire une plante. Il fort des racines de differens grains plufieurs iges, long.tems meme apres que le grain eft pourri. Plus it $y$ a donc de racines, plus il y a de jets \& de tiges: or, la quantité des racines paroit dépendre en partie du foin qu'on prend de pulyérifer la terre.

Il eft vrai que la terre peut aulfi etre trop divifée \& trop meuble : car il taut qu'elle ais 


\section{I16 Principes de 1 Agriculiure}

une certaine confiftence pour foutenir les plantes. Les terres fableufes ou graveleufes deviennent pires quand on les laboure fouvent; \& l'on a oblervé que les terres légeres, trop fumées, produifent des récoltes de pois moins abondantes, que quand elles ne font point fumées du tout; mais ce défaut eft rare dans les terres. La trop grande denfité eft beaucoup plus comnune \& donne beaticoup plus de peine aux Laboureurs.

Voyous dunc par quels moyens lesterres font tenues meuhles. Nous en diltinguerons de naturels \& d'artificiels.

\section{SE C.T I O N II.}

Effets de l'Atwofphere.

I

L ES viciffitudes ou changemens alterna. tifs de l'air , font les principaux moyens que la Nature employe pour parvenir à cette fin. I.e froid \& le chaud, la féchereffe \& l'hu* midité, refferrent \& dilatent la terre alternativement; \& par ces mouvemens alter. natifs en ćbraulent \& féparent les parties. Mais il n'y a point de moyens plus efficaces que la gelée \& le dégel. Il n'elt prefque per. 


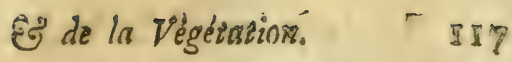

fonne qui n'ait obfervé combien la terre effo meuble après les gelées: on voit mème pluficurs végétaux jettés alors hors de terre. Or il parcîi que la gelée agit de plufieurs ma. nieres; $\mathrm{I}^{\circ}$. en mettant dans un état d'ćlafticité une partis de l'air fixe, qui divife \& fépare les parties de la terre pour fe faire une iffue; $2^{\circ}$. par la dilatation de l'eau, qui en fe gelant dans la terre, doit en défunir les parties adhćrentes entr'elles; $3^{\circ}$. les parties de l'eau en s'échappant de la terre à la maniere des fels, doivent la fendre \& la divifer.

Coroll. Afin que la terre puiffe recevoig tous les bons effers de la gelée, il paroit convenable de lui donner un labour avant que les gelées commencent. Une feule façon alors la pulverifera plus que deux après les gelées: mais il faut toujours avoir égard au climat car dans les pays on il tombe beaucoup de pluyes pendant l'hyver, cette pratique den viendroit préjudiciable, en expofant la bon. nec terre à être emportée par les caux.

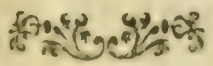


\$18 Principes de PAgriculurve

\section{SECTION III.}

Dis changement des efpecer?

I

\& y a des plantes deftinées par l'Auteur de la Nature à refferrer \& à raffermir la terre, \& d'autres à l'ouvrir \& à la divifer. Les plantes à racines fibreufes fe partagent en petits flets ou radicules, qui s'étendent dans touEes les dircetions, mais furtout horifontale. ment. Les plantes à pivot pouffent perpendiculairement une grande tige, accompa. gnée de radicules latérales. Les premieres, dans laquelle claffe on met tous les grains, rols que le feigle, \&c. confolident la terre, au lieu que les autres, parmi lefquels on range les plantes légumineufes, les carottes, anets, \&zc. divilent \& atrénuent extremement la terre. Souvent mème les treffles font jettés tout-à-fait hiors de terre après la gelée.

Cet effet provient de la nature des racines. Les racines fibreufes doivent lier \& reflerrer la terre comme autant de petites cordes; ats licu que les plantes pivotantes s'enfoncent duns la terre comme des coins, \& par cette force méchaniąue l'ouvrent \& la divifent. Peut etre ces dernieres plantes operent.elles 
encore, en donuant par leurs racines plus d'humiditc à la terre, qu'elles tiennent par.lì bcaucoup plus meuble. Il paroit que quelques-unes ont cette propriété. Un pied do mente qui a une partie de fes racines dans l'eau \&i les autres en torre, humecte la rerre par ces racines, felon l'expéricnce de Tul! Les plantes lógumineufes, on couvrant lis ecrre do leurs feuilles, la tiennent humide, empechent le foleil de la confoliter, \&z dé. truilent les mauvailes herbes qui la reller. tcut: c'eft par cette raifon que le changement d'efpecs améliore les terres. Quand une terre cit fouvent enfemencéc de bleds s: autres grains, elle fe condenfe trop. Une réculte depois, de feves, de navets, l'atténue \& la pulvérife.

Lcs Fermiers ont appris par expérience que toutes les plantes à racines fibreufes ap. pauviffont la tere, \& qu'elies reufifient mal, quana clles fe fuccedent immédiatement les unes aux autres. Au contraire les plantes à pivot fertilifent la terre, \& elles peuvent itre femées avec fuccis les unes apres les autres. C'eft yue ces dernieres, en ouvratut la terre, donnent un libre paffage ¿ l'air pour y pénetier plus avant, \& par confíguent favorilent la production de la nour. rituse vigctalc: ant lisu que les prenices, 
I20 Friacipes de 1 Agricaliure

an confolidant la terre, empechent en par: tie l'influence de l'air, \& rendent le fol moins fertile.

Il a été obfervé que non feulement le clungement d'efpece, mais même celui du grain eft neceffaite: le mêne grain femé dans la même terre y dégénere. Ceci vient d'une autre caufe. Il arrive fans doute rare ment que la nourriture végétale fe trouve mélangée dans toutes les proportions qu'il faudroit, \& qu'elle ait prévifément la confrr. tance qui conviendroit le mieux. Les terres étant ordinairement trop féches ou trop humides, trop légeres ou trop compactes, la nourriture végétale doit être auffi trop légere \& trop humide, ou trop épaiffe \& trop gluante. Les végétaux doivent donc fouffrir de recevoir toujours la mêne forte de nourriture, \& ne peuvent fe réfaire que dans une terre qui ait des qualités oppolées.

\section{S E C T I O N I V.}

Des Labours.

I

E labour eft la méthode artificiclle do pulvérifer la terre, la plus connue \& la plus pratiquée. Le labour produit cet effet de 


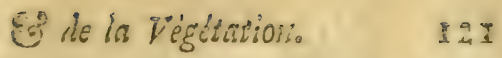

Ćeux manieres, $I^{\circ}$. par une divifion mécha. nique immédiate \& une trituration de la terIe; $2^{\circ}$. en l'expofant plus fouvent \& avec plus d'étendue, a l'infuence \& aux viciflieudes de l'atmofphere. Je crois meme que c'elt en cetre derniere opération que coufifte le principal avantage du liabour : car un inftrument auffi grroificr que la charrue, paroît peu propre de lui-même à préparer la terre à entrer dans les vaiffeaux capillaires des plantes; cependant fes efrets font trèsiemarquables. Nous les voyons parfaitement bien repréfentés dans l'hiftoirc que Pline raconte de C. Eurius Crefinus. Ce Laboureur ayant toujours de plus belles ré. coltes que fes voilins, fut foupçon né le mas gie, accufé devant le peuple, \& près d'etre condamué à mort. Quand les Tribus furent affemblées pour donner leurs fuffrages, il leur montra tous fes inftumens de labourage, ban icoup plus grands que ceux des autres, un coutre plus large, une churrue plus pefante; \& il ajoutaces paroles remarcquahles: "Romains, voila ma magie, \& jo ane puis produre ici mes travaux, mes "veilles \& mes fueurs". II fut renvoyé abm fous d'une voix unanime.

Lesions effets des lahours dévenitent de la fiherete de la terre, car fi clle cht imbi- 


\section{2\%5 Priscipes de Thricuiture}

Lée d'enu, elle fe confolide, au lieu de fe divifer, \& r rofte dans cet étar jufqu'à ce que les gelées de l'hyver l'atténuent \& la pulvé. rifent. Les corps fecs fent les fouls qui puifo tent fe réduire en peuffiere.

Les Liboureurs doivent ouvrir la terre à Ia mème prefondeur q̨ue les rasines du bled péuérrent ordinairenent, afin qu'elles puiffent tronver un libre pairage: mais ils doivent prendre garde de ne pas enfoncer la charrue au-delit du fol, autrement ils cnterfiroient ce qui atroit été amélioré par l'ill. fuence de l'air, \& y expoferoient ce qui ne pourroit peut.être cn recevoir aucune ané. Sioration. Ainfi la charrue ne doit cttre enfoncée qu'à pucportion de la profondeur de lia bonne terre.

Il elt furprenant que nous n'ayons point encore de noyen plus certain pour détermi. ner la profondeur de la charrue, \& la tenir dans la fituation précife que la terro demande, que l'attention du Laboureur ; attention çue les objets extérieurs \& la fatigue peuvent tiès. fouvent diflraire, dequoi fouffrent également les berufs \& la terre. La charrue à ruues ne prévient-elle pas cet inconvénient?

Plus la terreseft forte, plus cile duit être inbourée fouvent. L'argille ne Cụauroit l'ètre trop, mais las tetres pius légeres pourroicne 


\section{Gi do la Végérnation: 123}

Ieire. Pluficurs Laboureurs conviennent gue les labours trop fréquens nuifent aus terres fableufes \& graveleufes.

Comme cette opération dépend des principes de la méchanique \& non de ceux du la Chymie, je n'en parlerai pas plus au long. Je laiffe à d'autres le foin de traiter ce fujet véritablement intéreflant; \& qui, quoique affez bien entendu peut-être pour la pratiģue commune, n'a pourtant point cncore été ré. duit à l'exactitude mathématique, dont tous les agens méchaniques font fufceptibles. Io fouhaite qu'm jour quelque Laboureur ha. bile dans fon art \& inftruit dans les méch?. aiques, expofe les principes fur lefqueis los charues devroient être conltruites. Il rendrois un fervice important à toute la Société.

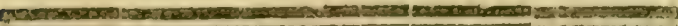

\section{SECTION V.}

\section{Des annandentens.}

Is eft un autre moyen que l'art cmpions: pour tenir la terre meuble, c'elt d'y melo des corps putrides \& en fermentation. Nous avons vu que ces corps ont un mouvemens inecrne conlidírahle avant qu'on les jute fiur 


\section{Primeipes de IAgrieult tripe}

la terre. Ils s'y corifervent, quoiquen un moindre dégré. La terre graffe des cimetieres, à cuufe de la fermentation où elle eft, fe rentle tellement quand elle eft expofée à l'air, qu'elle ne peut rentrer toute entiere dans les folfes d'oxi on l'a tirée. L'argille, qui ne contient que très peu de parties putrefcenres, ett de toutes les terres celle dont les par. ties ont le plus d'adhérence. Nous avons déja vu combien les coquilles, quand elles commencent à fe pourrir, divifent \& ameu. bliffent la terre.

Mais outre ces amandemens, il y en a encore qui, fans ètre du nombre des putrefcens, atténuent puiffamment la terre. De ce genre font les marnes, \& fur tont les plus douces, par exempie, l'argilleufe. Nous avons vu plus haut avec quelle promptitude les maruss perdent leur adherence \& tombent en poudre. Elles communiquent caste qualité aux dutres terres, meme aux plus adhéreutes \& aux plus compactes. L'expérienco fuivante en eft une preuve.

Exp. 31. Prenez des partics égales de marne \& d'argille. Pétriffez.les bien enfenible \& faites les fecher. Quand la fubitance compofée de ces deux matieres eft mife dans l'cau, elle tombe peuà peu en poudre ats fond du verre a au lieu qu'une boule d'argille 
pure refte dans l'eau fans fe diffoudre: preuve convaincante que la marne a, pour atté. nuer les terres, une vertu finguliere, \& done aucun autre corps n'approche. Il a été obfervó gite toutes les terres argilleufes, quand elles ont eté marnées, fe fechent quatorze jours plûtôt qu'elles ne faifoient auparavait. Ce qui provient dece que a terre étant plus divifée, elle ouvre plus de paifages à l'eau pour s'écouler.

Je fçais que ce fentiment contredit l'opi-' nion très commune que la marne n'elt pas propre pour lesterres agillenfes fo ne vois point ce qui a pu bumer lieu i cetre itée, finon que des corps qui fe retemblent fi ture ne patvente ètre regardés coinme capabies de s'aniéliorcr l'un l'autre; mais l'expérience de plulieurs pays où l'un employe ordinaire. ment la merne, quoique le fol tre forie yu'une forte argille, rétuteailez ces idées vulgarres. L'expénence fivivante va mettre la chole hors de doute.

Exp. 32. J'ai rempli un pot de la même argilie, que j'avois employée dans l'expérience précédente. Cette argille étoit reltéc expolée à l'air pendant quatre mois, \& paroiffoit n'etre melée d'aucune autre terre, ayant été tirée à fept ou huit pieds $d$ : profondeur. J'appellerai ce pot $n^{\circ}$. I. Le pot $n^{\circ}$. 2 fus 


\section{Irincipes à tAgriculerme}

rempli de parties ćgales d'argille \& de marnè No. 3 de parties égales d'argille \& de chaur éventée. $\mathrm{N}^{\circ} .4$ de parties égales d'argille \&z de fable de mer bien lavé. $N^{0}$. 5 de parties égales d'argille \& de fumier. Je retourna cous les jours ces différentes terres, \& le 26 d'Avril je femai dans chaque pot fix grains G'orge.

If $\mathrm{Mai}, \mathrm{n}^{\circ} .2$ avoit deux plantes fortics de tcrre. $\mathrm{N}^{0} .3$ en avoit quatre.

$x>\mathrm{Mni}, \mathrm{n}^{\circ} .2$ en avoit fis. № 3 Sept j deux defquelles étoient d'un mème grain. No.4\& s en avoient chacun une.

2 I $\mathrm{Mai}, \mathrm{N}^{\circ}$. I en avoit cinq, dont deu étoicnt d'un pouce \& demi de haut. $\mathrm{N}^{\circ} .2$ cn a voit fix, de deux pouces. $\mathrm{N}^{\circ} \cdot 3$, étoient de la mème hauteur. $N^{\circ} .4$, deux, dont l'une étoit d'un pouce. $N^{\circ} .5$ trois, chacune de đeux pouces.

4 Juin, No. 2, le plus haut \& le plus verd. $N^{\circ} .3$ enfuite. $N^{\circ}$. I \& $\{$ de la même hauteur entr'eux, mais le dernicr, d'un verd très foible. No. 4 le pire.

20 Août, $N^{\circ}$. I avoit environ neuf poü ces de haut, \& étoit devenia fort pâle. Il paroît que fes racines n'avoient pu percer l'ario' gille, \& qu'elles ne s'étoient ćtendues qu'i travers les fentes \& crevaffes. $N^{\circ} .2$ avoit ncul ćpis, \& d'un bean verd foncé. NT. 


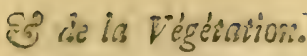

cn avoit huit, mais d'un verd pltus foille: $N^{\circ} .4$ en avoit cinq, \& c'étnient les plus petits de tous. $N^{\circ}$. S en avoit nenf, prefque aufi beaux que ceux du n. 2. Je n'ai point eu l'occafion de les revoir davantage.

Cor. I. On voit par cette expériencs combien la marne eft un amandement vo tile. Car la glaife d'elle-même ne peut pro. duire aucunes bonnes plantes, parce quue leurs racines ne f̧̧uroient y pénćirer.

Cor. 2. Il paroît, contre l'opinion com: mune, que le fable eft le moins bon de tous les amandemens que javois employés. II ns fçauroit divifer les petites parties d'argilie, feule divifion utile pour faire croitre les vígétaux. Le fable en petite quantité femble plûtôt fortifier l'union des petites parties de ìargille, comme on le voit dans les Misnito factures de briques.

Cor. 3. La chaux paroít être un bou :mandement pour l'argille. J'avois laiffé s'á. venter pendent quelque tems celle d'ont j'ai fait ufage. L'effet que l'air produit deflus en la changeant de chaux: vive en chaux éteinte, doit ameublir confidérablement la tertc.

Cor. 4. Il paroît ciue le fumicr \& la marne font les meillcurs am t. Pemens pour l'urgille. Le premier a une fermentation confidérable. l'autre perd toute adhćrence quand on $\mathrm{y} z$ joute de l'enu. 


\section{I28 Principes de l'Agriculutive.}

\section{SE C T I O N VI. \\ De la Végétation.}

I

I ne fer pas inutile de confidérer icien peu de mote ce qui doit arriver à la nourriture végétale dans les vaiffeaux des plante. Ce fujet ne demande point que nous entrions dans une difcuffion de l'anatomie des plantes. Je m'cn ticndrai à celle des Botaniftes.

Le fcl nitreux étant formé fur la fuperficie de la terre, lera entrainé dans l'intérieur avec les rofées \& les pluyes. Il y difioudra les huiles gu'il rencontrera fur fon pafiage, $\&$ formera avce elles un fuc favoneux, qui contindra, outre les principes précédens, un air \& un fcu fixes. Ce fuc fera retenu par la terre, parce que, comme je l'ai fait voir par expérience, la terre fertile agit crmme une éponge à l'égard de l'eau. Là il éprou* vera deux mouvemens, l'um de defcen。 fion, caufé par fa propre péfanteur; l'autre d'afcenfion, que lui donneront la chaleur de la terre \& l'influence du foleil. Dans cette agitation continuelle, il fera fans ceffe appliqué aux racincs deftinées à recevoir la nourciture des plantes. 
La premiere queftion qui fe préfente ici, c'eft comment ces fucs montent au haut des plantes \& des arbres. Malpigini croit qu'il faut attribuer cet effot, en grande partie aux véficules del'air qu'il a découvert dans la ítructure des plantes, \& qui lui paroîfent devoir fe contracter $\mathrm{e}$ fe dilater felon les di. vers changemens de l'atmofphere. Mais il me femble yue cette dilaration des vaificaux ne doit poit forcer les fucs à monter plûtot qu'à defcendre. Je croirois mème ọu'eile arrèteroit plûtôt tout à fait leur mouvement.

La raifon qu'on en donne ordinairement, c'eft à dire l'action des vaiffeaux capillaires, me paroît très fufiliante. Halés a démontré re fait aux yeux par plufieurs expériences, dans lefquelles une partie d'une branche ayant été coupée par les deur bouts \& ayant fa partie inféricure dans l'eau, l'humi. dieé fe faifoit voir aulfi:ut dans la partie fupérieure. Cet effet destubes capillaires doit venir d'une attractom mutuelle de leasu \& de la fubftance dont ces vaiteaux fount crimporés.

Il eft demortré par une cxpérience yue le Ducieur Taylord rapporte dans les Trant. actions Philofophiques, $n^{\circ} \cdot 368$, yuil y a entre le bois \& l'enu line tres-fuite attraction. Il attak ha à une balance un norceau de planclie do fapin, le fir tremper dans l'ean. 


\section{\$3 30 \\ Principes de $P$ Agriculture}

le péra \& le replongea dans l'eau. Ce murceau de planche avoit de furface un purc: en quarré. Pour le lever, lorfqu'il touchoir l'eau, il fallut cinquante grains au-deflus du prenier poids. Le poids ainfi fur ajouté dans différentes expériences qu'il fit encore, êtoit toujours en proportion avec la furface. La diftance de la furface inféricure de la planche à la furface de l'eau ftagnante au tenis de la Ceparation, étoit de la $\frac{15}{100}$ partie d'un pouce. $\mathrm{C} \varepsilon$ poids fur-ajouté elt la mefure réelle de l'attraction entre la furface du bois, \& l'eau en contact.

Une autre force qui contribue beaucoup à élever la feve, c'eft l'attraction naturelle entre les parties conftitutives de ce fluide. $\mathrm{Ce}$ doit être certainement le cas de la feve lorfqu'elle fe meut vivement, comme dans la vigne quand elle pleure. Ces deux caufes agiffant enfemble, \& l'évaporation fe faifant continuellement par les partics fupérieures des vaiffeaux, la feve s'éleve des racines des plantes jufqu'aux extrémités de leurs branches.

Mais la nature ne voulant pas que cette opération fe faffe trop promptement, il fe srouve plufieurs vaiffeaux en forme de fpirales \& plufieurs cellu!es dins lefquelles la fe. qe elt dépofée, \& qui en retardentla marche。 
Dans ces vaiffeaux \& cellules la nature de 1 角 feve eftaltérée par l'agitation des plantes, par les mouvemens continuels de ceux de leurs vaiffeaux qui contiennent de l'air, \& peut être par les particules de lumiere reçî́es dans leurs feuilles. Les fucs font rendus plus forts par l'expulfion des parties aqueufes, $\&$ ce qui refte eft ou appliqué aux extrémités des vaifeaux, qui courent dans toutes les directions horifontalement, comme perpendiculairement, \& fait croître la plante en groffeur \& en longueur; ou employé à former les feuilles, les fleurs \& le fruit.

La différence des plantes dans leurs fircs \&: dans leurs productions, s'explique aifément par les différentes combinaifons des cinq prit. cipes dont leur nourriture eft compofée, \& les différens dégrés de ces combinaifons. Si les parties plus groffieres font deftinées à quel: que ufage, les plus fubtiles font toutes enlevées par les vaiffeaux latéraux, jufqu'à ce qu'il ne refte plus que celles qui font nécef. faires. Si au contraire ce font les parties plua fubtiles qui doivent être employées, elles fe filtrent dans de petits vaiffenux propres à les recevoir, \& qui font placés foit dans de slus larges, foit dans les cellules, où les fucs fun dépofés. Ainfi les parties d'une certaine groffeur funt portées \& dépofées dans cer. 


\section{उ32 Principes de PAgriculeure}

- sines partics des plantes. De là cette variété de fels, d'huiles \& de figures dans les végétaux; de la cette différence d'odeurs, de gotits, de vertus, \& autres qualités.

On vuit par une expérience de $M$. Hombeig quel pouvuir inhérent ont les vaiffeaux des planres, prour changer $\&$ altér er les fubftances qui y font reçues. Il remplit d'une quantité fuffifante deux pots de terre, mêlée avec du falpêtre. II planta dans l'un du creffon, plante alkalifante \& qui donne un fel alkali volatil fans acide. Dans l'autre du fenouil, plante acefcente, \& qui dans la dif. tillation donne un acide fans fel alkali volatil. Il remplit deux autres pors d'une terre qu'il avoit dépouillée de tous fes fels, fi elle en avoit eu quelqques uns. Dans l'un il planta du fenouil, \& dans l'autre du creffon. Les deux plantes des deux pors où il avoit mèlé du falpêre vinrent beaucoup mieux \& pefoient beaucoup plus que celles des pots où il n'avoit point mis de nitre. Le creffon du pot où il y avoit du falpêtre ne donna auscun Sel acide dans la diftillation, quoiqu'il eût été nonuri d'un fel qui contcnoit un acide. Et le 'fonuuil venu dans a terre dépouiliée de ces fuls donna un acide, quniqu'il n'y en eût aucun dins cette terre. Cetıe expérience prouve que ies vaiffeaux des plantis ont la faculté 


\section{Eे de la Veggtatiou.}

de convertir les fels qu'elles tirent de la terre en leur fel propre; probablement en les combinant avec differentes proportions d'eau, d'air, d'huile, de terre \& de parties delumiere émanées du foleil.

Mais quelle raifon donner de la différence des formes extérieures des plantes? Recourreruns nous immédiatement à la main dus Souverain Etre; ou, ce qui doit être regardécomme le dernier pas que puifent taire les Philofophes, chercherons mous quclques agens chymiques capables de produire cet effer? Plufieurs expériences prouvent que les fels, fur tout les fels nitreux, ont un pouvoir naturel \& inhérent de fe former en végétations, comme on les appelle, \& de prendre la forme de plantes avec leurs branches, leurs feuilles, \& mème leurs fruits: pouvoir qui leur vient de la forte liaifon qu'il y a entr'eux \& l'eau. Ce fait m'a fouvent porté à croire que le pouvoir végétatif des plantes \& leurs formes particulieres de végétation proviennent du pouvoir vé sétatif inhérent à leurs fels. En eff $t$, on c bferve que cette faculté végétative des plantes it d'autant plus forte, qu'ilentre plus de fils dans leurs vaiffoaux.

Ainfi j’di tâché d'expliquer les effects dę amandemens fur les diffurcntes terres, l'élée 


\subsection{Principes de PAgriculture}

vation \& les changemens de la nourriture végétale dans les vaiffeaux des plantes par ces attractions \& affinités remarquables dont l'Auteur de la Nature a revêtu les petites parties de la matiere. Ces parties ne font pas, comme on fe l'imagine communément, des corps purement paffifs, mais pleins d'activité, de vigueur, \& capables de produire ces changemens qui renouvellent \& confervent la sature. Je les ai démontrées, ces affinités, par des expériences, ¿ n'ai point eu recours à d'autres principes. C'elt fur ce feul fondcnient que j'ai établi tout le plan de cet Ouvia. ge; je me flatte que fa fimplicité fera une forte preuve de fa vérité.

Mais d'où viennent ces attractions électi. ves qui mettent tout en mouvement dans l'Univers? De qui la matiere tient elle le pouvoir d'agir hors d'elle-même? Car elle agit de cette maniere, où il faut admettre une chaîne infinie d'agens matériels: De qui, dis je, tient elle donc ce pouvoir, fimon d'un Etre inımatériel, qui lui a donné d’abord ces propriétés, \& ıui, par fa volom. té inmédiate, les lui conferve conftamment duns le mème état. C'eft fur ces parties, dont la petiteffe échappe aux yeux des hommes, que l'Etre Tout-Puiflant prend plaifr à déployer fa puifance, \& fur leurs proprié- 
tés qu'il a voulu établir l'admirable fyftême du monde. De-là l'origine du mouvemint , de l'adhérence, de la croiffance, \& de l'organifation. Mais toutes les formes individuelles étant deftinées à n'avoir qu'une du. rée finie, Dieu a revêtu d'autres parties d'une force répulfive, \& neelés les femences de diffolution avec les premiers élémens de la vie organique. Tant que les vaifeaux reftent ouverts, \& que le mouvement des fluides fubfifte, les forces attractives l'emportent fur les répulfives \& la vie végécale ou animale continue. Mais quand ce mouve. ment ceffe, \& que d'autres circonftances concourent, les forces répulfives l'emportent fur les attractives, elles détruifent le compofé, \& réduifent le corps aux parties dont il avoit été formé d'abord. Voilà le grand cercle que fa fageffe infinic a tracé, \& dans lequel fa toute puiffance s'elt renfermée pout lo plus grand bien de l'Univers.

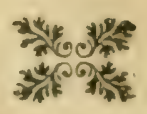




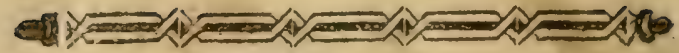

\section{$P A R T I E \quad V$.}

\section{SECTION PREMIERE.}

\section{Des mauvaifes berbes.}

\section{I}

Es obftacles de la végétation \& les mriyéns d'y remédier font le dernier objet que nous nous fommies propofé de confidérer. Les obftacles viennent nu de la terre, ou des plantes mèmes. Nous en traiterons fuivant cette divifion.

Quant aux obftacles gui viennent de la cerre, je nets d'aburd, avant tout, les végéraux, qui n'étant d'aucun ufage an Fermier, font appellés, par cette railon, herhes inutiles, ou mauvaifes herbes. Elles empêchent les bonnes plantes de croître, parce qu'elles confument une partie de la nourriture. Je mets au même rang ces racines qui courent fouvent dans la terre en fi grande quantité, qu'elles la refferrent \& la lient, pour ainfi dire, empêchent les racines du grain de s'étendre, \& emportent une grande partic de la nourriture végétale. Ces racines font ordinairement celles duchien- 
dent: l'arrêtebeuf a auffi une groffe racine qui s'étend fort avant dans la terre.

On détruit ces mauvailes herbes \& leurs racines, $\mathrm{I}^{\circ}$. par un labour d'éré: car alurs alles font retournées par la charue dans le tems qu'elles commencent à pouffer, \& leurs racines fe trouvant expofées au foleil, elles fechent \& meurent promptement, ou même elles font enfevelies fous la terre.

$2^{\circ}$. Un moyen analogue au précédent, c'eft d'enfoncer la charue à dix huit pouces de profundeur. Ces herbes fe trouvent parlà enfevelies fi avant dans la terre, qu'elles meurent bientôt; mais ce moyen ne doit être employé que quand la terre eft bonne à cette profondeur.

$3^{\circ}$. Une autre maniere de faire périr ces mauvaifes herbes, c'eft de les arracher avec le rateau quand elles font jeunes, parce qu'alors on en arrache en mème tems toutes les racines.

$4^{\circ}$. Nucune plante ne peut croître fans une fufflante quantité d'air frais: car l'air n'eft pas moins nécreffaire à la vie végétale qu'a la vie animale. Toutes les plantes qui couvrent entićement la terre doivent donc faire mourir celles qui pouffent au deffous d'elles. C'eft par cette raifon qu'une bonne récolte de pois détruit toutes les mauvaifes 


\section{Principes de 1 Agriculture}

herbes, en les couvrant d'ombre: de forte que les Fermiers fe promettent une bonne récolte de froment, quand celle ites pois a été bonne: fi au contraire la récolte des pois eft mauvaife, il vient alors plus de mauvailes herbes qu'à l'ordinaire, \& les Labou$x$ urs ne peuvent fe promettre qu'aucune des trois muiffons fuivantes foit bonne, à moins qu'ils ne donnent plufieurs façons à la terre.

C'elt par le mème moyen qu'on détruit la fougere. On tient l'enclos fermé depuis le milieu de Mai jufyu'au commencement de Décembre, on le fait paître depuis ce tems-là jufqu'au mois d'Avril, \& alors on y laiffe venir une récolte de foin. Couvert pendant fi long-tems par deux récoltes fucceffi. ves, il ne reçoit point l'influence de l'air, $c \approx$ qui le fait mourir.

10. Il y a encore une autre maniere de faire mourir les mauvaifes herbes; c'eft d'y employer la marne. J'ai vu le genêt détruit par ce moyen. Du froment ayant été femé dans un champ, dont une partie avoit été marnée, \& l'autre ne l'avoit point été; la parcie marnée fut délivrée de toutes les mauvaifes herbes, tandis que celle qui n'avoit point été marnée en étoit toute remplie. On avoit fené le même froment dans l'une \&: dans l'autre partie du champ. Je ne puis 


\section{E5 de la Végétation.}

expliquer cet effet de la marne qu'en difant qu'elle fit croître le froment li promptement qu'il ćtouffa \& fit périr les genêts.

\section{S E C T I O N II.}

Des terreins bumides.

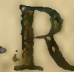

I E N n'clt plus contraire ḋ la végétation, que la trop grande humidité du fol. Elle vient toujours d'une couche de roc ou de glaife, qui fe trouve au deffuus de la fuper. ficie. Ces couches ne permettant pas aux eaux de pluye de fe filtrer, clles ne peuvent étre emportées que par la voye de l'évapo. ration: voye fort leute en comparaifon de la filtration. Les Laboureurs expriment l'effet. de l'eau cn difant, qu'elle rend la terre aigre: ce qui ne fignifie pas que la terre devient réellenent aigre, mais feulement qu'elle eft. alterée dans f nature, \& rendue peu propre à la végétation. Les pioductions naturclles de ces fortes de fols func les joncs \& cette efpece de mauvaife herbe, qu'on trouve quel. quetois dans le fond, $\mathrm{m}$ is rarement fur la crete des lillons, qui eft feche \& fans goût comme un coupeau de bois, S rude au tou. 


\section{צ4. Principes de PAgriculaure}

cher, quand on la manie à rebuurs. Je crois que l'effet naturel de l'eau, qui féjourne fur les terres, eft d'cm êcher l'air d'y pénétrer, \& par là de priver la terre de fes influences.

On corrige cet excès d'humidité en donnant aux raies des fillons une difpofition convenable, \& qui, fuivant 'a pente naturelle de la terre, procure à l'cau un libre écoulement. Il n'eft pis moins important yue ces raies foient droites, c.rr plus elles le font, moins l'eau refte fur ld terre. Il parnît encore que plus la crête des fillons fera étroice, pouvu qu'ils s'élevent au deffus de l'eau, plus l'eau s infinuera ai 'ément à travers pour tomber dans les raies qui joivent êre faites avec une charrue à doub e oreille, afin que les deux orcilles rejottent la terre de l'un \& de l'autre cô'é. La marne, cnin'ne je l'ai dit plus haut, leche la terre en la divifant \& en la pulvérifant. Un : hımpamandé de cette miniere, fera prêt à labourer au printems, quno ze jours p'ûtôr qu'il ne le feroit s'il n'é oit point mırné. Si ces moyens ne réufilfent pss, p.Ir rapport aux eaux qui viennent de fuurces, il faut faire a différentes diftances des faignées ou des canaux couverte. Los faignéss p iroifl nt convenir davantage quand les fources ne font pas en trop grande quantité. 


\section{SECTION III.}

Des pluyes.

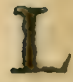

Es pluyes trop abondantes emnêchent la coction convenable des fucs dans les vaiffeaux des plantes, \& a'terent confitérablement la nature de ces fucs. En l'année 1705, dit un Auteur Françnis, il ne plut prefque pas en Juin \& en Juillet, \& les bleds furent excellens: mais en 1707, quoiqu'il y euc. eu des chaleurs extraordinaires, i! plut $\widehat{f i}$ abondamm: nt ces deux mois, que les bleds n'ont rien valu, \& fe font prefyue tous échauffés.

On a obfervé qu'après les p'uyes les plantes croiffent beatcot:p, non feulement les plantes terreftres, mais meme les aquatiques. On ne fquaroit fuppofer que celles ci ayent befoin d'tau : cet effet provient donc de quelque autre caufe, que de la nutrition des plantes par leurs racines. On a oblervé la même chole quand le ciel, de clair \& ferein, devient couvert \& orageux. Peut.être alors la trop grande tranfpir.tion des plantes aft-clle arretce: peut.êcre fucent.elles l'hu- 
I42 Principes de PAsviculine

midité par les pores de lcurs feuilles î de leur bois: peut être enfin que leur nourriture dépendant de la circulation de leurs fucs, \& cette circulation dépendant clle. même de la contraction de leurs trachées, fe. lon Malpighi, cette foudaine contraction remplit de fucs nourriciers leurs vaiffeaux les plus petits \& les plus éloignés, \& le fait avec affez de force pour étendre \& allonger. ces vaiffeaux. Comme ils fe trouvent alors pleins d'eau, \& que la tranfpiration eft moindre qu'à l'ordinaire, il n'eft pas étonmant que la coction des fucs ne fe fafle pas bien \& que le grain foit mauvais.

\section{SECTION IV.}

\section{Des defauts des Sémences.}

A la végétation caufés par la nature du fol, pa f. fons à ceux qui proviennent de la fémence.

Pour avoir de fortes plantes, il faut choifir de bonne \& forte femence. Le grain affamé dans une terre maigre ne fcauroit profiter.

Les vieux grains qu'on feme ne vienncut 


\section{ể de la Végération.}

pas bien: c'eft pourquoi les fermiers choiinflent toujours du bled de lannće. On a cru que le grain ne germe pas quand il a plus de cinq ans: mais on ne fçauroit fixer de tems précis, car tout dépend de la féchereffe $\&$ des huiles de la femence. Toutes les femences huileufes fe gardent long-tems; quelques unes font reftées en terre pendant dixhuit \& vingt ans. Deux mois après l'incendie de Londres, on vit croître une grande quantité d'une efpece d' Eryfrmum, dans des endroits nù il $\mathbf{y}$ avoit eu des hâtimens pendant mille ans. $M$. de Reaumur ayant femé quelques grains d'un bled qui avoit été confervé dans la citadelle de Metz pendant cent quarante ans, \& avec leguel, quoiqu'il cuc éré gardé fi long tems, on fit de fort bon pain : au bout de trois femaines quelquesuns de ces grains parurent gonflés, d'autres non, fix fentaines après il ne s'en trouva plus aucuns.

La ftérilité des vieux grains paroît venir , de ce que leurs vaiffeaux perdent la flexibilité néceffaire, pour qu'ils puiffent s'étendre \& fe remplir d'eau; \& de ce que la liqueur, qu'ils contiennent, n'a plus le mucilage gluant nécelfaire à leur nutrition. On en peut juger par l'iffet, que produit fur le grain l'ćvaporation de ces parties mucilagineufes; elle le rend fragile \& callant. 


\section{I44 Principes de PAgriculture}

\section{S E C T I O N V.}

\section{Maladies des Plantes.}

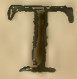

de vaiff:aux \& de fluides en mouvement dans ces vaiffeaux, il eft à craindre que ces fluides nes'alterent, \& que ce mouvement ne s'arrête. De là viennent toutes les maladiss des plantes. Tournefort les a divifées avec raifon en cing c'affes, parce qu'elles font tou. tes caufées ou $1^{\circ}$. par la trop grande abondance; ou $2^{\circ}$. par le défaut de fucs; ou $3^{\circ}$. par les mauvaifes qualités de ces fucs ;ou $4^{\circ}$. par leur inégale diftribution; ou enfin $5^{\circ}$. par des accidens étrangers.

La trop grande abondance des fucs faic qu'ils féjournent long tems dans les vaiffeaux, qu'ils s'y corrompent, qu'ils y caufent des varices, des cariofités, \&c. il paroit gue c'eft auffi de cette maniere que les pluyes excetfives nuif: nt aux plantes.

Le noir ne doit point être oublié ici, il s'attache ordinairement aux grains malades \& dans les tems de pluyes; il fe communi- 
que aufis par infection, fi je puis parler de la forte: le noir, comme les autres maladies contagieufes, gagne des grains infectés à ceux qui font fains. J'ai appris qu'on en a fait l'expérience, on a femé du bled noir avec de belle femence, \& tout ce qu'on en recueillit étoit noir. Il ne faut point être furpris qu'il arrive aux fucs des plantes, ce que nous voyons tous les jours arriver aux fucs des animaux, lefquels prennent les quaIités du levain contagieux qui leur eft com: muniqué. On prévient cette maladie, du moins en grande partie, en faifant tremper le grain dans une faumure de fel marin. La Saumure opere en deux manieres; elle fortin fie la femence, \& la met en état de chaffer les fucs aqueux qui feroient fuperflus: \& dailleurs comme elle eft péfante, elle fuus cient la mauvaife femence qui furnage; de forte qu'il n'y a que les grains les plus lourds \& les plus forts qui tombent au fond.

Il parnit que le fumier prévient les autres maladies caufées par le trop d'humidiet. L'expérience qu'en fit une perfonne de ma connoiffance prouve clairement oet effet dus fumier. Il fit labourer deux acres de terre maigre, qui n'avoient jamais été amandés. Se propofant d'y femer du froment. Mais: Bufuite ayaut changé d'idée, \& n'aỹant fus.- 


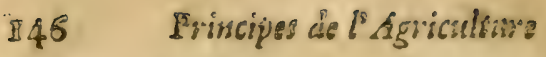

mé qu'une petite parzie du champ, il enfs: mença le tour d'orge, aplès cinq ou fix fă cons. Il tomia beaucoup de pluyes qui n'em. pêcherent pas que l'orge ne vînt très-biens dans la partie fumće: au lieu que ce qui avoit été femé dans le refte du champ jăunit eprès les piuyes; \& quand il fut mûr, il fe trouva fi mauvais. qu'il ne valut pas les frais de la récolte. Cette expérience fait voir que la maigreur \& l'humidité de la terre fus. rent la caufe de la maladie de ce grain, $\varepsilon_{5}$ que le fumier en fut le remede.

Les plantes \& les arbres dépériffent pas io manque de nourrieure; \& c'ef par cette raifon que les feuilles tombent aus appro. ches de l'hy ver. On le voit encore plus par l'cxpérience fuivante. Greffez un amandier fur un prunier de damas noir: la premiere année l'amandier fera de belle venue; mais enfuite l'un \& l'autre dépériffent infenfible. ment \& meurent: ce qui vient de ce que le prenier commence à végéter beaucoup plun tór que le dernier, \& par conféquent demande des fucs nourriciers, avant que celui-cs puiffe lui en fournir. Penciant qu'il eft jeune, il cn tire coujours affez: ma:s gyuand il dem vient plus fort, il épuife le prunier \& l'affame. Si l'on greffe au contraire le prunier fur l'as. mandier, lẹ lugs montaut dans celuil-sì, 


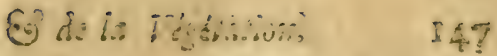

svant que l'autre foit en état de les tecerosir. s'en trouve furchargé \& meurt de répletion.

M. Duhamel dans les mém. acad. des fciences pour l'anncé 1728 , patle d'une maladie appellće le mort, qui attaque ie faffrars dans le printems. Cetre maładie eft caufée par une efpéce de trefle qui n'a point de tige, \& qui entrelaffe de fiamens violets, gृui font Fes racines, celles dis faffran, dont ils fucent le fuc nourricier. On prévient cette maladie en creufant des foffés qui empêchent les plantes de faffran d'être attaquuées par ces ttefles。 Toutes les maladies provenant du défaut do sourriture, font gueries par les cngrais \& amandemens.

Les fucs peuvent être défeotucux par. quelque mauvaife qualité. Quand ocux dis pin ou du fapin devicmnent trop épais, I'ar:bre meurt. On dit que les cannes à fucres viennent moins bien dans les bonnes terress naenves: c'eft que ces terres leur fournifient. zrop de fucs huileux, qui ne font pas propres à faire de bon fucre. Mais fi en les coupe quand elles ont un mois, qu'on en brible les feuilles, \& qu u'on en répande les cendres au. pied des cannes, elles donnient alors un meitieur fucre, parce que les fels allialis de ces cendecs atténuent les huiles, \&s par là rendent te fucre meilleur, De méne les plantes

$$
\text { K } 2
$$




\section{$\$ 48$ Trincipes de "Agriculicre.}

ou femences tranfportées d'un pays chaud dans un paysfroid, dégénerent, parce que les fucs n'y font pas affez atténués par la chaleur.

L'inégalité dans la difribution des fucs paroît étre une autre caufe des maladlies des végétaux. Dans le bled les fucs montent quelo giuefois aux feuilles en trop grande ahon. cance; pour y remétlier on coupe le bled ous on le fait paître par les beitiaux : cette opération fait réîuer les fucs nourriciers dans les tiges.

Les accidens extérieurs comme la gclée, la gréle, les mouches \& leurs oufs, les vers occafiunnent auffi plufieurs maladies; il fe trouve encre un petit ver blunc fort commun dans les terres neuves, qui fait périe les plantes en mangeant leurs racines. On tue ces vers avec la chaur vive ou l'eau de chaux.

Il faut mettre la nielle dans le méme rang: il paroîr qu'elle eft caufée par une matiere gluante \& fucrée qui tombe avec les pluyes ou ondées fines, \& qui arrête la tranfpiration des plantes dont elle houche les pores: on fent cette matiere au tact $\&$ au goût fur 12. fuperficie des plantes: \& le fait fuivant prouve que cictt de cette maniere qu'elle. opere. Ill y a d Briançon uno efpece de noi. 


\section{ES de ia Végeiration?}

fetier dont toutes les feuilles font convertes a'une fubfance fucrée qui provicut de la tranfpiration des fucs de la plante: lorfque cette matiere eft en rop grande quantité, l'arbre meurt.

Nous devons mettre encore dans la claffe Lesaccilens étrangers les efrets de la contiguité ouvoilinage de certaines plantes. Ily en a qui ne fcisunient cruire près de quel. ques autres; on l'a ubfervé paí rapport ats choux \& au cyclanen, à la cigue \& a la rue, aux rofeaux \& a la fougère : nous avons une infinité d'exemples de ces antiputh ics parmi les animaux. Ces effets viennenc lans doute des corpufcules qui s'échappent de tous les corps organifés.

Il elt étomant que ces objets, fi intéreffans pour la culture des plantes, aient été prefo qu'entierement négligés, de loric qu'on n's point encore alfez de faits \& d'ublervations pour écablir fur cette matiere aucun fyltemes régulier. Touresínis les maladies des plantes demandent plus de fecours, \& confé quemment plus d'attention que celles des animaux, fil'on ne confitére que le traitezuent \& la guérifon feule, fans penfer au rang, que les animaux tiennent parnii les críatures, \& par conféquent à leur valeur naturelie, srès-fupérisure à celle des plamzess

K. 3 
Les animaux ont une faculté fenfitive intê: rieure, qui, étant irritée par la caufe de la maladie, fäit que le coeur \& les arteres $\int_{6}$ meuvent avec plus de vivacité: \& ces agens méchaniques continuent jufqu'à ce que les parties marbifiques foient chatfées, ou qu'el. les ayent détruit l'aconomie animale: mais les végétrux niont point cette faculté intérieure: fi le remede n'eft appliqué extérieurement, ils refrent malades. Les remedes qu'on cmploye pour la guérifon des mala. dics des animaux, agiffent en dirigernt ecs mouvemens nacurels \& niéchaniques de la maniere qui convient, \& que la faculté motrice femble faire connoître: ats Rieu que les remedes des végétaux n'agiffent que par leurs feules forces, \& ne font aucuneznent fecondés par les végétaux mêrmes-

\section{SECTION VI.}

Rlan pous la perfaction de PAgricultura.

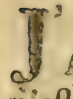

A I tâciné de faire voir que l'Agricultura rieft pas un art incertain, ainfi qu'on le croit cammunćnent; mais un art gुu'on peut rée 


\section{डิ de ln vigerestion:}

Gurire, comme les autres, à des principes fixes \& immuables. J'ai parlé des obftacles qui s'oppofent a fa perfection : examinune ici comment on pourroit y remédier \& favo. rifer fes progrès.

L'Agriculture ne doit pas fon origine auss raifonnemens, mais aus faits \& à l'expéo rience. C'elt une branche de la philofophie naturelle : elle ne \Çatsroit être perfectionnés que par la connoiffance des faits. C'elt par les obfervations \& par la connoiffance deb faits, que les autres branches de ta philofophie naturelle ont été pouffiées fi loin dans les deux derniers fiecles. La Médecine doit à l'hiltoire des maladies \& de leurs acciden la perfection où elle a été portée de notre tems: \& fi la Chymie eft maintenant réduite ì un fyiftême régulier, elle cn cit aredevable âx expériences faites ou par hazard ou à dérfein. Mais ou font les expériences qu'on ait faites dano l'Agriculture" Nous avons beatl jetter les yeux de tnutes parts, nous n'en trouverons qu'un très-petit nombre, \& voilà le plus grand obftacle auz progrès de cet art. Nous avons beaucoup de trairés d'A. griculture, il eft vrai; mais le Livre ọui zous manque, c'eft un livre d'ex péricnces.

On ne doit pont en etre furpris, quand on cosnoár la façun de penfer ordinaire de la

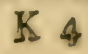




\section{íz Principes de lagriculiuse}

plupart des hommes. Ils craignent de s'ex: gager dans de pareilles entreprifes, à moins qu'ils ne puiffent $f e$ promettre d'en voir la fin complette, \& de former un fyltême plaus. fible. Or les expériences en fait d'agricul. zure demandent trop de tems, pour qu'une feule perfonne puife en faire un grand nomhre pendant fa vie. Peut-être y en a.t-il es beaucoup de faites, mais elles font répandues en différentes mains. Ce n'elt donc pas tant du manque de faits qu'il faut fe plaindre: le hazard \& les expériences faites aे deffein ont dû en fournir affez. Ce qui nous manque le plus, eft une voye furre \& aifée d'en faire part au Public, fans que la vanité naturelle à la plûpart des hommes en foir bleffée.

Jufqu'à préfent ces faits, ces expériences; renfermées dans le cercle étrait des converfations, font mortes avec ceux quiles ont tentées. Je propofe à cet inconvénient un remede très fimple: c'eft qu'on établiffe dans la Société d'Edimbourg une Conmiffion ou Confeil de cing perfonnes, uniquement pour la claffe de l'Agriculture, st qu'on charge cette Commiffion de recevoir les expériences détachées qui pourront y être envoyćes: de les mettre en meilleur ityle o fi ciles en ont befoin, \& de les donner au $P_{w}$ 
blic à certains tems marçućs. Ce moyen me femble très propre à exciter parmi nos Culrivateurs le goût des expéricnces.

Le Commiffaire chargé de faire le rapport . de ces expériences, le feroit d'une maniere claire \& fimple, féparant les fait d'avec fes raifonnemens. La clarté \& l'exactitude font les vrais ornemens du ftyle des expériences. Le fait feroit d'abord raconté nettement avec toutes fes circonftances; par exemple, la fituation du terrein, la nature du fol, la qualité de la femence, les façons données à la terre, le pays où l'expérience auroit été faite, la température de l'air dans le tenis des feo mailles \& apres; le chand, le froid, la rofée, la pluye, le vent, \&c. Les raifonnemens fur ces expériences vicndroient enfuite, \& n'en feroient que les conféquences naturclles. Quniqu'il ne futt point néccffaire d'cn nommer les Auteurs, quand on les pub. liernit, la Commiffon exigeroit pourtant que ceux qui les lui adrefferoient les fignafo fent, afin d'éviter toute furprife.

Pour exciter dans le pays l'émulation fur cet objet, je voudrois encore, que la Commifrum pût donner un ou deux prix hono: xablcs \& lucratifs à ceux qui auroieut envoyé les expériences les plus ingénieufes \& les plus utiles. Ces prix d'agriculture ne devroient 


\section{If4 Evincipes de l" Agriculiture}

point être propofés pour des objets fur le li: quels l'intérèt excite affez les Cultivateurs aे travailler; ils s'y appliquent communéments autant qu'ils le peuvent: mais fur des obo jets qui ne tendroient pas $f 1$ directement à leur probt, \& quiles forceroient a fortir de la routine ordinaire. Cette regle pourroit garoitre trop fevere dans les commencemens, \& peut etre feroit-il mi ux de recevoir peno dant quelque tems toutes fortes d'expérien. ces, juf́gu'a ce y̧ue le goût fut répandu dane le pays.

On fent quels heureux effets produiroit un tel plan. Les Laboureurs commenceo roient à appercevoir le feul moyen de cultio ver leur art avec luccès. Iis feroient atten. rifs aux noindres circontrances ausquelles ils n'avuient jamais penfé auparavant. I/s fe feroient un plailir de communigucr au $\mathrm{Pu}$. blic le fuccès de leurs expériences, des qu'ils le pourroient fiire par cette voye fecrete \& facile. Ils auroient un Distionnaire de faits qu'ils confulteroient dans l'occafion; \& ils tireroient un égal avantage des bons \& des mauvais fuccès des autres.

Ce plan fourniroit avec le tems un fond fuffirant de faits à quelque heureux Génie o qui raffemblant foutes ces diverfes expério ences fouvent oppofées les unes aux autres 


\section{Eo de la Vigetation? IIS}

\&s confiáérant toutes les circonftances qui̊ les auroient accompagnées, réduiroit la praø ciqque de l'Agriculture à àss regles fixes \& permanentes. Ce bonheur arrive rarement à ceux qui tentent les premieres expériences d'un art; ils apperçoivent les chofes dans un point de vûe trop étroit, \& fouvent avec un efprit trop prévenu: il eft réfervé à l'eprit impartial \& folide, qui fçait tirer de chaque opinion ce qu'elle peut avoir de vrai, \& de toutes ces vérités réunies former un fyftème régulier, utile \& durable.

Fin des Principes de l'Agriculture Es' de la Végétation.

\section{A V I S.}

Les deux risémoires qui fuivent inprimés en 7\%59. \& 1760, à l'Inprimeric Royale, ont été en. Fuyés par ordre du Miniftre à tous les Intendans des Provinces \& Génćtalitéc du Royaume. 


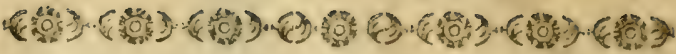

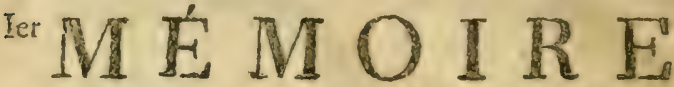

$S U R$ ia manima de préferor le Froo meni de la corruption 0 de le cusa Server.

is

o v s les Laboureurs fçivent que les differens noms de nzelle, bi uine, brourures Eoffe, chabon, carke, Eซ̃c. lervent à déligner un troment dont l'incérieur du grain elt converti en une poudre noire comme dus charhoil; mais plulicurs ignorent que cette poulre noire répandue, par hafard ou autre. ment, fur le fromenc le plus fain, qui fervit deftine pour enfemencer, le gatera tellement qu'a la réco!te prochaine on n'en aura que du troment noir autfi dans l'intérieur. Cette découverte importante eft dîe à $M$. Tillet, de l'Académie Royale des Sriences. Ses expériences ont été répétées à 1 rianon par ordre du kioi, tant pour êre alfuré de la communication de ce vice, que de l'cffica cité du moyen qui le prérient. C'eßt ce moyen préfervatif, dont le fuccès eft conftaté, que l'os conmunique à tous les $\mathrm{C}$ islo tivatcurs. 
Si le grain qu'on veut femer eft net \& fans moucheture noire, il fuffira de le laver dans la leffive ci après décrite.

Si au contraire, ce grain eft t ıché de noir, il faut le laver plufieurs fois dans de l'eau de pluis ou de riviere, \& ne le patfer dans la leffive que quand il n'y aura plus de noir.

Pcur faire cette leffive, on prendia des cendres de bois neuf, c'eft-à diice qui n'ait point été flotté. On en emp'ira un cuvicr aus trois quarts: on y verfera une fuffifante quantité d'eau; celle de la leffive, deltinée pour le grain, doit être de deux pintes, mefure de Par is, ou quatre livres d'eau pour une livre de cindre: cette proportion don. mera une leffive affez forte; lorfqu'elle fera coulcee, on la fera chatifir, \& l'on y fera fufer ou diffoudre affez de chaux vive, pour qu'elle prenne un blanc de lait.

Cent livres de cendres \& deux cents pintes d'eau donneront cent vingt pintes de leffive, auxquelles on ajoutera quinze livres de chaux. Cette quantité ile leffive, ainfi préparée, fuffit pour foixante boiffeaux de froment, \& ne revient au plus qu'à yuarante Iols, ce qui fait huit deniers pour shaque boilleau.

On attendra, pour faire ufage de cette betrove chauffée, que fa chaleur foit dimi- 


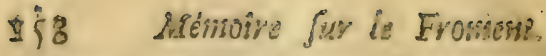

gués as point qu'on puiffe y tenir la stain? Alors on verfera le frornent, déja lavé, dans une corbeille d'un tiffu peu ferré \& qui ait deux anfes relevées, \& on la plotigera à diverfes reprifes dans cette leffive blanche; on $y$ remuera le grain avec la main ou avec une palette de bois, pour qu'il en foit éz̧alemené nnouillé. On foulevera la corbeille pour le laiffer égoûter fur le cuvier, puis on éters. elra ce grain fur des charriers ou fur des t?a bles pour le faire fécher plus promptemene. On remplira la corbeille de nouveau grain , \& on la trempera, comme ci-deffus, dans is cuvier, dont on aura remué le fond avec un bàton, jufg̨u'à ce qu'on ait fait paffer les foì zante boiffeaux.

Le Laboureur pourra profiter des beaus fours \& de fes momens de loifir pour préparer tout le grain , fufpecté de nielle, dont It aura befoin pour les femailles prochaines.

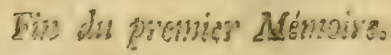




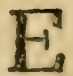

POUR fervir à indiquer le Plan quì s éséf fuivi pour parvenir à connoître se qui profuit le bied noir dans les bleds; E̊ à connoître les remedes propres à détruire cette corruption.

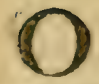

N verra par quelques-unes des lignes ঘue l'on a tracées, ce qui a ćté pratiqué pour produire le bled noir; \& à d'autres, ce que a'on a fait, \& les remedes dont on s'elt fervi pour le détruire.

Chacune de ces lignes elt de feize pieds delong, \& eft à un pied de diftance l'une de l'autre; on a noté ce que l'on a trouvé de remarquable dans chacune d'icelles.

On verra auffi que la femence de ce plan a ćcé faice dans lix carés éc dans trnis diffém rens tems, pour connostre s'il n'y a point de ienas pendant la lemence qui occalionne da. vantage la corruption du bled noir.

On connoit deux furies de bled noirs nous en nommons un cloyue, bronine, ou ramplement bledroir, c'elt le plus nauvais, 
c'eft celuì à qui on doit s'attacher plus parti.s culierement pour le détruire: l'autre nous le nommons bled noir en fumée; quoique ce foit du bled corrompu, il n'elt pas dangereux comme l'autre, puifgu'il fe diffipe de très bonne heure en fumée, \& le trouve entierement détruit par le vent \& la pluye, prefqu'aufitôt que fes épis font fortis de leur fourreau, de forte qu'il ne s'en trouve plus à la récolice.

LE PREMIER carré ci deffous, qui eft do huit rangées, \& chacune de feire pieds le long, eft femé en entier d'épis de bled done on a pris la femence en la récolie de I 759 , \& qui étoient partie de grains bons, \& partie de grains que nous nommons cloque, brouine, ou bled noir.

Il eft à remarquer qu'il fe trouve dans quelques. uns des épis de bled noir des grains qui font bons \& bien fains, qui portent leus germe; on s'imagineroit que ces grains fortant des épis corrompus devroient produire le bled noir, mais on trouvera la preuve du contraire dans ce premier carré qui a été fe. mé en entier de ces épis défectueux.

Ce carré a été femé le 280 Octobre I759.

Les lignes font les rangées de bled.

La rangée de bled ci.deffous a été femés; ईans être ni lavé ni échaudé. 
Ii ne s'eft trouvé aucun épi de bled noir。 mais il s'elt trouvé dix épis de bled nuir en fumée.

Ire.

La rangée de bled qui fuit a été femés après avoir été échaudé à notre méthode or. dinaire feulement:

Tous les épis de cette rangée fe font trolivés bons \& bien fains, à l'exception de deux épis de noir en fumée.

$2 \mathrm{me}$.

La rangée ci-deffous a été femée aprè avoir été lavé à l'eau commune, \& après lavé \& échaudé à l'eau de cendre, comme l'enfei. gne M. Tillet.

Tous les épis de cette rangée fe font trous vés bons \& bien fains.

\section{$3 \mathrm{me}$.}

La rangée de bled qui fuit a été femé après avoir été échaudé à notre méthode or. dinaire.

Tous les épis fe font trouvés bons, à l'er. eeption de quatre épis de noir en fumée. $4 \mathrm{me}$.

La rangée de bled ci-defious a été fernéc. apress avoir été barbouillé avec de la pouffiere. de bled noir, \& n’a puint été ni lavé n: échaudé: 
Dans cette ranzće il s'êt trouvê cuviron Ia moitié des épis bons \& bien fains, l'autre moitié s'eft trouvée enticrement de bled noir. sme.

La rangée ci.leffous a été femée après avoir céć lavé \& échaudé, n'a point été barbouillé de noir, mais en le femant, il a été fenzé par-deffus le bled de la poulfiere de bied noir avant de l'enterrer.

Il s'eft trouvé dans cette rangée environ ฝ̉enx tiers ciont les épis funt de bon bled, anais l'autze ticrs s'eft trouvé entieremens de bled tioir.

rme.

La rangée ci deffous a été barbouiiiée de moir \& \& avant de le femer, il a écé lavé à l'eaus commune, \& après lavé \& Echaudé à l'eats बe cendre.

Dans ceute rangée les épis fe font trouvés - bons, à l'exception de douze épis de noir en fumée.

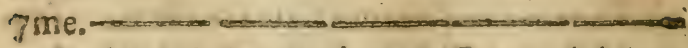

Le bled de la rangée ci-dellous a été barbouillé de noir, É avant de le femer a été 'schaudé à notre méthode ordinaire.

Il s'sft trouvé dans ceite rangée environ les trois quatts des épis bons \& bien fainss o l'autre quart fe trouve rempli de bieci noira $\mathrm{S}_{\mathrm{m}} \mathrm{C}$ 


\section{Sur le Ble. $\quad 263$}

LE. SECOND carré fuivant, qqui eft aufli de huit rangẻes, elt femé en entier de bled très-fain pris dans la grange; il a été préparé pour le femer ainfi qu'il va être expliqué à chaģue rangée; on verra auffi à chaque rangée ce qui s'eft trouvé do remarquable dans chacune d'icelle, ce qui a été exactement recherché.

Ce carré a été femé le 28 Octobre I759\%

Les lignes tirées font de même les rangées de bled.

La rangée de bled ci-defous a été femée. Lans être ni lavé ni échaudé.

Tous les épis da cette rangée fe font trous wés bons, à l'ezception de quatre épis de noir en fumée.

In re

Le bled de la rangée cindeffous a été femé après avoir été lavé à l'ean commune, if échaudé à l'ordinaire.

Tous les épis de ceste rangée fe font trotra vés bons \& bien fains, aे l'exception de cinq tópis de noir en fumée.

ame.

Le bled de la rangée ciodeffous a été femé après que lo bled a été lavé dans l'eau rommune, \& après avoir été layé \& échaud dans l'rau de cendre,

\section{In.}


Tous les épis de cette rangée fe font trồ: vés bons \& hien fains.

\section{sิme.}

Le bled do la rangée çui fuit a été femé sprès avoir étó échatidé à notre méthode ordinaire fimplement.

Tous les épis de cette rangée fe font trou. vés bons \& bien fains.

Aqme.

La rangée de bled ci-deffous a été femée après que la femence a été barbouillée avec de la pouffere de bled noir \& \& n’a point été ni lavé ni échaudé.

Dans cetee rangée il s'eft trouvé près de la moirié des épis de bled noir, le refte des épis font dé bon bled. sme

Le bled de la rangée fuivante a été lavé \& échauté \& n’a point été barbruillé dè noir, mais en le femant, il a été femé pardeflus de la pouffiere de bled noir.

Dans cette rangée il s'eft trouvé environ deux ticrs dont les épis font bons, l'autro tiers eft enticrement de bled noir.

бme.

Le bled de la rangée ci-deffous a été barbouillé avec de la pouffiere de bled noir; \& avant de le femer, il a été lavé à l'eau commune, \& aprés lavé \& échaudé à l'esis de cendre. 


\section{fur le Blè.}

96

Tous les épis de cette rangée í font trou viés bons \& bien fains.

\section{$7 \mathrm{me}$.}

Le bled de la rangéce ci delious à été aurij barbouillé de la poulfiere de bled noir; s avant de lo feme:, il a ćté échauté à notre méthode ordinaire fans être lavé.

Il s'eft trouvé dans cette rangée environ une vingtaine d'épis de bled noir, le furplus des épis en font bons \& bien fains. 8 me.

LE TROISIEME carré ci deflous, qui eft aujourdhoi rangé, eít femé en entier de bled tris fain pris dans la grunge; mais il a été fratiqué, pous le femer, ce qui va êtrs expliqué à chaque rangée: on verra aulfi à chacune defdites rangées ce qu'on a trouvé de remarquable, ce qui a été exactemen: recherché.

Cecarréa écé feméle 10 Od̂obre 1759. Les lignes tirées font les rangées de bled.

La rangée de blat ci-delfouls a éié feméo fans être ni lavé ni écliaudé.

Les épis de cette rangée fo font trouvé ? bons \& bien fains, à l'exception cependan!s d'un éni de bled noir, \&e de çuatre autres de noir en fumée.

Le bied de la rangéc fuivant a céé femí 


\section{$180^{\circ}$}

\section{Mérisoire}

fans être ni lavé ni échaudé.

Les épis de cette rangée fé font trouvés tons \& bien fains, à l'exception cependant d'un épi de bled noir.

\section{ame.}

La rangée de bled qui fuit a été femée a près avoir été lavé dans l'eau commune, \& enfuite lavé \&z échaudé dans l'eau de cendre.

Tous les épis de cotte rangée fe font trou. vés bons \& bien fains, à l'exception d'uri feul épi de noir en fumée.

3 me.

Le bled de la rangée ci-dellous à été, avant de le femer, lavé à l'eau conmune, \& en. fuite lavé \& échaudé dans l'eau de cendre, ainfi que le rang ci-defius.

Tous les épis de cette rangée fe font troL:? vés bons $\&$ bien fains. 4me.

Le bled de la rangée fuivante a été lemé après avoir été lavé à l'eau commune, \& échaudé à notre méthode ordinaire.

Les épis de cette rangée fe font trouvés tous bons, à l'exception de deux épis do noir en fumée.

jme.

La rangée ci-deffous a été lavée à l'eaL commune, \& échaudée à notre méthode o:dinaire avant de le femer. 


\section{Sur le Ble:}

Tous les épis fe font trouvés bons dans eette rangée, à l'exception de trois ćpis łe noir en fumée.

$6 \mathrm{me}$.

Le bled de la rangée qui fuir a été fencé Eans être lavé, ma:s a été échaudé à notrs méthode ordinaire.

Dans cette rangée rous les épis fo font erouvés bons \& bien fains, à l'exception ca deux épis de noir en fumée.

gme.

La rangée fuivance a étŕaufi fenús fams êre lavée, \& a tié échaudée à notre més thode ordinairs.

Tous les épis de cette rangée fe funt tron-. vés bons \& bien fains.

\$me.

LE QUATRIEMia Catré ci âprès, qui ell auffi de huit rangées, eft femé en entier de bled fain, pris dans la grange, \& a cété apprèté pour le femuei, ainliqu'il va tire dit à chaque rangée: on verra à chacune ce gqu'oı a trouvé de remarquable.

Ce carré a été ferné le ro Octobre i75\%.

Les lignes tirées font les rangées de bled.

La rangée de biled ci deffous a été barbouillée de poutfiere de bled noic avant de le fosoer, \& n'a point été lavé ni ćchaudé.

Lans cctse rang'é la moitié des épis s'of?

14 
trouvée être de bled noir, l'autre moitiẻ dę̄ épis étoient bons \& bien fains.

\section{xre.}

L.e bled de la rangée ci-deffous a été aurf barbouillé de noir avant de le femer, \& n'a point été ni lavé ni échaudé.

La moitié des épis étoit d'épis bons \& bicn fains, l'autre entierement de bled noir.

\section{$2 m e$.}

Le bied de la rangće ci-deffous n'a point été barbouillé ce pouffiere de bled noir, il a été échaudé avant de le femer, mais après yu'il a été femé dans le fillon, on y a femé par-defius, avant de l'enterrer, de la poul.. fiere le bled noir.

Dans celte rangée s'elt trouvé enviror. deux tiers dont les épis font bons \& fains o les épis de l'autre ticrs font entierement de bled noir.

joile.

La rangée de bled q̨ui fuit a été femćs comme celle ci defius.

Il s'eft aulii trouvé dans cette rangée eni. viron deux tiers dont les épis font bons, l'autre tiers elt aufi entierement de bled noir.

$4 \mathrm{mc}$.

Le bled de la rangée ci-deffous a été bar. bouillé avec de la poufficre de bled noir, $£$ 


\section{fur le Blé:}

tivant de le femer il a été lavé \& échaudé avec de l'éau de cendre.

Tous les épis de cette rangée fe font trouv'és bons \& bien fains, à l'exception de cin Épis qui fe font trouvés de noir en fumée.

sime.

La rangée de bled fuivante a été aufifi prasiqquée comme elle ci deffus, le bled a éré barbouillé de noir, \& enfuite lavé \& échaudé à l'eau de cendre.

Tous les épis font bons, aे l'cxception de trois de noir en fumée.

ame.

Le bled de la rangée fuivante a été barbouillé auffi avee de la poufiere de bled noir, \& avant de le femer il a été ćchaudé à notre méthode ordinaire feulement.

Il s'eft trouvé dans cette rangée environ un fixiéme de bled noir, \&s le furplus eft bon; il s'crt trouvé auffí lix épis de noir cn fumée.

3 me.

La rangée de hled qui fuit a été aulfi barbouillée de noir, \& avant de le femer il a été érhaudé à nutre méthode ordinaire.

Il s'eft trouvé dans cette rancée au moins un lixiéme de bled noir, è fept épis de noir enfumíc; le refte cit hon se bicn fain.

sine. 
LE CrNotreme carté s qui efie de quatro. rangées marquées ci-après, eft auli femé de bled bicn fain, pris dang la grance, leçuel aćté pratiqué pour le fenser, sinfi qu'il va étre expliqué à chaque rangée: on verra unfi ce qu'on a trouvé de remarquuable ì chacune.

Ce carré aété fomé le zo Oçobre Impg.

La rangée de blcd fuivante a été femée à près avoir été barbouillé avec de la pouffiers ¿e bled noir \& n'a point ćé lavé ni échaudé.

Dans cette rangés il fe trouve environ les deux tiers des épis qui font bons, l'autro tiers eft tout bled noir.

rre.

Le bled de la rangée ci deffous a été aufre barbouillé de poufiere de bled noir; mais avant de le femer il a été lavé à l'ealz cum. mune, \& après lavé $\&$ échaudé dans l'eau do cendre. fains.

Tout les épis fe font trouvés bons \& bien a $\mathrm{me}_{0}$

Le bled de la rangée fuivante a été auf? barbouillé de noir \& \& avant de le femer il a été échaudé à notre méthods ordinaire feule. sment.

Dans cette rangée il fe trouve environ deur tiers dont les épis font bons \& bisı 


\section{Sur le Blé.}

Fains, l'autre tiers eft entiescment de blsd noir.: -

3 me.

Le bled de cctte derniere raisgée a été femé Eatts être barbouillé, ni lavé, ni échaudé, \& tel qu'il eft venu de la grange.

Dars cette rangée il of venu environ un dixieme de bled noir, le furplus des épis ef bon \& bien fain.

\section{\&me.}

LE sIXIEMe Carré ci-deffous eft auffi de quatre rangées, lequel a été femé après avois été accommodé, ainfí qu'on vale voir à chąque rangée, avec une note de ce qu'on: trouvé de remarquable à chiacune.

Ce carró a ćté autifi fomé le 20. Octobre I759.

La rangée ci.defious a été femée fans avoir lavé ni échiaudé le bied.

Tous les épis en font bons \& bien fains. yre.

Le blèd de la rangée fuivante a été, avant de le femer, lavé a l'eau commune; \& après lavé \& échaudé dans l'eau de cenủre.

Tous los épis en funt bons \& bien fains. 2 me. - - . -

Le bled de ia rangée fuivante aété, avant de le femer, lavé dans l'cau commune, Ss échaudé à notre méthode erdinaire. 
Lez épis de anterangée fe trouvent tous bons \& bien fains.

\section{3 me.}

Le bled de la rangée ci deftous n'a point été lavé, mais il a été échauré à notre mé. thote ordinaire avant de le femer.

Les épis de cette rargée font tous bons \&e bien fains. $4 \mathrm{me}$ -

On voir par ces détails qu'il eft très néré. Saire de bien laver le bied avant de l'échaudor pour le nertoyer de la pouffiere du bled sioir, qui paroit sater \& corrompre le germe diu bled le plus fain, \& on doit s'y attacher encore davantage quand on en elt entiché.

Cur croit ailfi que ce roir en fumée, lustc il eit parlé dans quelques rangées, fạt pritie de la corruption du bled noir; mais En apportant ie remede qu'il convient, il fe souvera entierement détruit.

Qnelques-uils pourront dire, "ce fera s, bien de l'ouvrage $\&$ bien de l'embarras ss pour un Laboureur quiaura cent acres de "bled à femer, à qui it faut au moins cerst ¿Setiers de bled de femence. S'il faut qu'il "s faffe laver cent fetiers de bled, il ne pourra , jamais le faire comme il faut, il pourroit y "avnir de la peste fo le tems ne fe trouvcis sa pas favorable pour le faire fécher, il pour. 


\section{fir te Bie.}

i. roit même fe gáter ou s'échauffer, de forte 5: que le germe s'en trouvant éteint, la $\int_{c}$ : 5) mence fe trouveroit manquée, , mais il $y$ a un moyen bien fimple, \& je dis que pour éviter ce grand ouvrage qui pourroit etre difficile à pratiquer comme il faut, il eft au moins à propos qu'un Laboureur qui auroit cent acres de bied à femer, fe propofe de nettoyer, laver a échauder dix ou douze fetifrs de bled qui lui femeront dix ou douze acres le terre, ce quilui fourniroit in feo mence en entier de l'année fuivante; \& de cette femence, qui atrurément deviendrois faine, en prendre encore l'année fuivante dix ou douze fetiers que l'on acrommodcroit de la même maniere que les douźc premiers, \& tous les ans continuer de mème, on fernit affuré par là de n'avoir jamais un feul épi de bled noir. L'on propole dix à douze fetiers pour un Labourcur quj: auroit cent acres de ierreà femer en bleá; ce n'eft pas affurément an $\widehat{\complement}$ grand nuvrage pour ne le pas faire avec foin is avec exactiudes les aurres qui ont rnoins de terres en laveroient moins à proportion. Commo ce n'ct pas un travail fort conlidérable, ie ne manquerai pas chaque année de m'y livrer par l'expérience que i'n? des bons effers gu'il a produits. 


\section{7\% Lisemoire fwor lo Bls.}

Tondes ces expérierces ont été faites par un Laloureur inselighent da l'crin, qais en a formé lo réfumé ci defJus. Ca Némonre eft celua çz'il a crronyé, ह5 que l'on a laifé fubfafter sel qu'it a cere fait par ce Laboureur. On a cru ne devoir chenger ni l'ordre qu'il préfente de fos ¿diées, ni celui gu'il a objervé dens fos expéricnces; on a rième conjervé fes propres exprefions, ajin que leur fomplicité trounât dovantage la

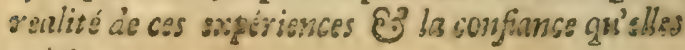
mérisento.

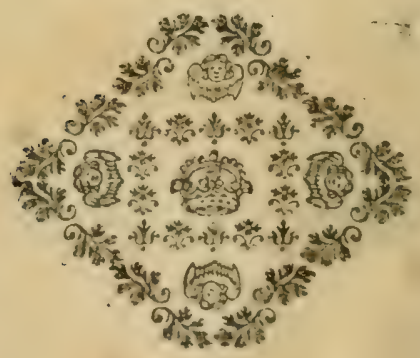





\section{NOT I \\ i $\mathrm{FROM}$}

F TO 
